Tennessee Valley Authority

Engineering Laboratory
TVA/PUB--90/1

DE9 1005475

\title{
TWO-DIMENS IONAL WATER QUALITY \\ MODELING OF TOWN CREEK EMBAYMENT \\ ON GUNTERSVILLE RESERVOIR
}

Report No. WR28-1-6-104

\author{
Prepared by \\ Merlynn D. Bender \\ Ming C. Shiao \\ Gary E. Hauser \\ Engineering Laboratory \\ and \\ Steven R. Butkus \\ Water Quality Repartment \\ Nozris, Tennessee \\ September 1990
}

DISTRIBLITION OF THIS DOCUMENT IS UNLIMITEL,

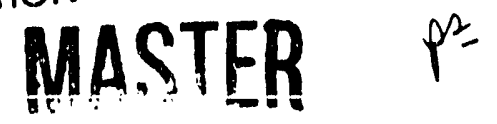




\section{ABSTRACT}

TVA investigated wacer quality of Town Creek embayment using a branched two-dimensional model of Guntersville Reservoir. Simulation results were compared in terms of algal biomass, nutrient concentrations, and volume of embayment with depleted dissolved oxygen. Stratification and flushing play a significant role in the embayment water quality. Storms introduce large loadings of organics, nutrients, and suspended solids. Dissolved oxygen depletion is most severe after storms followed by low flow that fails to flush the embayment. Embayment water quality responses to potential animal waste and erosion controls were explored. Modeling indicated animal waste controls were much more cost-effective than erosion controls. Erosion controls will decrease embayment suspended solids and thereby increase algal bi mass due to greater light penetration. 


\section{EXECUTIVE SUMMARY}

Located in close proximity to Guntersville State Park, Town Creek embayment is an important portion of Guntersville Reservoir. Embayments provide a key role in recreation and water use. Water quality in the embayment deteriorates in the summer due to nutrient and organic loading, resulting in depletion of dissolved oxygen (DO) in the embayment. Objectives of this study included (1) quantification of important physical, chemical, and biological processes, (2) testing the feasibility and utility of using the BETTER two-dimensional model as a tool for embayment water quality analysis, (3) exploration of embayment responses to potential management activities, and (4) determination of the cost-effectiveness of suspended solids and animal waste pollutant ccntrol technologies.

Seasonal patterns of temperature, dissolved oxygen (DO), nutrients/algae, and suspended solids of Town Creek embayment were modeled with a generalized branched two-dimensional water quality model using 1988 observations for calibration. Guntersville Reservoir was coarsely modeled to provide downstream boundary conditions. Model comparison to 1988 field data provided confidence in simulation results. Model calibration was followed by flow and loading sensitivity simulations. Reductions in pollutant loadings were simulated by reducing Town Creek inflow concentrations. Wiater quality improvement was indicated by modeled responses in algal biomass and embayment volume with DO concentrations less than $3.0 \mathrm{mg} / \mathrm{L}$.

Simulations fell into two categories. One category of simulations applied separate inflow concentrations to base flow and storm flow components of the hydrograph. Storm flow concentrations were derived from the literature and information specific to the watershed, while 1988 concentrations (measured largely during low flows) were applied to the base flow. The other category of simulations applied a single inflow concentration to the total hydrograph. Actual conditions probably lie somewhere between these two categories of simulations. 
Model results indicated that animal waste controls are more cost-effective and improve water quality much more than suspended solids controls. Animal. waste reductions applied to 1969 (average) basecase loads reduced mean algae by 11 percent and reduced the mean volume of DO less than $3.0 \mathrm{mg} / \mathrm{L}$ by 31 percent. Suspended solids reductions improved water quality in terms of DO but not in terms of algal biomass. With the modeled storm concentrations, suspended solids reductions increase algal biomass due to greater light penetration.

Modeling revealed complex responses to animal waste and suspended solids reductions. For example, the combination of cutting suspended solids and animal waste improved water quality in dry or average years but not in wet years. In wet years, cutting on $1 y$ anima1 wastes improved water quality more than cutting both animal wastes and suspended solids.

Based on loadings estimated during modeling, Town Creek embayment contributes only a small part of the total loading to Guntersville Reservoir. During the 1988 simulation period (April through September), less than 2 percent of the total nutrients and organics entering Guntersville Reservoir came from Town Creek. About one-third of the Guntersville Reservoir loadings originated from local inflow. Reduction of all loadings including those from Nickajack Dam would improve Town Creek water quality. Reduction of Town Creek loadings alone would benefit water quality in the embayment, but would have minimal effect on the Guntersville Reservoir main channel and release quality.

Mode1 results indicated that a large fraction of nonpoint source (NPS) nutrients and organics must be eliminated from Town Creek inflows to improve embayment water quality because algae have a surplus of nutrients. Simulations suggest that phosphorus is the primary limiting nutilient for algal growth during much of the high growth season. At low loadings, such as those seen during 1988, phosphorus limitation has a significant effect on algae and DO.

Stratification and flushing also play an important role in Town Creek embayment water quality. Inflow temperature (density) plays a role in water quality by establishing where nutrients and suspended solids are 
placed vertically in the embayment. Stratification prevents some of the suspended solids, nutrient, and organic load arriving with cool inflows from reaching the algae-rich surface layer. Wind and cooling events improve embayment water quality frequently during summer by mixing surface water that is high in DO with bottom water that is low in DO.

Do depletion is most. severe after storms followed by low flow that fails to flush Town Creek cmbayment. Large inflows to the embayment reduce residence times and introduce large amounts of nutrients and organics. Small inflows result in long residence times, and allow opportunity for Do depletion. Embayment residence times can be days to months depending on flows. Do depletion is greatly influenced by sediment oxygen demand in addition to oxygen demands in the water column. Model calibration indicated that upstream sediment oxygen demands may be about twice as large as downstream sediment oxygen demands.

Town Creek watershed is a dynamic system with flows ranging from no flow to 17,700 cfs (in 1963). Flood flows could either scour sediments out of Town Creek embayment into the main reservoir channe1 or could wash excessive bedload into Town Creek embayment. These questions cannot be addressed with the BETTER model because only suspended solids and settling are modeled; bedload and resuspension are not.

Sediment accumulation is a dynamic process which requires further study. Cross sections should be collected at intervals to determine if the embayment is filling. Sediment cores should be collected to determine the history of deposition. Bedload during wet years may be a large portion of the total solids loading. The extent to which bedload affects light penetration requires further study.

The BETTER model can be used as an effective tool for embayment water quality analysis if a suitable data base is available for calibration and simulation. Relative differences between simulations provide a reasonable basis for comparison of water quality effects and for management decisions.

Uncertainties in estimating reservoir loadings, potential loading reductions, and costs of controls were large. Therefore, reported results should be considered a first-cut analysis. Delivery of 
NPS loadings to Town Creek is a large uncertainty that deserves further study. Storm flow runoff concentrations should be collected during major runoff events to improve estimates of spiked loadings to the embayment. Additional data might be collected for verification/explanation of processing of nutrients through settling and adsorption. 


\section{ACKNOWLEDGMENTS}

This project investigation was sponsored and directed by the Tennessee Valley Authority Reservoir Water Quality Management Program. Services, information, and guidance provided by the staffs of the Water Quality Department, Data Systems Department, and Engineering Laboratory are greatly appreciated. Special thanks to Teresa McBee, Catherine Patty, and Elaine Davis for word processing, and Cindy Webb for editorial review. 
Abstract . . . . . . . . . . . . . . . . . . . . . j

Executive Summary . . . . . . . . . . . . . . . . i i

Acknowledgments ...................... . . vi

List of figures ...................... . vifi

List of Tables... . . . . . . . . . . . . . . . . y

Introduction .......................... . 1

Mode1 Input Development . . . . . . . . . . . . . . 4

Mode1 Inputs . . . . . . . . . . . . . . . 4

1988 Calibration Loading Estimates . . . . . . . . . . . 5

Storm Flow and Base Flow Ccncentration Estimates . . . . . . . 6

Selection of Flow Years . . . . . . . . . . . . . . . . . 7

Sediment and Animal Waste Control Technologies . . . . . . . . 9

Mode1 Results and Discussion .................. 11

Scenarios . . . . . . . . . . . . . . . . . . . 11

Observations on Limiting Factors for Algal Growth . . . . . 13

Water Quality Response Indicators . . . . . . . . . . . . 13

Analysis of Animal Waste and Suspended Solids Controls . . . . 16

Analysis of Town Creek Flow . . . . . . . . . . . . . 26

Analysis of Meteorology . . . . . . . . . . . . . . . 26

Analysis of Town Creek Embayment Inflow Temperature . . . . . 26

Analysis of Loading Sensitivity Simulations . . . . . . . . 27

Summary of Model Results . . . . . . . . . . . . . . 30

Effects of Loading on Water Quality . . . . . . . . . 30

Probability of Nonexceedence Based on Flow . . . . . . . . 35

Cost-Effectiveness of Controls................. 35

Effectiveness of Using the BETTER Mode1 for Embayments . . . . . 36

References ........................ . . 38

Appendix A - Model Changes and Calibration . . . . . . . . . . 41

Flow and Water Quality Mode1 ................ 41

Mode1 Changes ........................ 41

Calibration Flows and Loadings . . . . . . . . . . . . 44

Mode1 Calibration .................. 50 


\section{CONTENTS}

(continued)

Appendix B - Loading Estimation for Calibration and Simulations .............. . 71

Local Loadings . . . . . . . . . . . . . . . . . 71

Nickajack Dam Loadings . . . . . . . . . . . . . 71

Town Creek Inflow Concentrations . . . . . . . . . . . . 73

Town Creek Embayment Inflow Hydrograph Separation . . . . . 73

Town Creek Storm and Base Flow Concentrations . . . . . . 73

Appendix C - Miscellaneous Sensitivity Simulations . . . . . . 89

Upstream versus Total Embayment Water Quality . . . . . . 89

Reductions to All Inflow Sources . . . . . . . . . . 89

Appendix D - Meteorology . . . . . . . . . . . . . . 94

Appendix E - Rate of Sediment Depssition in Town Creek 101

\section{LIST OF FIGURES}

1. Map of Town Creek Watershed . . . . . . . . . . . . 2

2. Most Limiting Constituent for Algal Growth for Each Model Segment (1988 Calibration Basecase, Julian Day 124) . . . . . 14

3. Modeled Algal Limiting Factors for Surface Layer of Town Creek Embayment . . . . . . . . . . . . . . . . 15

4. Effects of Suspended Solids and Animal Waste Reductions on Town Creek Embayment Epilimnetic Phosphorus, Algae, and DO (Year 1971 Dry Inflow) . . . . . . . . . . . . . .

5. Effects of Suspended Solids and Animal Waste Reductions on Town Creek Embayment Epilimnetic Phosphorus, Algae, and DO (Year 1969 Average Inflow) . . . . . . . . . . . . .

6. Effects of Susperided Solids and Animal Waste Reductions on Town Creek Embayinent Epilimnetic Phosphorus, Algae, and DO (Year 1967 Wet inflow) . . . . . . . . . . . . . . . 19

7. Effects of Flow on Town Creek Embayment Epilimnetic Phosphorus, Algae, and DO . . . . . . . . . . . . 20

8. Effects of Metecirology on Town Creek Embayment Epilimnetic Phosphorus, Algae, and DO (Year 1969 Inflow) . . 21

9. Effects of Town Creek Inflow Temperature on Embayment Epilimnetic Phosphorus, Algae, and DO (Year 1969 Inflow). . 


\section{CUNTENTS}

(continued)

Page

\section{LIST OF FIGURES}

10. Effects of Reducing Storm Concentrations on Town Creek Embayment Epilimnetic Phosphorus, Algae, and DO (Year 1969 Inflow) . . . . . . . . . . . . . . .

11. Effects of Applying Storm F1ow Concentrations to Peak Flow Portions of 1988 Calibration Town Creek Inflow Hydrograph . . . . . . . . . . . . . . . . . . . 24

12. Effects of Cutting Town Creek Inflow Calibration Loadings on Town Creek Embayment Epilimnetic Phosphorus, Algae and DO . . . . . . . . . . . . . . . . . . . .

13. Summary of Modeled Effects of Bioavailable Phosphorus Loading Changes on Town Creek Embayment Algae and DO . . . . . 31

14. Summary of Modeled Effects of Suspended Solids Loading Changes on Town Creek Embayment Algae and DO . . . . . . . . . 32

15. Town Creek Embayment Algae and Do versus Nonexceedence Frequency Based on Flow . . . . . . . . . . . . . . . . . . . 33

16. Cost-Effectiveness of Suspended Solids and Animal Waste Reductions on Town Creek Embayment A1gae and DO . . . . . . . 34

A1. Major Physical and Biochemical Processes in the BETTER Mode1 .. . . . . . . . . . . . . . . . . 42

A2. Modeled Water Quality Processes . . . . . . . . . . . 43

A3. Modeled Guntersville Reservoir Inflows (1988 Calibration Basecase ) . . . . . . . . . . . . . . . . 45

A4. Modeled Bioavailable Phosphorus Loading (1988 Calibration Basecase) . . . . . . . . . . . . . . . . . 46

A5. Modeled Inorganic Nitrogen Loading (1988 Calibration Basecase ) . . . . . . . . . . . . . . . . . 47

A6. Modeled 5-Day BOD Loading (1988 Calibration Basecase) . . . 48

A7. Modeled Suspended Solids Loading (1988 Calibration Basecase ) . . . . . . . . . . . . . . . . . 49

A8. Measured and Modeled Temperature for 1988 Calibration (Town Creek Embayment) .. . . . . . . . . . . . . . 53

A9. Comparison of Guntersville and Chickamauga Reservoir Surface and Bottom Temperatures and Nickajack Release Temperatures (Chickamauga Station 13) . . . . . . . . . . . . . .

A10. Comparison of Guntersville and Chickamauga Reservoir Surface and Bottom Temperatures and Nickajack Release Temperatures (Chickamauga Station 8) .. . . . . . . . . . . . . . . 57

A11. Measured and Modeled Guntersville Dam Release Temperature, DO, and pH (1988 Calibration) . . . . . . . . . . . 58

A12. Measured and Modeled Dissolved Oxygen for 1988 Calibration (Town Creek Embayment) . . . . . . . . . . . . . . . 59

A13. Modeled Algae for 1988 Calibration (Town Creek Embayment and Guntersville Reservoir) . . . . . . . . . . . . . 
CONTENTS

(continued)

Page

LIST OF FIGURES

A14. Measured and Modeled pH for 1988 Calibration (Town Creek Embayment) . . . . . . . . . . . . . . . . .

A15. Modeled Suspended Solids for 1988 Calibration (Town Creek Embayment and Guntersville Reservoir) . . . . . . 66

A16. Measured and Modeled Bioavailable Phosphorus for Town Creek Embayment (1988 Calibration) . . . . . . . . . 67

A17. Measured and Modeled Ammonia for 1988 Calibration (Town Creek Embayment) . . . . . . . . . . . . 68

A18. Measured and Modeled Nitrate for 1988 Calibration (Town Creek Embayment and Guntersville Reservoir) . . . . . 69

A19. Modeled Cumulative Trave1 Time (Age) of Water for 1988 Calibration (Town Creek Embayment and Guntersville Reservoir) . . . . . . . . . . . . . "70 70

B.. Very Dry (Year 1960) Town Creek Inflows . . . . . . . . . . 74

B2. Dry (Year 1971) Town Creek Inflows . . . . . . . . . . . 75

B3. Calibration (Year 1988) Town Creek Inflows . . . . . . . 76

B4. Average (Year 1969) Town Creek Inflows . . . . . . . . 77

B5. Wet (Year 1967) Town Creek Inflows ............. 78

B6. Very Wet (Year 1979) Town Creek Inflcws . . . . . . . . . 79

C1. Effects of Phosphorus Reductions on the Upstream versus

"'otal Town Creek Embayment . . . . . . . . . . . . . . . 90

C2. Effects of Cutting Phosphorus at Town Creek versus Al1

Sources of Epilimnetic Phosphorus, Algae, and DO . . . . . 91

D1. Warm (1988 Calibration) versus Cool (1974) Meteorology at Huntsville Alabama Airport . . . . . . . . . . . 95

\section{LIST OF TABLES}

1. 1988 Calibration Basecase Loadings (Apri1 - September) . .

2. Town Creek F1ow Nonexceedence Probability and Embayment Residence Time ..................... 8

3. Town Creek Mile 9.0 Monthly Inflow Data ........... 9

4. Meaning of Mnemonics Used in Plot Labels . . . . . . . . . . 11

A1. Interpretation of Modeled Constituents . . . . . . . . . . . 44

A2. Summary of BETTER Mode1 Coefficients Guntersville Reservoir/Town Creek Embayment . . . . . . . . . . 51

A3. Initial Conditions . . . . . . . . . . . . . . . . . . . 52

B1. 1988 Calibration Input Concentrations to BETTER Mode1 . . . . 72

B2. Information Used to Estimate Storm Flow Concentrations

Contributed from Animal Waste . . . . . . . . . . 81 
CONTENTS

(continued)

Page

LIST OF TABLES

B3. Information Used to Estimate Storm Flow Concentrations Contributed from Soil Erosion . . . . . . . . . . . 82

B4. Loadings Used in Model Simulations . . . . . . . . . . . . . 83

B5. Summary of Town Creek Embayment Simulation Loadings, Water Quality, and Cost ................ 
TWO-DIMENSIONAL WATER QUALITY

MODELING OF TOWN CREEK EMBAYMENT

ON GUNTERSVILLE RESERVOIR

\section{INTRODUCTION}

Guntersville Reservoir is located in northeast Alabama as an impoundment of the Tennessee River. The immediate Guntersville watershed consists of several embayment subwatersheds, one of which is Towi Crefk embayment in the Sand Mountain region. Town Creek embayment is located at Tennessee River Mile (TRii) 362.5 about 13.5 miles upstream of Guntersville Dam (TRM 349) and 62.2 miles downstream of Nickajack Dam (TRM 424.7). The total drainage area between Guntersville and Nickajack Dams is 2580 square miles with 216 square miles in the Town Creek embayment watershed (Figure 1). A majority of the Town Creek watershed resides on a plateau, but downstream of the Geraldine stream gage at Town Creek Mile (TCM) 20.4, Town Creek drops considerably.

Town Creek embayment. had the highest total nitrogen and total phosphorus concentrations of the Guntersville tributary sources surveyed during 1973 (Doppe, 1987b, p 42). An extensive assessment of Guntersville Reservoir can be found in the report "Guntersville Reservoir Water Quality and Aquatic Resource Assessment," by Poppe et al. (1987a). An abundance of nutrients stimulating algal and aquatic growth degrades the general water quality of Guntersville Reservoir.

In 1988, TVA initiated a water quality management study to investigate continuing degradation of the trophic status of Town Creek embayment. Primary objectives of this study included: (1) quantification of important physical, chemical and biological processes, (2) testing the feasibility and utility of using the BETTER two-dimensional model (description in Appendix A) as a tool for embayment water quality analysis, and (3) exploration of embayment responses to potential management activities. An additional objective that developed during the course of this investigation was, (4) the determination of the cost-effectiveness of suspended solids and animal waste pollutant control technologies. 


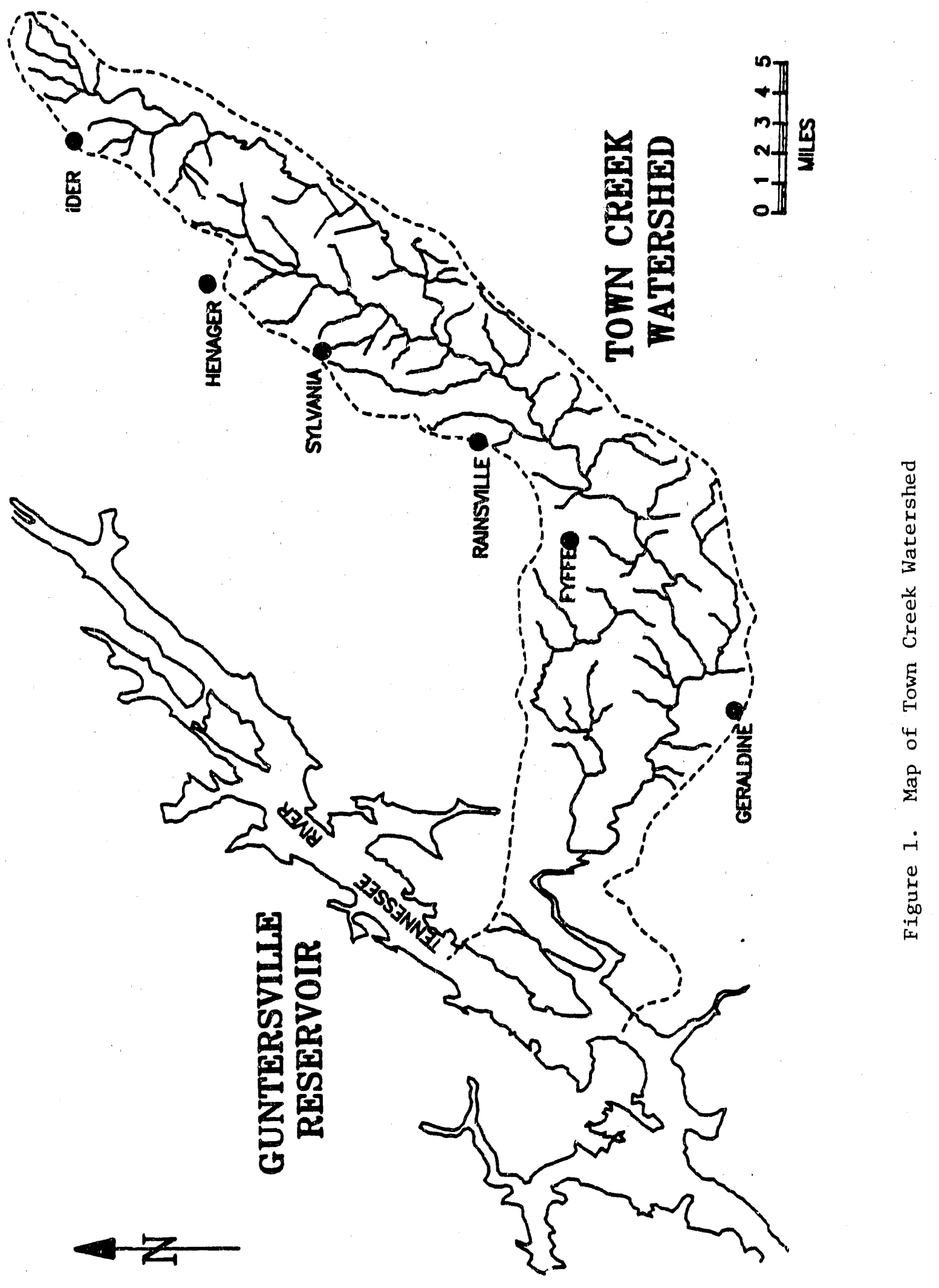


During 1988, hydrodynamic and water quality data were collected for the following purposes: (1) to improve the understanding and hydrodynamics of Town Creek embayment, (2) to provide data for a two-dimensional model, and (3) to explore the development of an embayment exchange algorithm. For a detailed discussion of data collection and preliminary analysis, see the report, "Town. Creek Embayment Investigation," by Bender, et al. (1990a).

The BETTER model was calibrated to conditions observed in 1988 . The model, refinements to the model, and calibration are described in. Appendix A. The calibrated model was used to predict responses to changes in water quality constituents by varying Town Creek embayment suspended solids, nutrient, and BOD loadings as well as flow, inflow temperature, and meteorology. To show seasonal effects, total epilimnetic phosphorus, algal biomass, volume with Do less than $3 \mathrm{mg} / \mathrm{L}$, and hypolimnetic Do near the mouth were plotted against time. To summarize simulations, Town Creek algal biomass and volume of DO less than $3.0 \mathrm{mg} / \mathrm{L}$ were averaged for each six-month simulation period (April through september). These averages were plotted against bioavailable phosphorus loading, suspended solids loading, probability of nonexceedence based on flow, and cost of pollutant control technologies. 
MODEL INPUT DEVELOPMENT

\section{Mode1 Inputs}

The BETTER model requires inflow temperature, pH, alkalinity, nutrient, $B C D$, suspended solids, and algae concentrations as well as flow and meteorology. Modeled sources of input loading (concentration multiplied by f1nw) to Guntersville Reservoir included releases from Nickajack Dam, Town Creek embayment, and locai nonpoint runoff. Loadings used in calibration and simulations are summarized in Appendix $B$, Table B4. Pojnt sources (PSs) were small in comparison to total NPS loadings (Poppe, 1987b, p 41) and were not modeled directly. PS loadings were included in loca1 NPS loadings to Town Creek embayment and Guntersville Reservoir. Local loadings are defined as those from the watersheds immediately surrounding Guntersville Reservoir and Town Creek embayment. Local loadings were distributed according to drainage area corresponding to modeled segments and introduced into the surface layer of the model.

Most of the modeling uncertainty lies in the determination of the nutrient, organic and suspended solids loadings to the reservoir. The 1988 calibration loadings to Guntersville Res -rvoir were approximated from tributary and PS estimates in the report, "Guntersville Reservoir Water Quality and Aquatic Resource Assessment," (Poppe, et a1., 1987a) and 1988 field data reservoir profiles used in model calibration. Reservoir concentration profiles are actual measurements that, in conjunction with a model, can provide backcalculated estimates of long-term nutrient and BOD loadings entering the reservoir.

NPS nutrient and BOD loadings determined at the source (i.e., barnyard) or in tributaries often do not reflect what actually reaches the reservoir. Sedimentation, infiltration, adsorption (to sediments and particles in the water column), and processing of nutrients and BOD occur in route to the reservoir. The delivery of NPS nutrients and BOD to the reservoir remains an uncertainty that deserves further study.

The primary nutrients and BOD for model input are bioavailable phosphorus, inorganic nitrogen (ammonia-N and nitrate-N), dissolved organics, and detritus. Bioavailable phosphorus was assumed to be either 
dissolved phosphorus or half of total phosphorus (used for local inflow), depending on the availability of data. Reservoir profiles and spot measurements of local inflow indicated approximately 6 percent of total inorganic nitrogen is amnonia-N and 94 percent is nitrite-N or nitrate-N. These percentages were used to divide local and Town Creek inorganic nicrogen loads. Nickajack Dam release data inticated that of the total inorganic nitrogen 19 percent was ammonia-N and 81 percent was nitrite-N or nitrate-N. For reductions due to controls, it wias assumed that one-fifth of the inflowing available nitrogen and two-fifths of the inflowing available phosphorus was bound to the suspended solids.

BOD contains detritus which is an indirect source of nutrients (through recycle of algae) for algal growth, as well as an important direct oxygen demand. The model assumes u1timate BOD which was taken to be twice the 5-day BOD. Dissolved organics and detritus were assumed to contribute equally to the ultimate carbonaceous BOD. Assuming the 5-day BOD is half of the ultimate BOD snd that a milligram of oxygen is consumed for each milligram of decritus, dissolved organics and detritus were assumed individually equal to the 5-day BOD.

\section{Calibration Loading Estimates}

Table 1 and Appendix Figures A3-A7 summarize 1988 calibration inf low loadings.

\section{TABLE 1}

1988 Calibration Basecast Loaüings (April - September)

\begin{tabular}{lrccc} 
Source & BOD5 & $\begin{array}{c}\text { Phosphorus } \\
\text { (Bioavailable) }\end{array}$ & $\begin{array}{c}\text { Tota1 } \\
\text { Inorganic-N }\end{array}$ & $\begin{array}{c}\text { Suspended } \\
\text { Solids }\end{array}$ \\
Nickajack Dam & $71.8 \%$ & $71.1 \%$ & $67.7 \%$ & $40.8 \%$ \\
Town Creek & $0.9 \%$ & $1.4 \%$ & $1.6 \%$ & $3.2 \%$ \\
Local inflow & $27.3 \%$ & $27.2 \%$ & $-30.7 \%$ & $56.0 \%$ \\
\cline { 2 - 3 } Total (1bs.) & $26,352,028$ & 294,282 & $6,512,702$ & $70,078,000$
\end{tabular}

Drainage area upstream of the Town Creek embayment inflow point (about where backwater begins, $\operatorname{TCM} 9.0$ ) is 7.4 percent of the entire 
local inflow between Nickajack and Guntersville Dams. Local inflow in Table 1 does not include the drainage area upstream of the inflow point of Town Creek embayment (TCM 9.0). It does include the local drainage along Town Creek embayment which is one percent of the local inflow shown in Table 1.

Local inflow concentrations used for calibration may be high since they are based on measurements from 1973, a wet year. During 1973, the Tennessee River had over twice the flow seen in 1988, the calibration year. Poppe, et a1. (1987a, p 48) estimated that approximately 87 percent of the phosphorus and 81 percent of total nitrogen budgets were supplied by Nickajack Dam flows during 1973. For the calibration period, April through September 1988, it was estimated that five percent of the phosphorus and five percent of the inorganic nitrogen from the entire local watershed between Nickajack and Guntersville Dams originated from Town Creek watershed above TCM 9.0.

\section{Storm Flow and Base Flow Concentration Estimates}

Each Town Creek inflow hydrograph was split into base flow and storm flow components with storm flow concentrations being applied to the peak flow portion. This was done since 1988 observed data practically missed al1 storm events, and larger concentrations would be expected in runoff during storm events.

Concentrations of $\mathrm{n}$ utrients and suspended solids were estimated for storm events using available information specific to Town Creek watershed. Two sources contribute the bulk of the pollutants in stormwater runoff. These are land-applied animal waste and soil erosion. Concentrations estimated for total phosphorus were reduced to reflect the portion available for algal growth. In general, soluble forms are immediately available for uptake by algae. Other forms become available through transformation, such as during degradation of organic material. Some forms, such as apatite, are never available for algal growth. A biological measurement technique, such as the algal growth potential test, can determine the availability of nutrients occurring in several different forms (Raschke and Schultz, 1987; Miller, et al., 1978 ). 
Measurements of nutrient bioavailability using a1ga1 bioassays varied considerably over the season (Raschke, 1988), so median values were used. The median bioavailable portion of total phosphorus was measured at 25 percent for Town Creek. This value is in the range reported in the 1iterature (Butkus, et al., 1988; Dorich, et al., 1985; Wendt and Corey, 1980; Schaffner and Oglesby, 1978; Cowen and Lee, 1976). The median bioavailable nitrogen (BAN) was 23 percent (Raschke, $1988)$.

Concentrations of total phosphorus, total nitrogen and BOD from animal waste sources were determined according to the specific land use in Town Creek watershed. Standard runoff concentrations were used in conjunction with known land use and approximated areas of application to estimate the contribution from animal waste. Concentrations from soil erosion were determined from average soil nutrient concentrations and sediment delivery to the embayment. Appendix $B$ presents the assumptions and information sources for estimating the concentrations used in the model for storm flows.

Loadings for split hydrograph simulations were estimated by using average daily flow data from water records, storm concentrations for the storm flow portion of the split hydrograph, and 1988 concentrations for the base flow portion of the hydrograph. Most of the 1988 Town Creek concentration data was taken during base flow conditions due to low precipitation in the spring and summer. Dam rolease loadings and local loadings were assumed to remain at the 1988 levels. Use of 1988 dam releases and loadings allowed comparison of basecase and sensitivity simulations with a minimum of variations.

\section{Selection of Flow Years}

Very dry, dry, average, and wet flow years were selected for plotting water quality against probability of nonexceedence based on flow. Flow statistics were based on 24 years of data from surface water records (USGS, 1958-1980, 1988). Town Creek Elows at TCM 9.0 were developed from stream flow records at TCM 20.4, adjusted according to drainage area. The six-month period from April through september was 
used in developing flow statistics, since this period was used in all model simulations. A twelve-month average was not used since wet winters skew the results. Nonexceedence probability, or probability that flow is less than the flow for that year, is shown in Table 2 for selected hydrologic years.

Estimated Town Creek embayment total and upstream end residence times, based on an average 1988 embayment volume, are also given. During 1988, Guntersville headwater elevation ranged from 593.2 to 595.3 feet above mean sea level ( $\mathrm{ft}-\mathrm{ms} 1$ ) indicating that volume did not fluctuate greatly. The upstream end is the portion above the bridge causeway at TCM 2.9. During extreme floods, embayment volume could be replaced in a couple of days.

TABLE 2

Town Creek Flow Nonexceedence Probability and Embayment Residence Time

\begin{tabular}{|c|c|c|c|c|c|}
\hline \multirow{4}{*}{ Year } & \multirow{4}{*}{$\begin{array}{l}\text { F1owt } \\
\text { (cfs) }\end{array}$} & \multirow{4}{*}{$\begin{array}{l}\text { Nonexceedence } \\
\text { Probability t* }\end{array}$} & \multirow{4}{*}{ Description } & \multicolumn{2}{|c|}{ Embayment } \\
\hline & & & & Residence Time & es (Days) krtk \\
\hline & & & & Tota1 Embayment & Upstream End \\
\hline & & & & & \\
\hline 1960 & 79.8 & 0.04 & Very Dry & 146.8 & 23.9 \\
\hline 1971 & 133.7 & 0.08 & Dry & 87.6 & 14.3 \\
\hline 1988 & 147.5 & 0.24 & Calibration & 79.4 & 12.9 \\
\hline 1969 & 235.8 & 0.48 & Average & 49.7 & 8.1 \\
\hline 1967 & 350.3 & 0.92 & Wet & 33.4 & 5.4 \\
\hline 1979 & 397.6 & 0.96 & Very Wet & 29.5 & 4.8 \\
\hline
\end{tabular}

According to a Log-Pearson Type III cumilative probability distribution, the 80 percent nonexceedence flow (5-year return period) is $298 \mathrm{cfs}$. Restated in general terms, 20 percent of the average summer (Apri1-September) flows would exceed $298 \mathrm{cfs}$.

The wettest six-month period, 1979, was not ured for simulations since this high flow might be an extreme value. Town Creek flows during 
1967 (used for wet simulations) reflect summer flooding rather than large spring flows. The calibration year, 1988, was fairly dry as shown in Tab1e 2 .

A six-month average masks seasonal variation in flow patterns. Tab e 3 provides an indication of ranges of flows possible, based on monthly data. Values in Table 3 are minimum, average, and maximum month1y flows (Q) at TCM 9.0 for the period Apri1 through September.

\section{TABLE 3}

Town Creek Mile 9.0 Month1y Inflow Data*

(Apri1-September)

(cfs)

$\begin{array}{lccccc} & \text { Dry } & \text { Ca1 } & \text { Avg } & \text { Wet } \\ \text { Year } & =-1971- & -1988- & -1969- & =-1967- \\ & & & & \\ \text { Max Q } & 409 & 442 & 726 & 1.035 \\ \text { Avg Q } & 134 & 148 & 236 & 350 \\ \text { Min Q } & 32 & 12 & 35 & 125\end{array}$

*Recorded at TCM 20.4 and adjusted by drainage area to TCM 9.0

Table 3 indicates that the calibration year, 1988, had extremely low minimum flow, but the overall inflow was higher than for the dry year, 1971. This is due in part to the September 1988 flow (442 cfs) which was the wettest September in the 24 years of record.

\section{Sediment and Anima1 Waste Control Technologies}

Determining the cost-effectiveness of pollutant control technology was a major objective that developed during the course of the project. Pollution abatement activities planned in Town Creek watershed can be divided into two categories; animal waste management and erosion contro1. The Water Quality P1an for Sand Mountain proposed and estimated costs for the control of animal waste and soil erosion (SMLGWQC, 1986). To determine the water quality improvement in Town Creek embayment resulting from watershed management, reductions in both base flow and storm flow concentrations were related to percent of improvements that 
could be achieved. Load reductions were applied on $1 \mathrm{y}$ to those NPSs on the Town Creek watershed above the poins of inflow a TCM 9.0. Pollutant reductions due to animal waste management was determined from the fraction of the total confined animal operations that require new or upgraded waste systems. A 50 percent reduction in phosphorus, nitrogen, and BOD from animal waste contributions was considered possible. A. 60 percent reduction in stormwater suspended solid concentrations due to erosion control measures is estimated. This projection was for the year 2015 and assurned additional funds would be available through the U.S. Departient of Agricultire Special Small Watershed Program (PL- 66 ). This 60 percent reduction was applied to the $273 \mathrm{mg} / \mathrm{L}$ suspended solids concentration presented in the Water Quality Plan for Lake Guntersville (SMLGWQC, 1986). The plan states that 273 $\mathrm{mg} / \mathrm{L}$ is the annual average concentration, but samples collected by the Alabama Department of Environmental Management indicate that this value is more representative ol: storm flows (Foster, 1989). Appendix B presents details on assumptions and costs associated with the projected reductions in runoff concentrations from potential pollution abatement activities in Town Creek watershed. 
MODEL RESULTS AND DISCUSSION

Loading sensitivity simulations were done with the storm flow concentrations (split hydrograph) and with the 1988 calibration loadings (hydrograph not split). Simulations applying animal weste and suspended solids controls were done using split hydrographs. A11 simulations use the 1988 dam and local inflows. Definitions of mnemonics required to interpret plot and figure labels are given in Table 4 .

\section{ABLE 4}

Meaning oï Mnemonics Used in Plot Labels

Mnemonic

$\mathrm{N}$ dissolved inorganic nitrogen (ammonia-N and nitrate-N)

$P \quad$ bioavailable inorganic phosphorus

BOD

(1988)

(1960)

(1967)

(1969)

(1971)

CUT

SS

AW

ALL

VERY DRY

DRY

AVG

WET

\section{Meaning}

dissolved organics and detritus (for NPS)

(note that detritus represents indirect nutrient source as well as an oxygen demand)

dam and local inflows used with 1988 calibration

1960 Town Creek inflows used with 1988 dam and local inflow

1967 Town Creek inflows used with 1988 dam and local inflow

1969 Town Creek inflows used with 1988 dam and local inflow

1971 Town Creek inflows used with 1988 dam and local inflow reduce the loading by the $s$ tated percent

suspended solids reduction with available technology

animal waste reduction with available technology

refers to Nickajack releases, Town Creek inflow, and local inflow

very dry flow ( $4 \chi$ nonexceedence probability) (1960)

dry flow ( $8 \%$ nonexceedence probability) (1971)

average flow ( $48 \%$ nonexceedence probability) (1969)

wet flow ( $92 \%$ nonexceedence probability) (1967)

exanple p1ot labels: CUT SS 60\% AND AW 50\% (1967)

means

"from Town Creek inflows, cut suspended solids by $60 \%$ and animal waste nutrients (bioavailable phosphorus, ammonia-N, and nitrate-N) and BOD (dissolved organics and detritus) by 50\% in 1967 basecase, which was the wet year basecase"

\section{Scenarios}

Tables B4 and B5 (Appendix B) 1ist the simulations by run number. The 1988 calibration (Run 1) served as a basecase for calibration loading sensitivity simulations. Sensitivity to inflowing 
bioavailable phosphorus, inorganic nitrogen, BOD, and suspended solids loadings was investigated by simulating 50 percent reductions from the 1988 calibration loadings (Runs 2 through 6). Constant inflow concentrations were applied to the entire hydrograph.

For the remaining runs (Runs 7 through 23) Town Creek inf 1 ow hydrograph was split into base flow and storm flow components to apply base flok and storm flow concentrations. Sensitivity to suspended solids and animal waste controls was done for 1971 (dry), 1967 (wet), and 1969 (average) flow years. Suspended solids controls, animal waste controls, or both were simulated for each of these flow years. Town Creek flows for 1971 were used for Runs 7 through 10; Town Creek flows for 1967 were used for Runs 11 ihrough 14; and Town Creek flows for 1969 were used for Runs 15 through 18. A worst (very dry) Town Creek inflow case was run using 1960 flows (Run 19).

Sensitivity to cool meteorology (Run 20) was done using $\operatorname{coo} 1$ meteorology (1974) and average Town Creek inflows (1969). The 1974 meteorology was chosen based on deviation from the mean Apri1-0ctober (1948-1988) Chattanooga Airport air temperature. Mean 1974 Apri1-0ctober air temperature deviated about $1.8^{\circ} \mathrm{C}$ cooler than the average.

Sensitivity to warm Town Creek inflows (Run 21) was investigated using average (1969) flows cooled $5^{\circ} \mathrm{C}$. Inflow DO concentrations werr increased by $1 \mathrm{mg} / \mathrm{L}$ to account for larger saturation values at cooler temperatures.

Sensitivity to splitting and not splitting hydrographs on the 1988 calibration basecase (Run 22) was done to determine the effect of a never ending watershed loading source which is assumed with constant storm concentrations. In reality, storn concentrations would dilute with rainstorm duration. Sensitivity to cutting the 1969 average flow year storm concentrations for nutrients, BOD, and suspended solids to midway between the base flow and storm flow concentrations was also done (Run 23). Table B5 lists the values of algal biomass and volume of DO less than $3 \mathrm{mg} / \mathrm{L}$ for each simulation. 
Observations on Limiting Factorg for Algal Growth

Modeling suggested that during 1988 phosphorus was the most

limiting nutrient for algal growth in Town Creek embayment and the main channel. During late summer, modeling and field data suggested that nitrogen and phosphorus colimited algae in Town Creek embayment. For the 1988 calibration basecase, the top half of Figure 2 shows the most limiting constituent at midnight of Julian day 124 (May 3) for algal growth in each model segment. The segments are arranged as longitudinal profiles of each reservoir arm. The seasonal variation for the surface model segments (top $5 \mathrm{feet}$ ) is shown on the bottom half of Figure 2 and for selected simulations in Figure 3. If more than one constituent limited algal growth in the surface layer, both or several are given with the top constituent being the most predoninant. After storm events (Appendix B, Figures B1-B6), light is often the most limiting factor as seen in hun 7 and Run 15 of Figure 3. Several surface segments in Town Creek embayment showed carbon limitation for a short period after the spring algal bloom and also after storms when suspended solids had settled. In the model, carbon limitation indicates rapid growth.

Because algae are primarily limited by light and phosphorus, decreases in the nitrogen budget have limited effects on water quality. Blue-green algae can $f i x$ atmospheric nitrogen into soluble form. Therefore, decreasing nitrogen levels may not decrease lake productivity to any great extent.

Water Quality Response Indicators

Model results were presented with water quality indicators that may or may not be easily measured. Indicators were chosen that emphasize salient results and differences between simulations. Measurable criteria for monitoring reservoir water quality changes are difficult to define. Criteria based on causes (i.e., total. phosphorus and total nitrugen) or effects (i.e., DO, chlorophy11-a) have pros and cons associated with each (Institute of Environmental Negotiation, 1987). A brief summary of advantages and disadvantages of water quality indicators is given in the report, "Modeling Boone Reservoir To Evaluate the Cost-Effectiveness of 


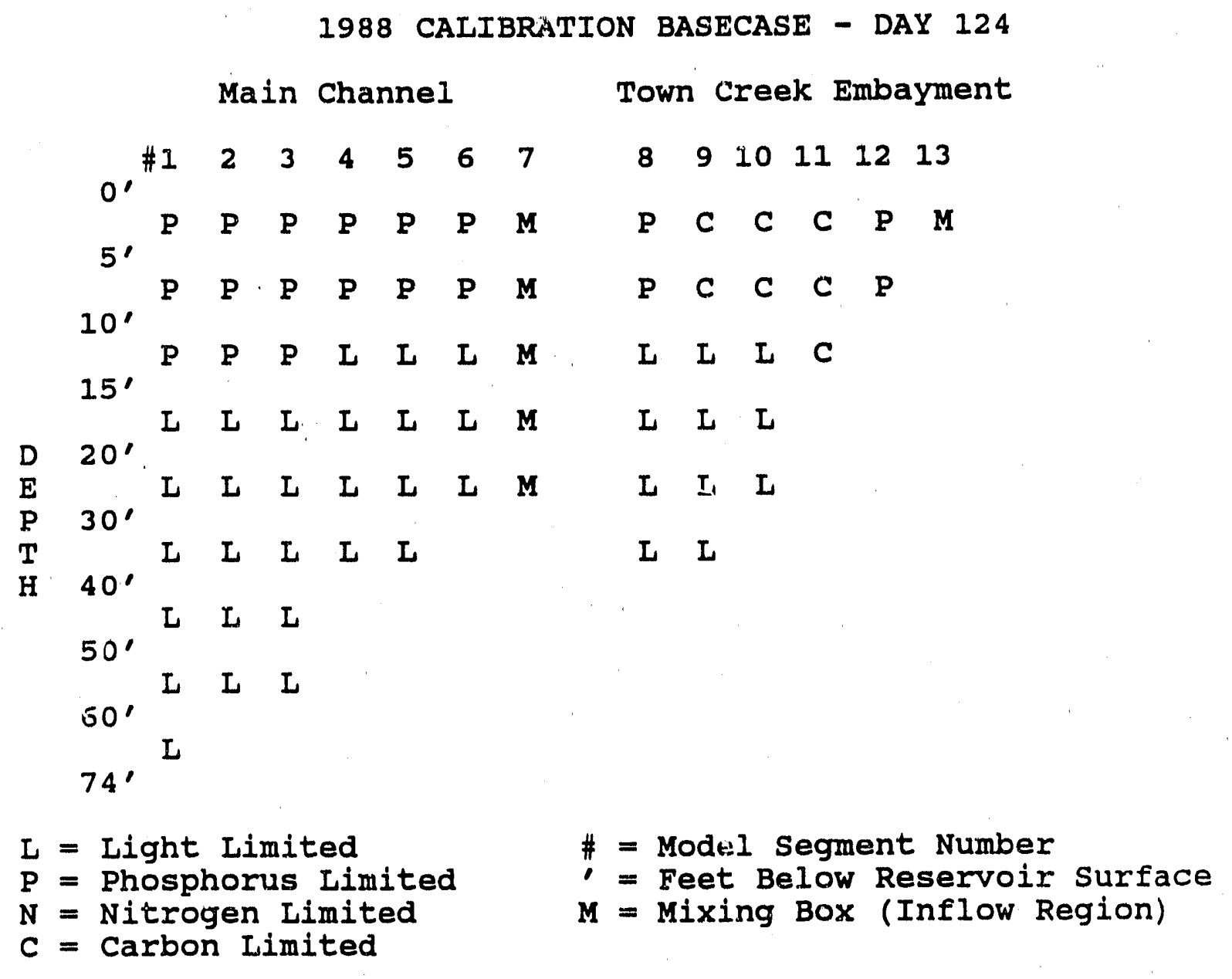

SURFACE LAYER SEASONAT VARIATION (1988 CALIBRATION BASECASE)

Limiting Constituents For Main Reservoir Channel

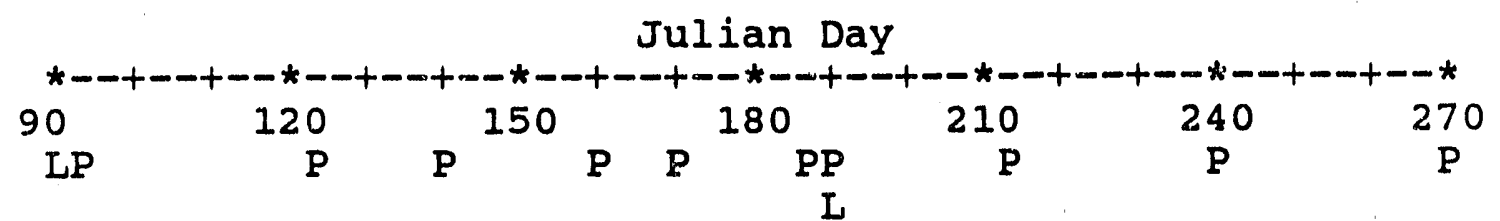

Limiting Constituents For Town Creek Embayment

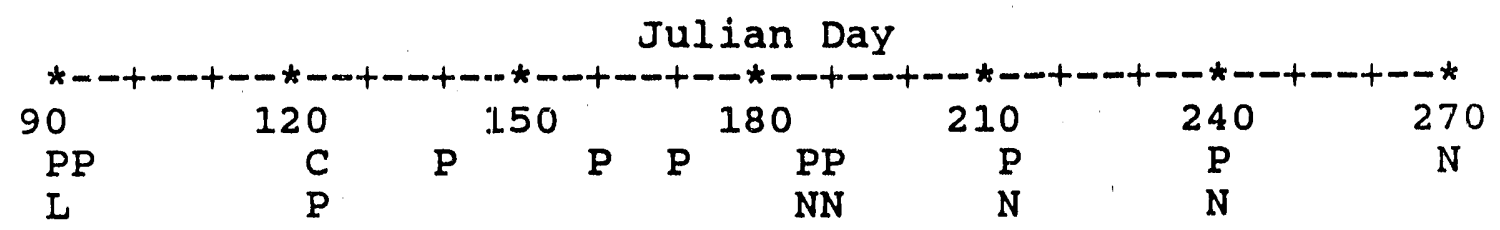

Figure 2. Most Limiting Constituent for Algal Growth for Each Model Segment (1988 Calibration Basecase, Julian Day 12.4) 
Julian Day

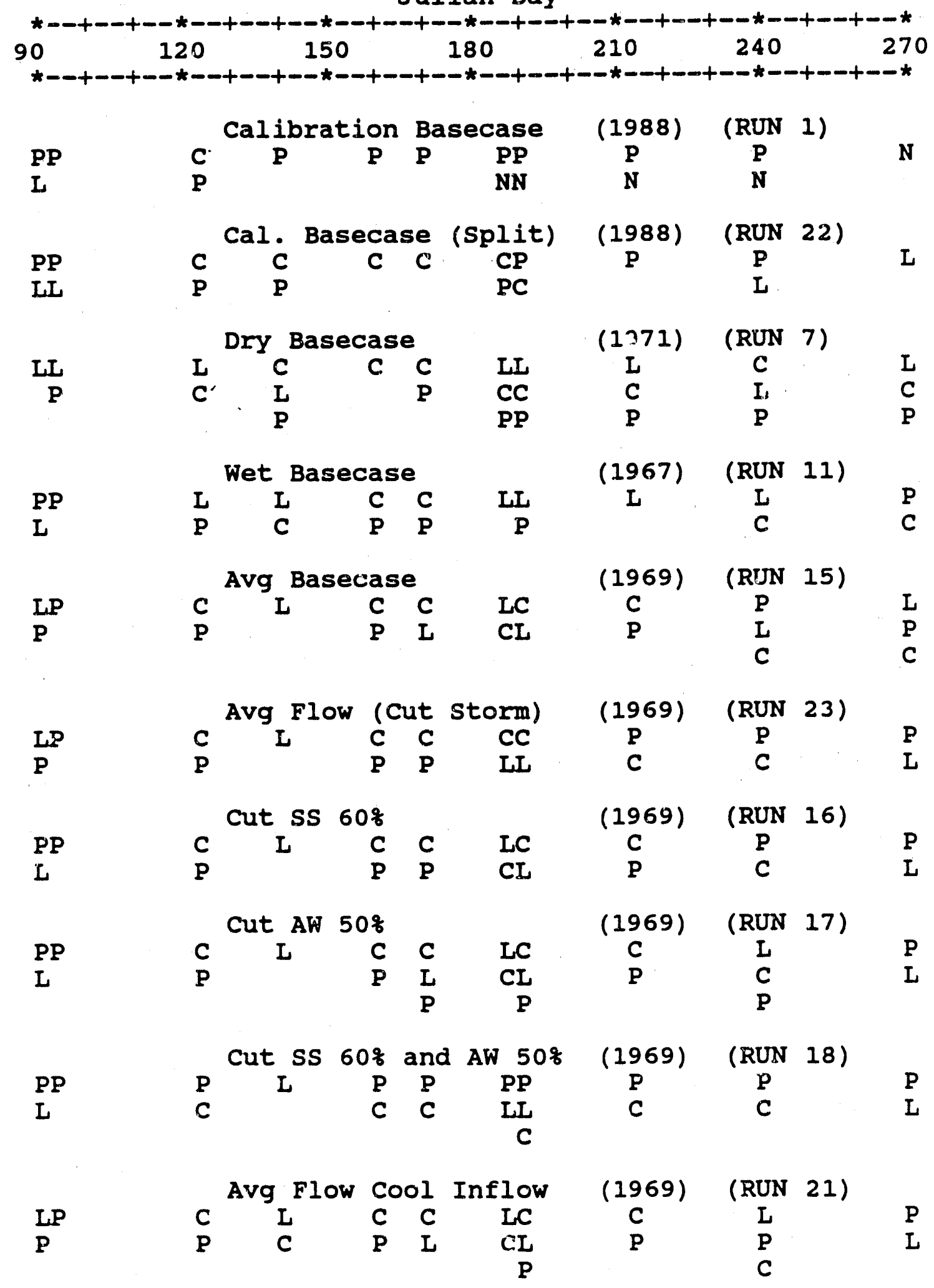

Figure 3. Modeled Algal Limiting Factors for Surface Layer of Town Creek Embayment. 
Point and Nonpoint Source Pollutant Controls," (Bender, et a1., 1990b). Advantages and disadvantages of water quality indicators are addressed in "Nutrient Control Standards Workshop, A Summary Report", which was prepared by the Institute of Environmental Negotiation, Division of Urban and Environmental Planning, University of Virginia (1987).

Modeling efforts focussed on DO and algal biomass; however, the model is structured to predict Do more accurately than algae.

Modeled seasonal changes in Town Creek embayment water quality are shown in Figures 4 through 12 using the indicators of total epilimnetic phosphorus, algal biomass, Town Creek embayment volume with DO less than $3.0 \mathrm{mg} / \mathrm{L}$, and hypolimnetic plus metalimnetic DO concentrations near the embayment mouth. Near the mouth indicates the area below the bridge or causeway (TCM 2.9) and the mouth. These figures are organized in a cause-effect order (i.e., phosphorus affects algae, algae affects DO, reservoir affects releases). Total epilimnetic phosphorus, as defined here, includes free bioavailable phosphorus plus the phosphorus contained by algae and detritus in the epilimnion.

Analysis of Animal Waste and Suspended Solids Controls

Figures 4,5 , and 6 show that algal biomass fluctuates with storm inflows in years of dry, average and wet Town Creek inflow. Storm flows flush algae out of the embayment and introduce turbidity that limits algal growth. Volume of Do 1 ess than $3.0 \mathrm{mg} / \mathrm{L}$ is influenced by both flow and meteorological cooling events. This is shown more dramatically in the plot of hypolimnetic DO near the mouth. Surface cooling events cause mixing that dramatically increases the hypolimnetic DO.

The plots of reservoir volume with Do less than $3.0 \mathrm{mg} / \mathrm{L}$ gives an indication of the volume of water or habitat unsuited for most aquatic 1ife. Modeling indicated that during stratified periods of 1988 , over 20 percent of Town Creek embayment volume had DO less than $3.0 \mathrm{mg} / \mathrm{L}$. The average total volume of the entire Guntersvilie Reservoir was estimated at 1133 million cubic meters du:ing 1988; Town Creek embayment ccintains about 30 million cubic meters which is about 2.7 percent of the total 

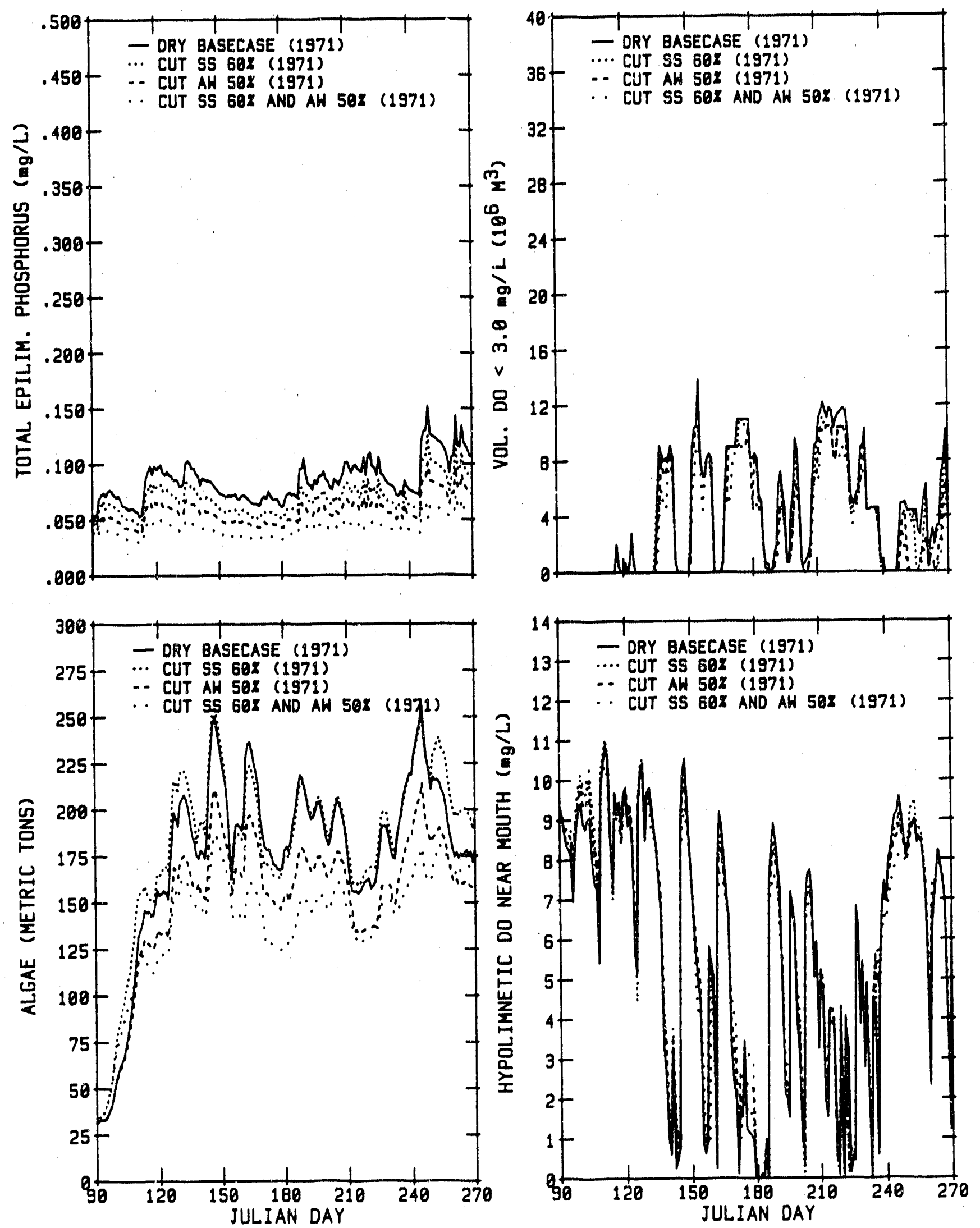

Figure 4. Effects of Suspended Solids and Animal Waste Reductions on Town' reek Embayment Eplimnetic Phosphorus, Algae, and DO (Year 1971 Dry Inflow) 

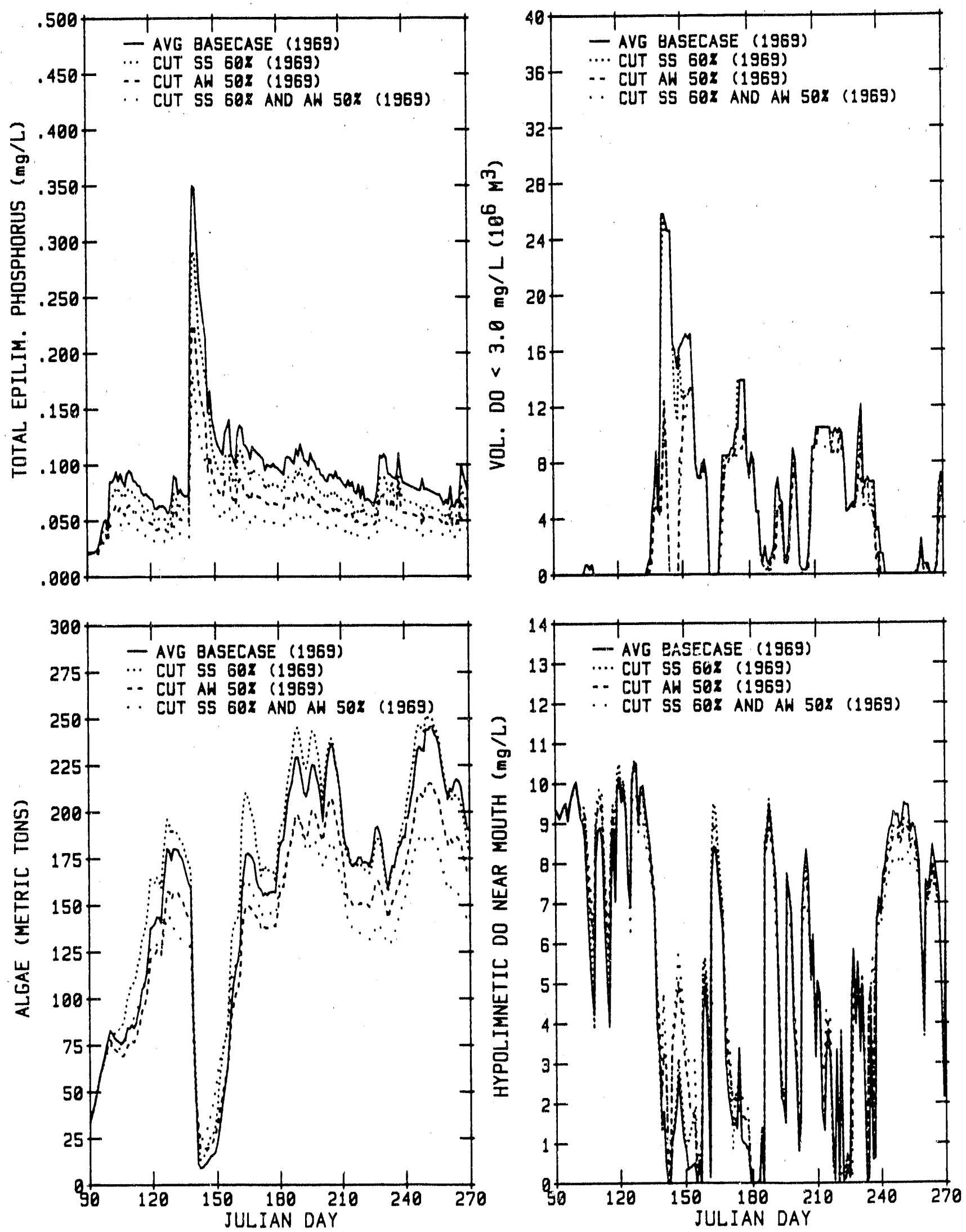

Figure 5. Effects of Suspended Solids and Animal Waste Reductions on Town Creek Embayment Epilimnetic Phosphorus, Algae, and DO (Year 1969 Average Inflow) 

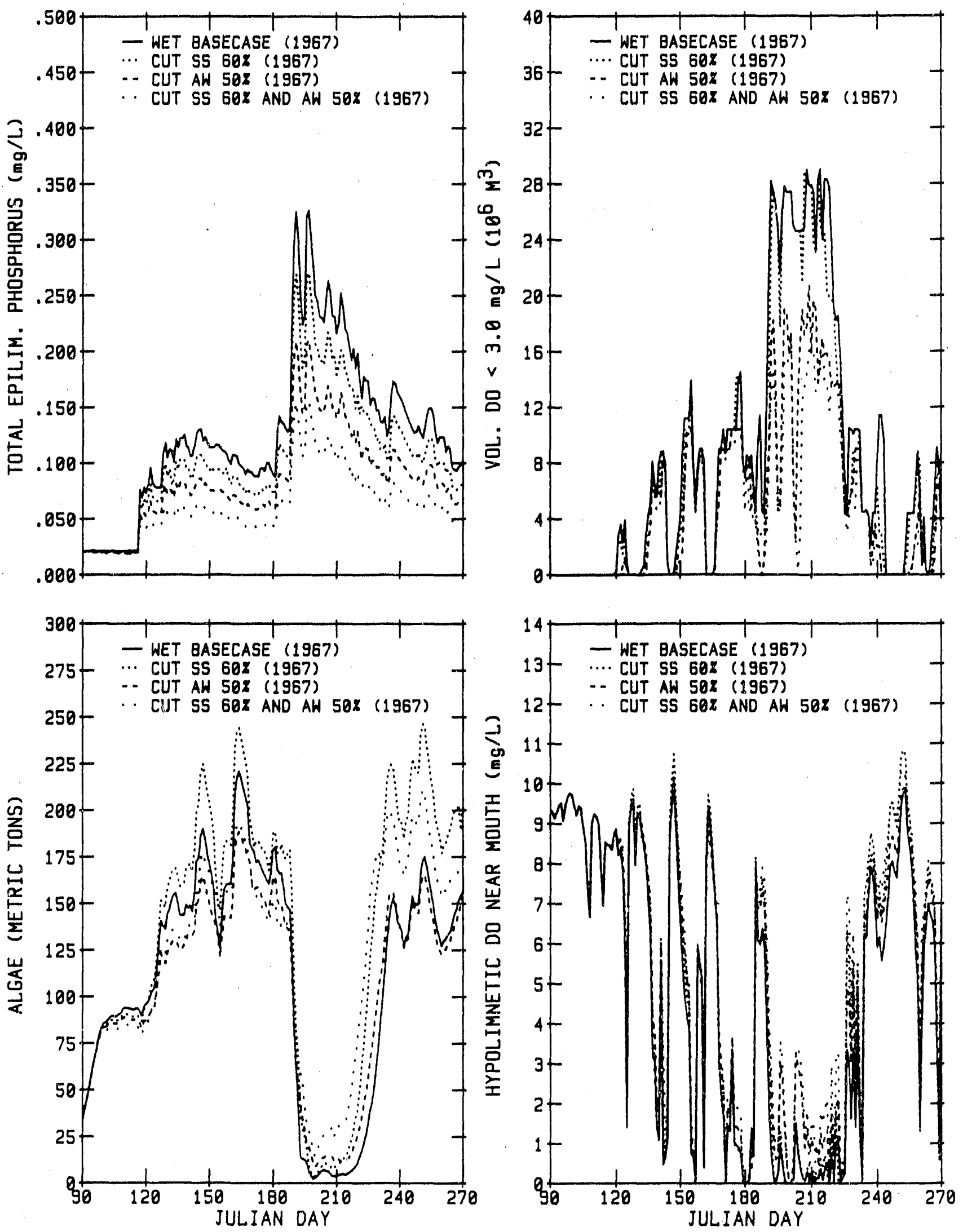

Fibure 6. Effects of Suspended Solids and Animal Waste Reductions on Town Creek Embayment Epilimnetic Phosphorus, Algae, and DO (Year 1967 Wet Inflow) 

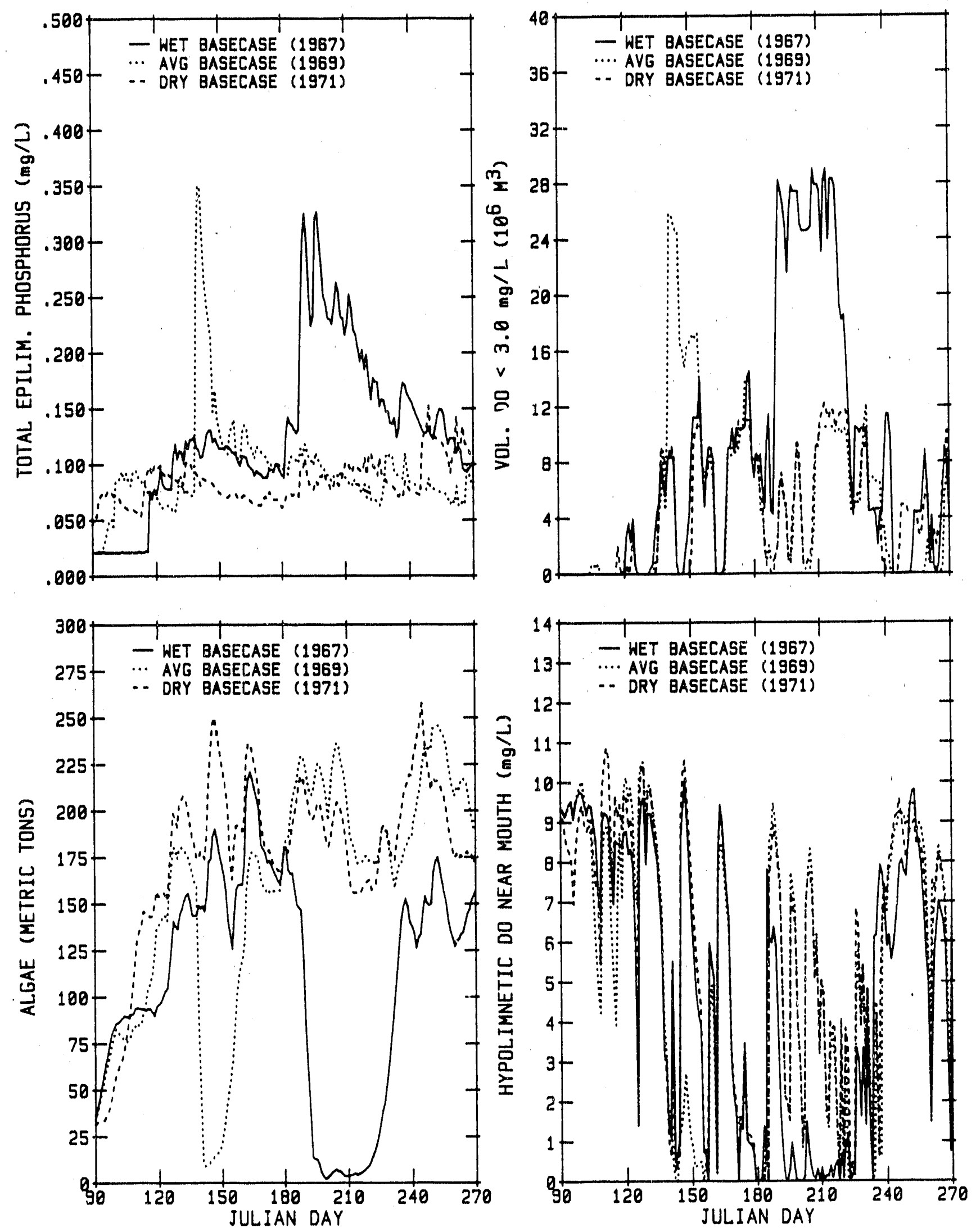

Figure 7. Effects of Flow on Town Creek Embayment Epilimnetic Phosphorus, Algae, and DO 

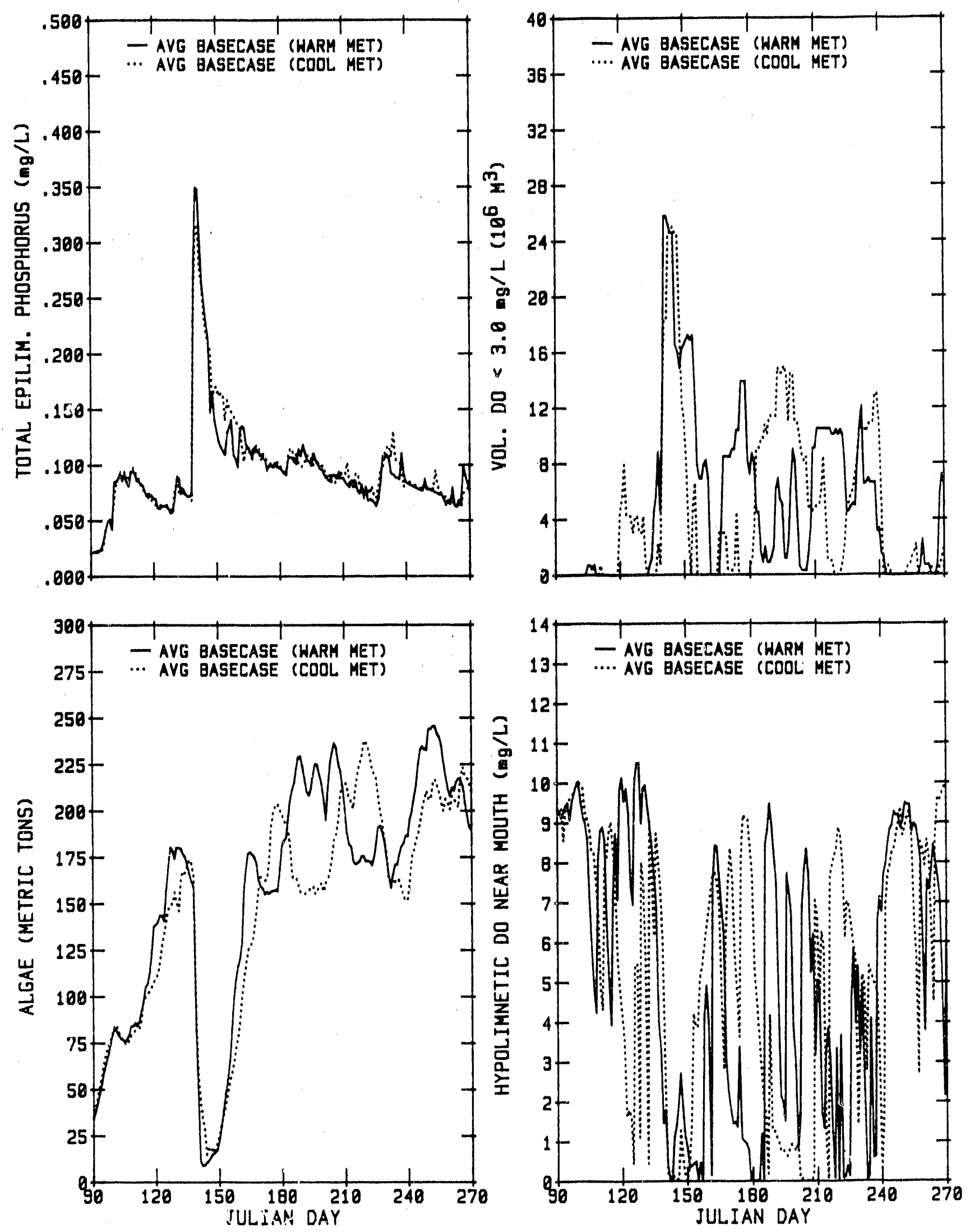

Figure 8. Effects of Meteorology on Town Creek Embayment Epilimnetic Phosphorus, Algae, and DO (Year 1969 Inflow) 

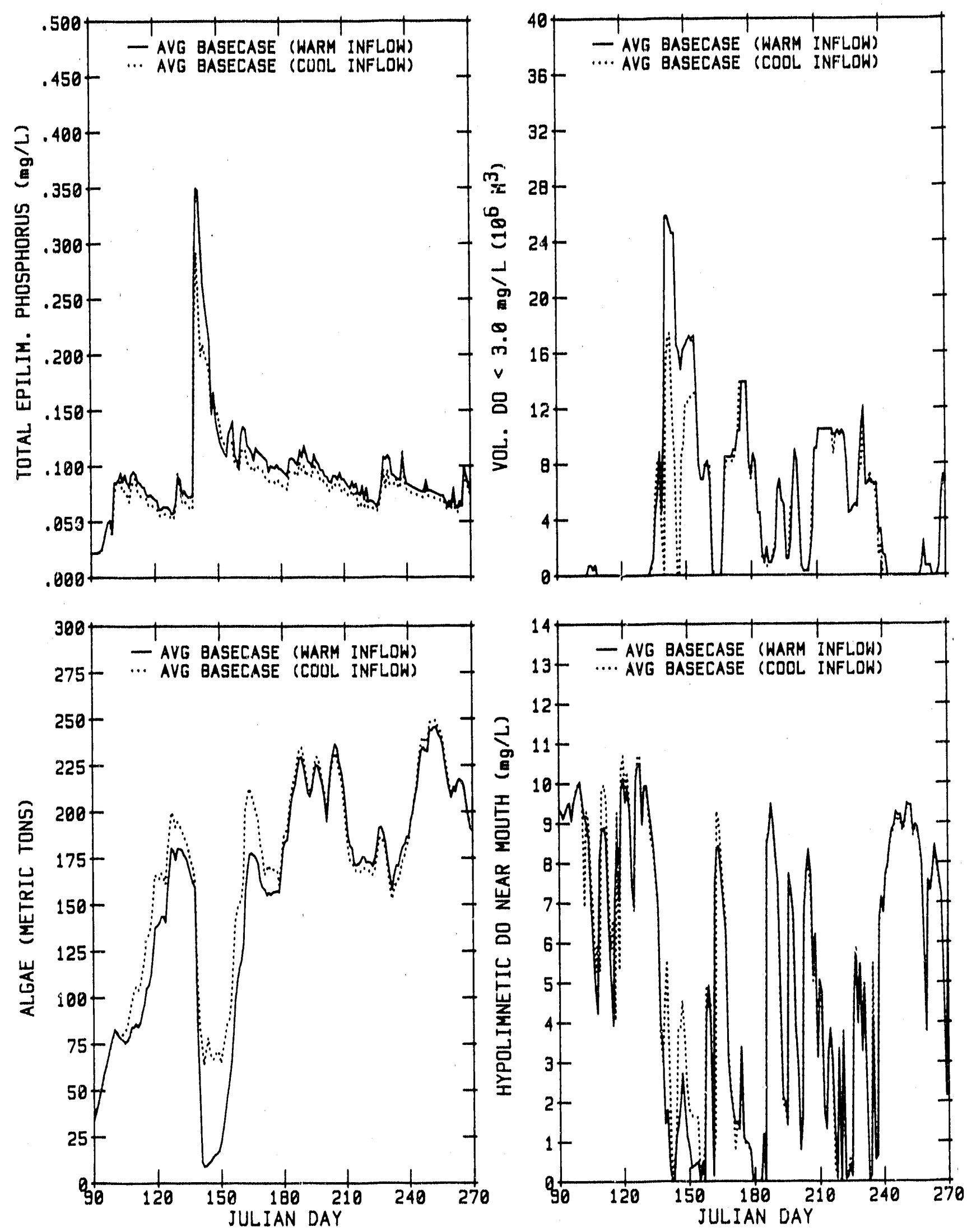

Figure 9. Effects of Town Creek Inflow Temperature on Embayment Epilimnetic Phosphorus, Algae, and DO (Year 1969 Inflow) 

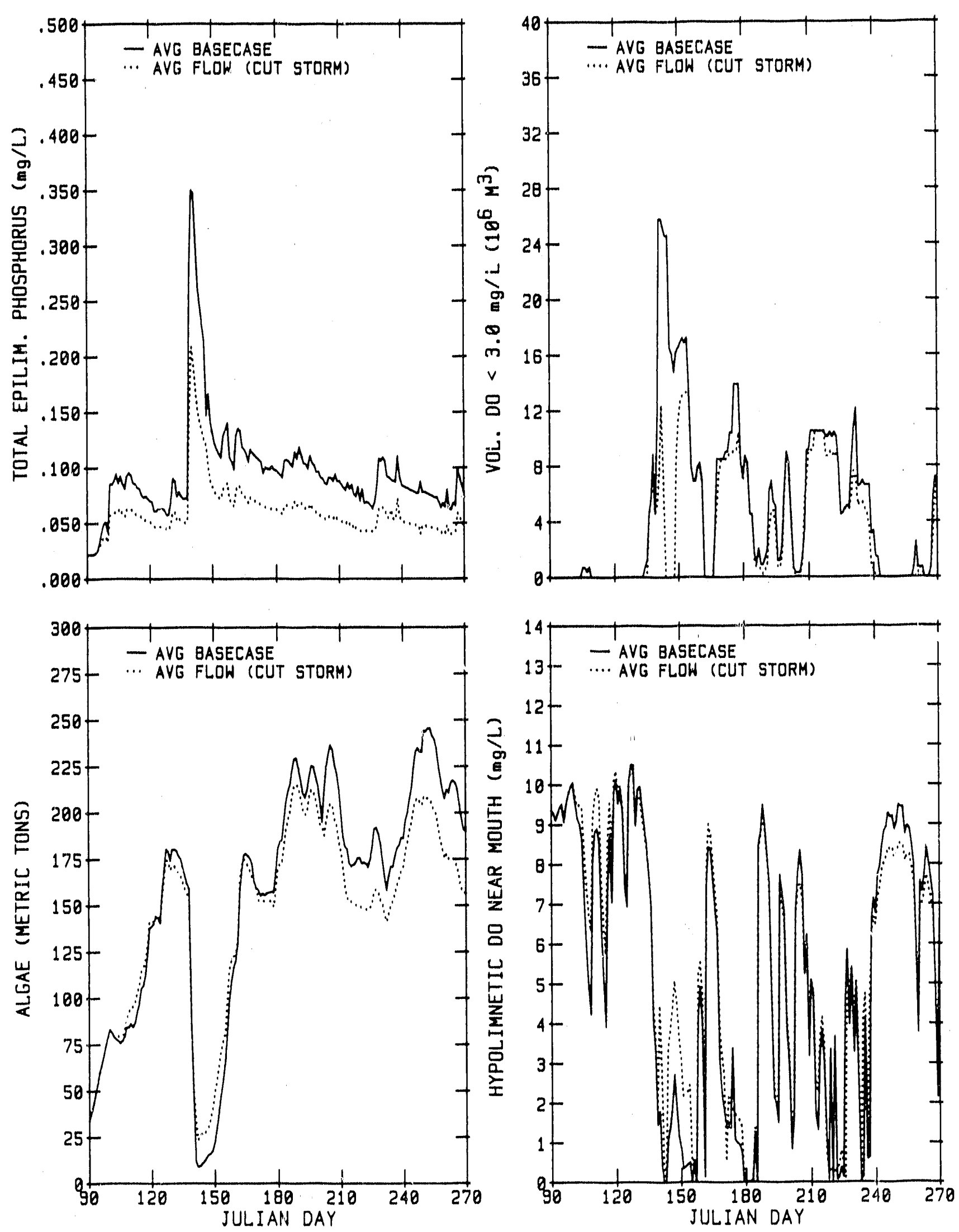

Figure 10. Effects of Reducing Storm Concentrations on Town Creek Embayment Epilimnetic Phosphorus, Algae, and DO (Year 1969 Inflow) 

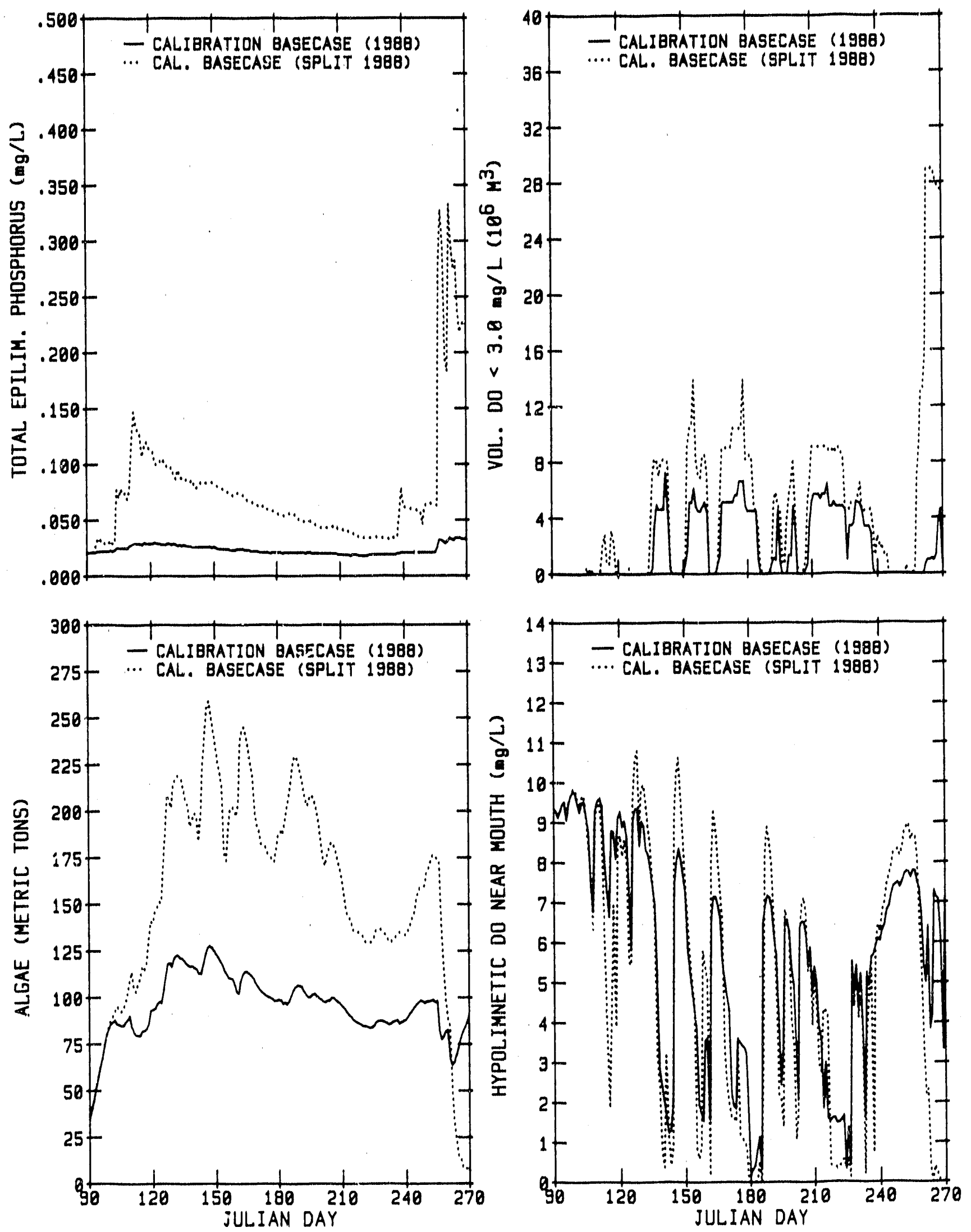

Figure 11. Effects of Applying Storm Flow Concentrations to Peak Flow Portions of 1988 Calibration Town Creek Inflow Hydrograph 

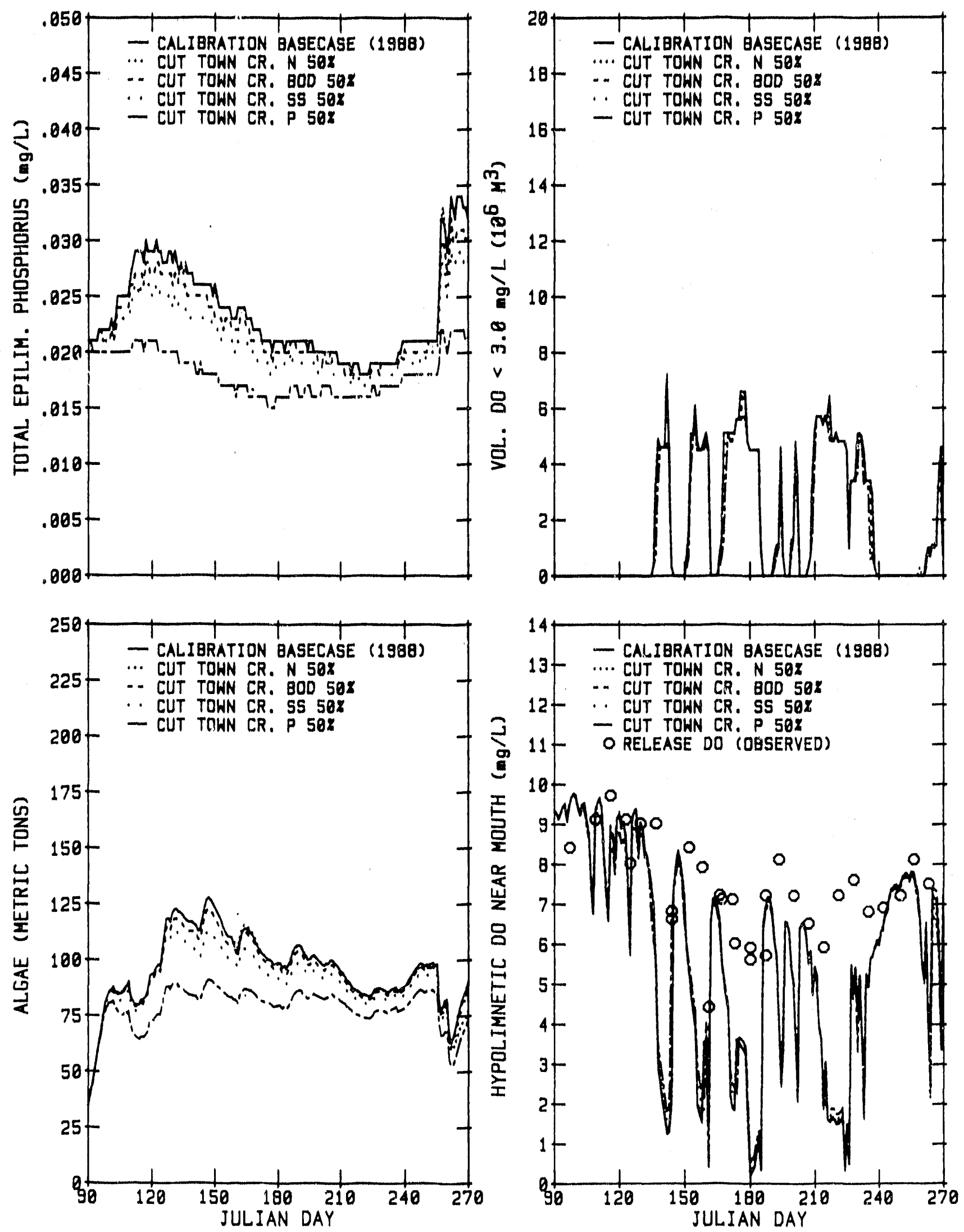

Figure 12. Effects of Cutting Town Creek Inflow Calibration Loadings on Town Creek Embayment Epilimnetic Phosphorus, Algae and DO 
reservoir volume. Approximately 5 million cubic meters (one-sixth of the embayment) is above the bridge located at TCM 2.9 .

\section{Analysis of Town Creek F'low}

Figure 7 in combination with Figures B2, B4, and B5 shows the significant effects of flow on epliimnetic phosphorus, algal biomass, and Do in Town Creek embayment. Figure 7 compares wet, average, and dry Town Creek flow cases. Total epilimnetic phosphorus spikes reflect high flows. Decreases in algal biomass correspond directly with large increases in flow (see Figures B2, B4, and B5) and thus suspended solids. Note that large spikes on Figures B3-B6 do not $f$ it on the plot. During storms, large flows flush water with poor quality out of the embayment. However, modeling indicates that excessive BOD and ammonia are introduced into the embayment. These carbonaceous and nitrogenous oxygen demands increase the volume of DO less than $3 \mathrm{mg} / \mathrm{L}$ (Figure 7, top right plot). Hypolimnetic Do near the mouth fluctuates rapidly with both flow and changes in meteorology.

\section{Analysis of Meteorology}

Figure 8 shows the effect of meteorology on Town Creek embayment epilimetic phosphorus, algae, and DO. It appears that DO in T'own Creek embayment is greatly affected by meteorology, specifically air temperature and wind (Figure D1). Meterrology has minimal effects on algae. Guntersville Reservoir can stratify, but stratification is usually weak. During periods of stratification, DO depletion occurs in the lower layers. In Figure 8, low DO spikes are shown in the plots of reservoir volume less than $3.0 \mathrm{mg} / \mathrm{L}$ and hypolimnetic $D O$ near the embayment nouth. In addition to wind, stratification is greatly affected by air temperature. Cooling periods drop surface temperatures below reservoir inflow temperatures and cause the reservoir to mix oxygenated surface waters into the lower layers.

\section{Analysis of Town Creek Embayment Inflow Temperature}

Figure 9 shows the effect of cool Town Creek inflow temperatures on epilimnetic phosphorus, algae, and DO. Town Creek cool inflows were 
taken to be $5^{\circ} \mathrm{C}$ lower than basedsat inflow temperatures. Inflow DO concentrations were increased by $1 \mathrm{mg} / \mathrm{L}$ to account for larger saturation values at cooler temperatures. Cool inflows dive under surface water. The cool underflows and interflows carry nutrients, organics, and suspended solids. Since less suspended solids end up in the surface layer, more light is avallable for algal growth.

\section{Analysis of Loading Sensitivity Simulations}

Figure 10 shows the effect of reducing storm concentrations of suspended solids, nutrients, and organics which were applied to the peak flow portion of the Town Creek inflow hydrograph for 1969. Storm concentrations were taken midway between base flow concentrations used in calibration and storm flow concentrations previously described. This cut the storm flow concentrations nearly in half. Total epilimnetic phosphorus showed a large decrease throughout the simulation due to reduced inflow phosphorus and reduced algal biomass. Even at these reduced concentrations, enough suspended solids remained to severely limit algal growth after storms. During dry periods (late summer and fa11), reduced nutrient loads limited algal growth. The effects of reduction in organics is seen after the spring storm in the plots of DO versus time. During dry months little change in DO was seen. These plots indicate that suspended solids loadings greatly affect algal biomass and that organic loadings have a large effect on DO.

Sensitivity to splitting and not splitting hydrographs on the 1988 calibration basecase was done to determine the effect of a never ending large watershed loading source (Figure 11). Splitting hydrographs and applying storm concentrations to the storm flow portion assumes that the source of loading is constant, i.e., it is not depleted with large amounts of runoff. The split hydrograph case shows that if excessive nutrients and organics were introduced during the early 1988 spring storm, algal biomass and volume of Do less than $3.0 \mathrm{mg} / \mathrm{L}$ would increase greatly. This does not match 1988 observed reservoir profiles. Mode1 pH profiles were about one $\mathrm{pH}$ unit too large and Do profiles showed excessive supersaturation. These observations provide further confidence 
in the 1988 calibration which did not split hydrographs and used a constant concentration. The discrepancies between splitting and not splitting hydrographs suggest actual conditions lie somewhere between the two cases.

Figure 12 shows the sensitivity to reducing individual nutrients, BOD or suspended solids by 50 percent in Town Creek embayment compared to the 1988 calibration basecase. The Town Creek inflow hydrograph was neither split for the calibration basecase nor for these sensitivity simulations. Little loading was deposited in the reservoir during the dry summer of 1988. The basic conclusion of Figure 12 is that water quality in Town Creek embayment is affected by loading changes at low loading conditions. Suepended solids concentrations were low for the calibration and did not greatly restrict light for algal growth. Cuts were applied to Town Creek inflows only and did not apply to local inflow surrounding the embayment.

The plot of total epilimnetic phosphorus versus time (Figure 12) indicates that cutting Town Creek inflowing phosphorus by 50 percent reduces total epilimetic phosphorus concentrations by about one-third. Even with a 50 percent cut, epilimetic phosphorus concentrations were about $0.02 \mathrm{mg} / \mathrm{L}$ which is plenty to sustain algal growth. A 50 percent cut would reduce algae and maintain a more constant algal biomass as shown in the plot of algal biomass versus time. Cutting suspended solids also affects epilimetic phosphorus concentrations and algae since it was assumed that one-fifth of the inflowing available nitrogen and two-fifths of the inflowing available phosphorus was bound to the suspended solids. Thus, cutting suspended solids by 50 percent also cuts inflowing phosphorus by one-fifth; however, 50 percent cuts in nitrogen and BOD had minimal effects. The same conclusions can be drawn from the plot of algae versus time (lower left). Plots of DO versus time (top right and bottom right) indicate that DO is not greatly affected by cuts to Town Creek inflowing nutrients, BOD, or suspended solids. At 1988 calibration loadings, cutting Town Creek loadings will not greatly affect D0 since meteorology and flow dominate Town Creek embayment DO. Spikes in volume of DO less than $3.0 \mathrm{mg} / \mathrm{L}$ correspond directly with hypolimetic DO. These 
spikes correlate to periods of stratification. Surface cooling events destratify the reservoir and embayment and therefore improve DO.

As was shown for Boone Reservoir (Bender, et a1., 1990b), DO is greatly affected by removal of BOD and nutrients as well as phosphorus. Cutting ammonia-N, nitrate-N, and $\mathrm{BOD}$ in addition to phosphorus has a larger effect on DO than on algae due to direct carbonaceous and nitrogenous oxygen demands exerted by organics. Approximately $4.3 \mathrm{mg}$ of DO is required to reduce $1 \mathrm{mg}$ of ammonia to nitrate. Ammonia reduction therefore has the dual effect of reducing DO as well as reducing nitrogen for algal growth. Ammonia and dissolved organics exert jumediate oxygen demanis whereas there is a lag associated with decaying detritus. Detritus requires some time to settle and decay. 
SUMMARY OF MODEL RESULTS

Mode1 results were summarized by averaging water quality indicator time series over the six-month simulation period. Averaging reduces each simulation to a single number that can be compared to loadings, probability of nonexceedence based on flow, or costs. While this practice provides a means to digest the overali effects between various strategies, it eliminates seasonal variations observed in previous plots of water quality versus time. For instance, summary plots (Figures 13 through 16) do not indicate whether average seasonal daily algal biomass is lower due to elimination of a spring algal bloom or because less algae was grown throughout the simulation period. Meanings of memonics for surmary plots are found in Table 4. An interpretation of modeled constituents is given in Appendix A, Table A1.

\section{Effects of Loading on Water Quality}

Figure 13 summarizes modeled effects of bioavailable phosphorus (BAP) loading changes on Town Creek embayment algae and DO using split hydrograph conditions. Mean reservoir algae and mean volume with DO less than $3.0 \mathrm{mg} / \mathrm{L}$ for the simulation period were plotted against BAP loading given in units of mass for the simulation period. Curves connect similar reduction scenarios for different flow conditions. Each symbol represents a flow year (i.e., squares are for 1969). Another informative way to view the results would be to connect like symbols. This would connect similar flow condicions for different load reduction scenarios. Animal waste reductions alone provide a considerable reduction in both algal biomass and mean volume of Do less than $3.0 \mathrm{mg} / \mathrm{L}$. Reductions in suspended solids reduce mean volume of DO less than $3.0 \mathrm{mg} / \mathrm{L}$ but can produce more algal biomass. The combination of cutting suspended solids and animal waste improves water quality in dry or average years but may not in wet years.

Figure 14 summarizes modeled effects of suspended solids loading changes on Town Creek embayment algae and DO using split hydrograph conditions. Mean reservoir algae and DO less than $3.0 \mathrm{mg} / \mathrm{L}$ for the 

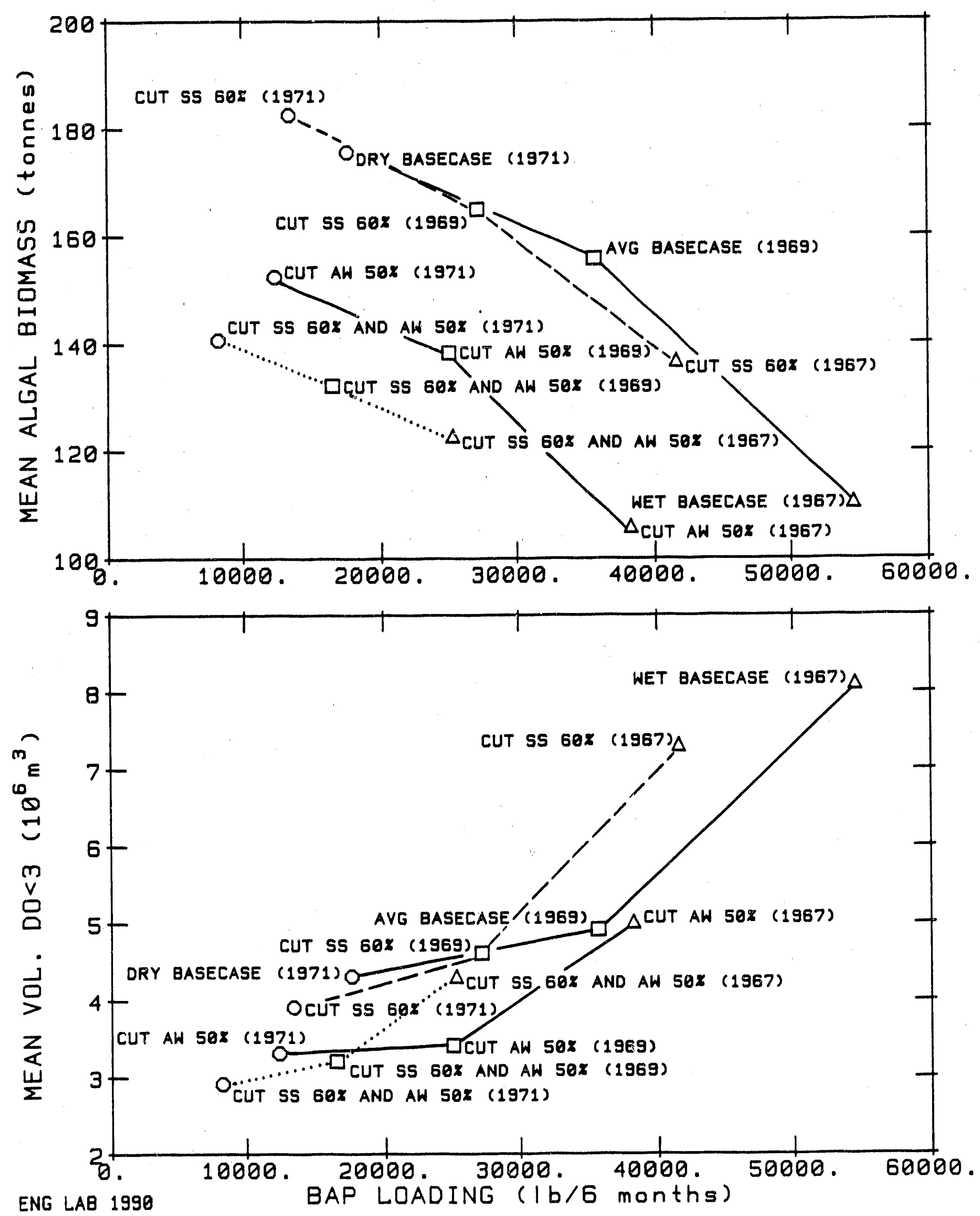

Figure 13. Summary of Modeled Effects of Bioavailable Phosphorus Loading Changes on Town Creek Embayment Algae and DO 

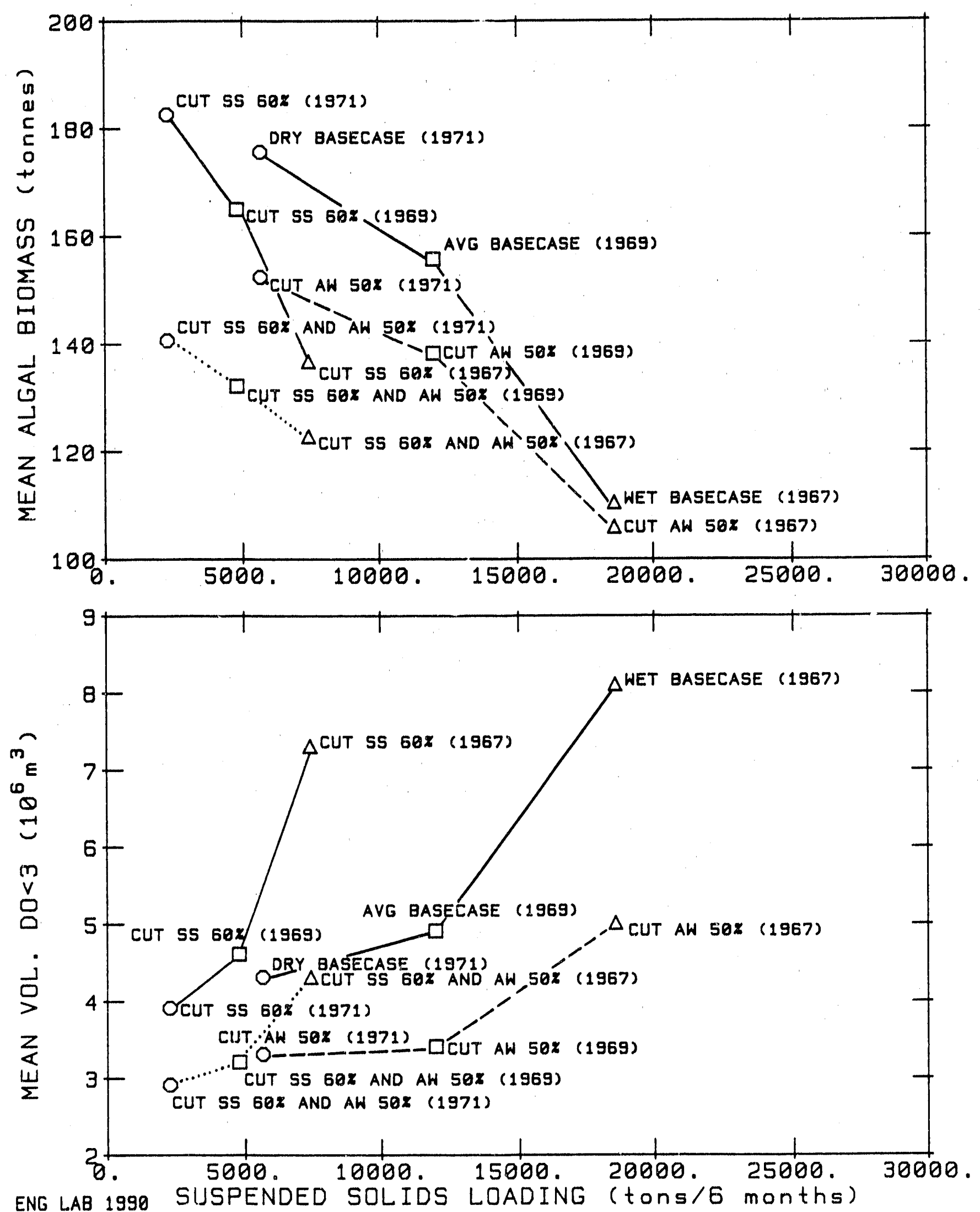

Figure 14. Summary of Modeled Effects of Suspended Solids Loading Changes on Town Creek Embayment Algae and DO 


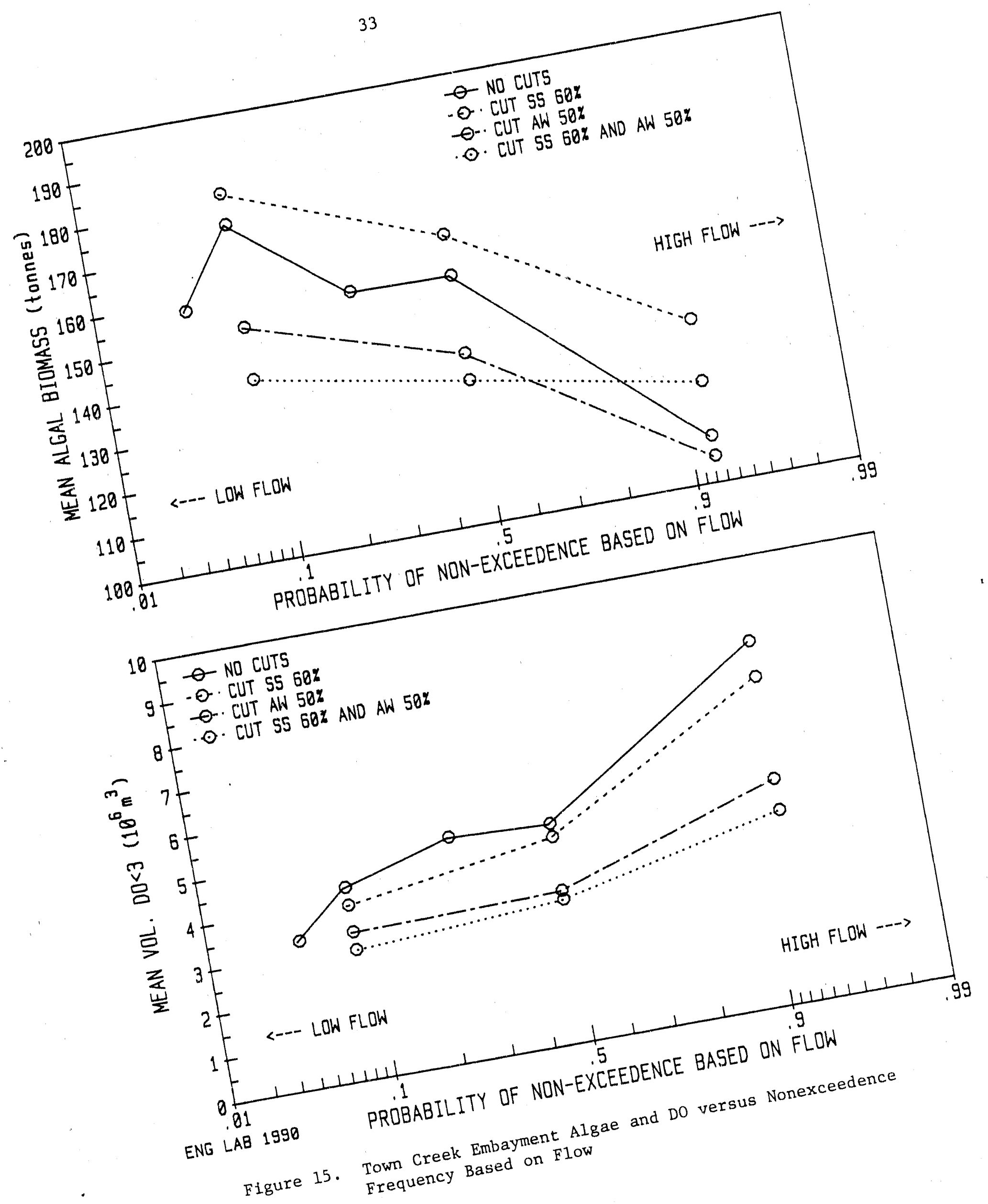



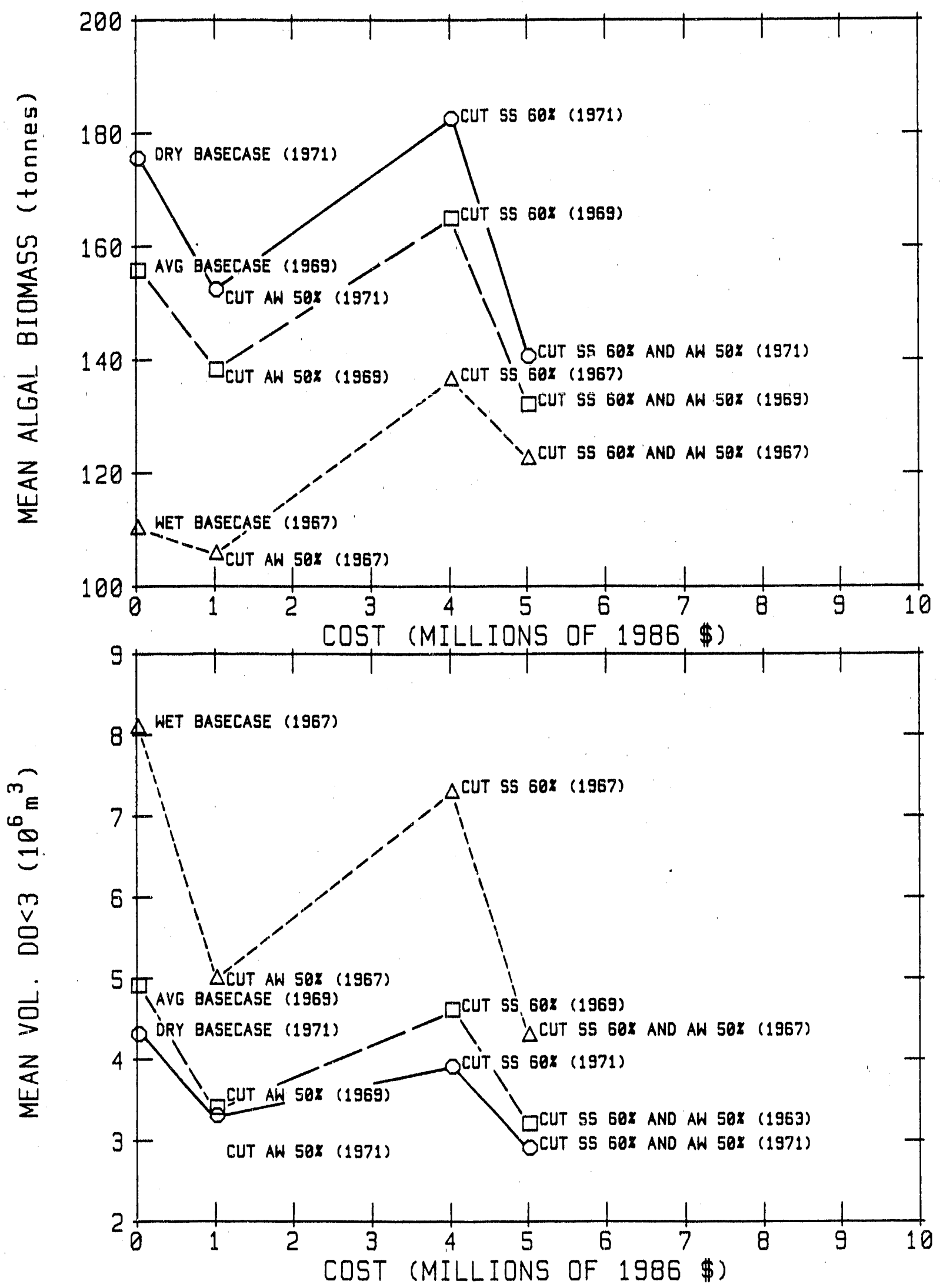

ENG LAB 1990

Figure 16. Cost-Effectiveness of Suspended Solids and Animal Waste Reductions on Town Creek Embayment Algae and DO 
simulation period were plotted against suspended solids loading. Figure 14 also shows that animal waste reductions alone provide a considerable reduction in both algal biomass and mean volume of DO less than $3.0 \mathrm{mg} / \mathrm{L}$. Suspended solids reductions alone reduce mean volume of Do less than $3.0 \mathrm{mg} / \mathrm{L}$ but can produce more algal biomass. Also Figure 14 shows that the combination of cutting suspended solids and animal waste improves water quality in dry or average years but not in wet years.

Figures 13 and 14 indicate that water quality improvement is not a linear function of either phosphorus or suspended solids load reduction. Algae in Town Creek have a surplus of nutrients at loadings used in simulations. Therefore, to severely limit algal growth requires large nutrient reductions. Under large loading conditions, algae are limited more by light than by nutrients. The effect of subsequent or cumulative suspended solids reductions appear to have less effect than initial reductions.

Probability of Nonexceedence Based on Flow

Figure 15 shows water quality conditions versus probability of nonexceedence based on flow. All simulations relate to split hydrograph conditions. Simulations with high flows (i.e., probability that flow will be less than the 1967 wet year flow is 92 percent) are located on the right portion of each plot. The top plot shows that algal biomass increases with cuts in suspended solids. In wet years, the affect of cutting only animal wastes improves water quality more than cutting both animal wastes and suspended solids. The bottom plot shows that volume of Do less than $3.0 \mathrm{mg} / \mathrm{L}$ increases with increasing flow. Do depletion is due to large quantities of organic material (carbonaceous and nitrogenous oxygen demands) being flushed into the embayment during storms.

\section{Cost-Effectiveness of Controls}

Figure 16 shows the cost-effectiveness of suspended solids and animal waste reductions using split hydrograph inputs. The more cost-effective scenarios are located in the lower left corner of each plot (greater water quality improvement for less cost). Effects on algae 
and reservoir DO indicate that animal waste reductions are more cost-effective and improve water quality much more than suspended solids reductions. Animal waste reductions applied to average 1969 basecase loads reduced mean algae by on $1 y$ 11 percent but reduced the mean volume of DO less than $3.0 \mathrm{mg} / \mathrm{L}$ by 31 percent. Suspended solids reductions improve water quality in terms of DO but not in terms of algal biomass. Cutting suspended solids and detritus increases the amount of 1 ight for algal growth. At the assumed storm concentrations, Town Creek algae are affected more by changes in light level than by changes in loading assoctated with suspended solids reductions. Suspended solids introduced during storms can suppress light levels to the point of severely limiting algal growth. Storms also introduce large amounts of nutrients and organics which may cause water quality to degrade with time. Nitrogenous and carbonaceous oxygen demands can significant1y decrease DO.

\section{Effectiveness of Using the BETTER Mode1 For Embayments}

The BETTER mode1 can be used as an effective tool for embayment water quality analysis if a suitable data base is avallable for calibration and simulations. The model allows for identification of seasonal water quality patterns and responses to uncontrollable and controllable variations in forcing functions such as hydrology and loading. Relative differences between simulations provide a basis for prediction of water quality effects and for management decisions.

The BETTER mode1 is primarily limited by a two-dimensional structure, heuristic flow fields, empirical hydrodynamics (flat pool assumption), and uncertainties in certain model formulations and inputs such as inflow loadings. The two-dimensional structure assumes that lateral variations in flow, temperatures, or constituents are negligible or can be represented by an avexage value. The effects of many sma11 embayments, shoreline morphology, and shoreline convective mixing are averaged. Heuristic flow fields based on empirical hydrodynamics (i.e., the momentum equation is not employed) enables greater model stability while allowing reproduction of flushing caused by throughflow and a rough approximation of density currents. But empirical hydrodynamics do not 
allow for simulation of waves, slope storage, shear-induced mixing at the confluence, or seiching. Shallow watex stratification at inflow points might not be effectively modeled due to a coarse grid and mixing associated with modeled inflows. Exchange at the embayment mouth might not be effectively modeled due to empirical hydrodynamics. However, uncertainty in estimating loadings appears to be a major limiting factor for embayment water quality prediction. 
Bender, Merlynn D., Gary E. Hauser, and B111 E. Johnson, "Town Creek Embayment Investigation," Tennessee Valley Authority, Englneering Laboratory Report No. WR28-1-6-102, 1990a (In Draft).

Bender, Merlynn D., Gary E. Hauser, and Ming C. Shlao, "Modeling Boone Reservoir to Evaluate Cost-Effectiveness of Point and Nonpoint Source Pollutant Controls," Tennessee Valley Authority, Engineering Laboratory Report No. WR28-1-31-107, 1990b (In Draft).

Butkus, S. R., E. B. Welch, R. R. Horner, and D. E. Spyridakis, "Lake Response Modeling Using Blologically Available Phosphorus," Journat of Watur Pollution Control Federation, Vol. 60, No. 9, pp 1663-1669, September 1988.

Butkus, Steven R., Ming C. Shiao, and Bruce L. Yeager, "The Effect of Sequoyah Nuclear Plant on Dissolved Oxygen in Chickamauga Reservoir," [Chapter 4, "Dissolved Oxygen Distribution in Chickamauga Reservoir," by Ming C. Shiao], Tennessee Valley Authority, Resource Development, River Basin Operations, Water Resources, TVA/WR/WQ-90, Chat tanooga, Tennessee, June 1990.

Cowen, W. F., and G. F. Lee, "Algal Nutrient Availability and Limitation In Lake Ontario During IFYGL. Part 1. Available Phosphorus in Urban Runoff and Lake Ontario Tributary Waters," U.S. Environmental Protection Agency, Environmental Research Laboratory, Duluth, MN, EPA-600/3-76-094a, 1976.

Dollar, Mason, Soil Conservation Service, Auburn, AL, personal communication, 1989.

Dorich, R. A., D. W. Nelson, and L. E. Sommers, "Estimating Alga1 Available Phosphorus in Suspended Sediments by Chemtcal Extraction," Journal of Environmental Quality, Vo1. 14, No. 3, pp 400-405, 1985.

Foster, Steve, Alabama Department of Environmental Management, Montgomery, AL, personal communication, 1989.

Hagerman, James R., "Aeria1 Inventory of Land Uses and Non-point Sources: Sand Mountain - Guntersville Reservoir," Tennessee Valley Authority, Water Quality Department, Report No. TVA/WR/WQ--90-7, Apri1, 1990 .

Haith, D. A., and L. L. Shoemaker, "Generalized Watershed Loading Functions for Stream Flow Nutrients," Water Resources Bulletin, Vo1. 23, No. 3, pp 471-478, June 1987. 
Haith, D. A., and L. J. Tubbs, "Watershed Loading Functions for Non-Point Sources," Proceedings of the Amertcan Society of Civil Englneers, Journal of the Environmental Engtneering DIvigton, Vo1. 107, No. EE1, pp 121-137, 1981 .

Institute of Environmental Negotiation, Division of Urban and Environmental Planning, University of Virginia, "Nutrient Control Standards Workshop, A Summary Report," Williamsburg, Virginia, May 14-15, 1987.

Jorgensen, S. E. (Editor), Handbook of Envidronmenta1 Data and Ecologica1 Parameters, Pergamon Press, New York, 1979.

Linsley, Ray K., Jr., Max A. Kohler, and Joseph L.H. Paulhus, Hydrology. for Engineers, 2nd Edition, McGraw-Hi11 Book Company, New York, 1975.

Mt1ler, W. E., J. C. Greene, and T. Shiroyama, "The Selenastrum Capricornutum Printz Algal Assay Bottle Test - Experimental Design, Application, and Data Interpretation Protocol," U.S. Envtronmenta1 Protection Agency, Environmental Research Laboratory, Corvalils, OR, EPA-600/9-78-018, July 1978 .

Mi11s, W. B., D. B. Porce1la, M. J. Ungs, S. A. Gherini, K. V. Summers, L. Mok, G. L. Rupp, G. L. Bowle, and D. A. Haith, "Water Quality Assessment: A Screenting Procedure for Toxic and Conventional Pollutants in Surface and Ground Water," U.S. Environmental Protection Agency, Athens, GA, EPA-600/6-85-002, 1985.

Poppe, Wayne, Johnny P. Buchanan, Donald L. Dycus, John J. Jenkinson, Jeffery J. Longaker, Gary L. Springston, Donald C. Wade, and David H. Webb, "Guntersville Reservoir Water Quality and Aquatic Resource Assessment," Tennessee Valley Authority, Division of Air and Water Resources, Report No. TVA/ONRED/AWR-87/29, May 1987a.

Poppe, Wayne, "Guntersville Reservoir Water Quality and Aquatic Resource Assessment Management Plan," Tennessee Valley Authority, Division of Air and Water Resources, Report No. TVA/ONRED/AWR-87/42, Ju1y $1987 \mathrm{~b}$.

Raschke, R. L., and D. A. Schultz, "The Use of the Algal Growth Potential Test for Data Assessment," Journal of Water Pollution Control Federation, Vo1. 59, No. 4, pp 222-227, Apri1 1987.

Raschke, R. L., "The Algal Growth Potential Test, a Serisitive and Reliable Monitoring Method for Non-Point Nutrient Enrichment Assessment at the Sand Mountain Basin of Lake Guntersville, Alabama," U.S. EPA, Environmental Services Division, Athens Georgia, November 1988.

Sand Mountain - Lake Guntersville Water Quality Committee, "Water Quality Plan," technical coordination by Soil Conservation Service, Auburn, AL, December 1986 . 
Sand Mountain - Lake Guntersville Water Quality Committee, "Water Quality Plan - Supplement I," technical coordination by Soll Condervation Service, Auburn, AL, January 1987.

Schaffner, W. R., and R. T. Oglesby, "Phosphorus Loadings to Lakes and Some of Their Responses. Part 1. A New Calculation of Phosphorus Loading and Its Application to 13 New York Lakes," Limnology and Oceanography, Vo1. 23, pp 120-134, 1978.

Tchobanoglous G., and E. D. Schroeder, Water Quadity: Characterfistics. Modeling. Modification, Addison-Wesley Publishing Company, 768 pp, 1985.

Trimble, Stanley W., and William P. Carey, "Sediment Characteristics of Tennessee Streams and Reservolrs," Department of the Intertor, U.S. Geological Survey Open-File Report No. 84-749, prepared in cooperation with the Tennessee Department of Health and Environment, Nashville, TN, 1984.

U.S. Department of Agriculture, "Animal Waste Utilization on Cropland and Pastureland: A Manual for Evaluating Agronomic and Environmental Effects," USDA Utilization Research Report No. 6, EPA-600/2-79-059, October 1979.

U.S. Geological Survey (USGS), Department of the Interior, "Water Resources Data for Alabama," Surface Water Records, 1958-1988.

Vanoni, V. A. (editor), Sedimentation Engineering, American Society of Engineers, New York, NY, 1975.

Wendt, R. C., and R. B. Corey, "Phosphorus Variations in Surface Runoff from Agricultural Lands as a Function of Land Use," Journal of Environmental Quality, Vol, 9, pp 130-136, 1980. 


\section{APPENDIX A}

Model Changes and Calibration

\section{Flow and Water Quality Model.}

The flow model and water quality model of Guntersville Reservoir and Town Creek embayment was developed from a generalized water quality model of Chickamauga Reservoir (Butkus, et al., 1990). The model is a two-dimensional box model with two arms. The model simulates water quality constituents as a function of longitudinal and vertical location and time for various transient, hydraulic, meteorological, and inflow temperature conditions. Hydraulic variables plus a tri-hourly time series of dry bulb temperature, dew point temperature, wind speed, solar radiation, and inflow temperature were used to drive the model heat budget. Modeled watex temperatures were therefore responsive to changes in meteorology over the seasonal cycle as well as to flow hydraulics and inflow temperature. The BETTER model uses suspended solids load and does not consider bedload, scouring, or resuspension.

For calibration, dam and NPS loadings were input by using constant nutrient, suspended solids, and BOD concentrations multiplied by a corresponding flow; thus, load varied as a function of flow. The PS loadings were included in the local NPS loadings. Local NPS loads were fed to the surface layer. Local loadings were distributed to the respective portion of the reservoir by local drainage area. Table A1 defines modeled constituents. Figure A1 shows major physical and blochemical processes modeled in the BETTER model. Figure A2 shows details on coupling of modeled water quality processes.

Mode1 Changes

The BETTER model was changed to handle a smaller timestep on input boundary conditions (from one day down to one hour). A mass balance checker was developed to quantify the numerical accuracy of the model simulations. Mass is checked for water, phosphorus, inorganic nitrogen, and carbon. Expressed as a percentage of inflow or inflow loading, 1988 calibration mass balance differences resulted in 


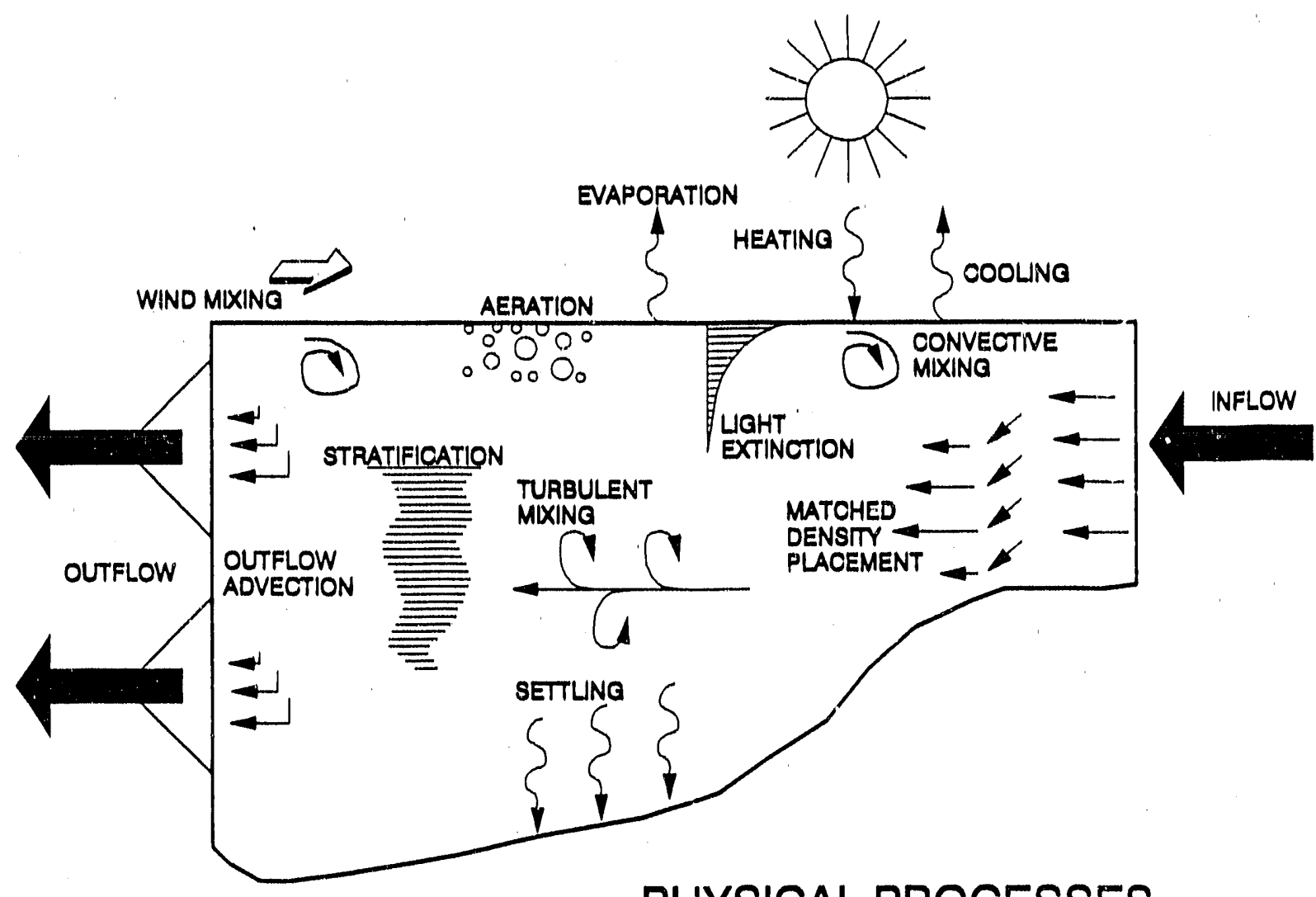

PHYSICAL PROCESSES

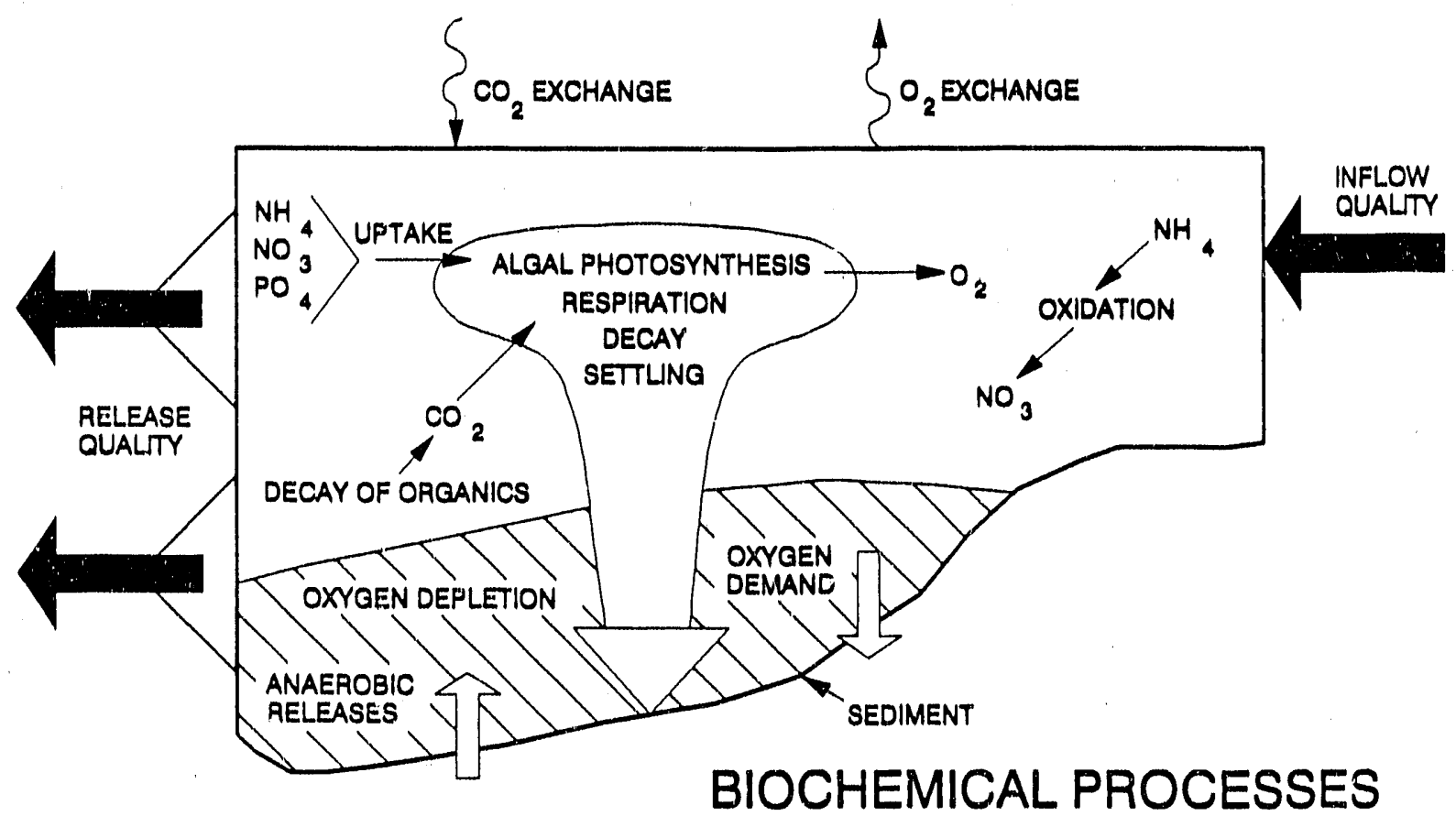

Figure A1. Major Physical and Blochemical Processes in the BETTER Mode1 


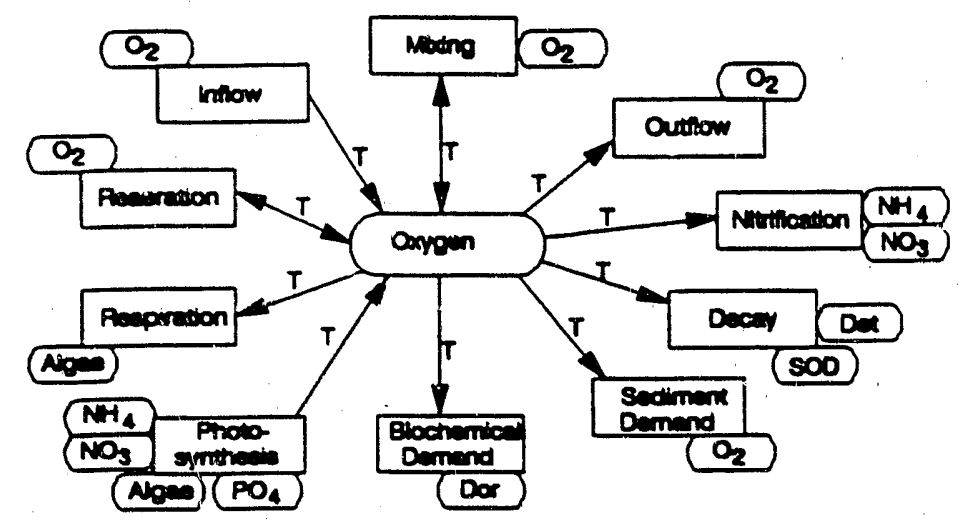

LEGEND
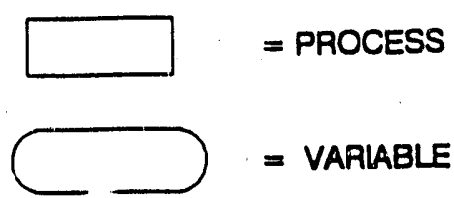

$T \quad=$ TEMP. DEPENDENT
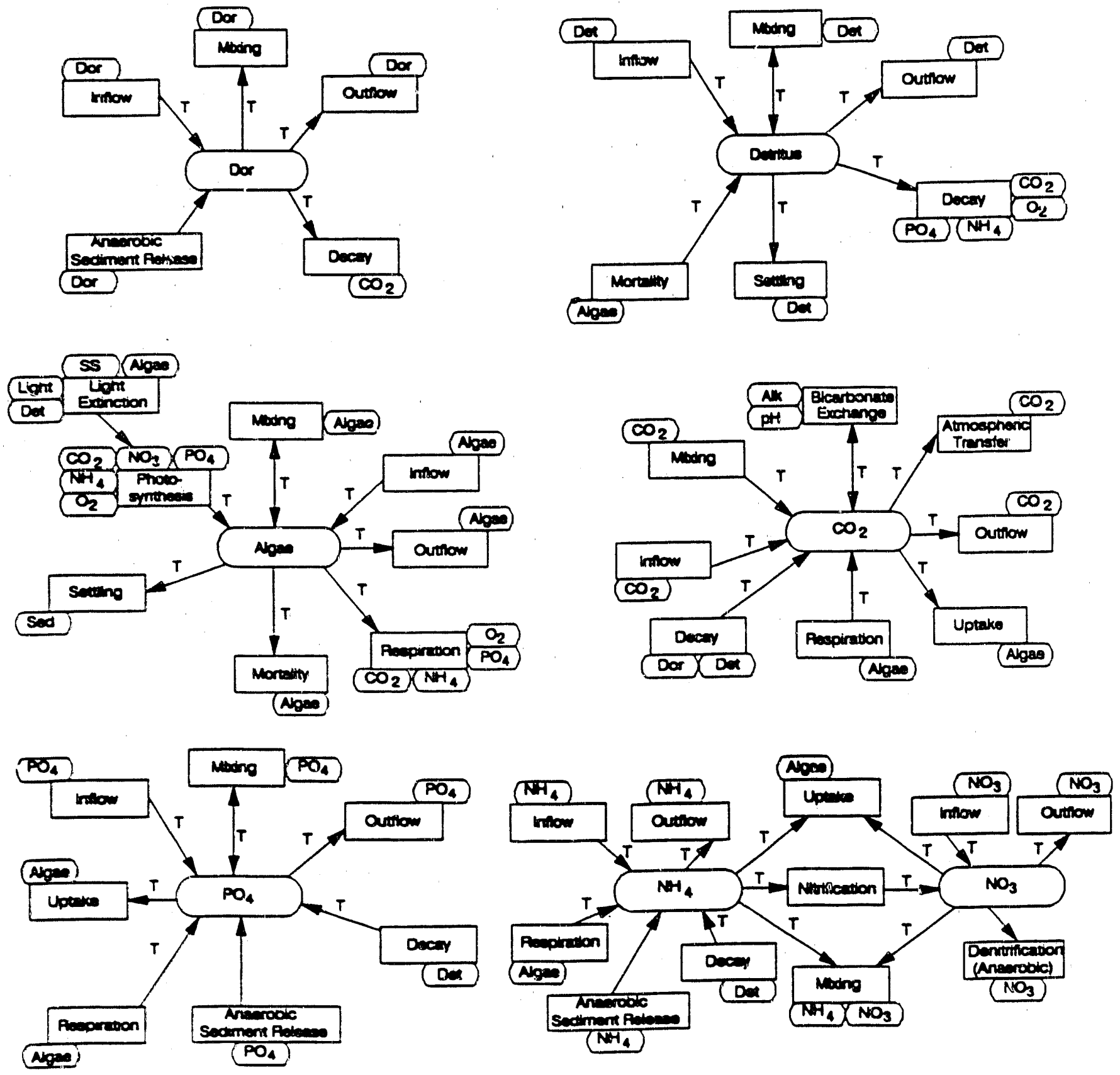

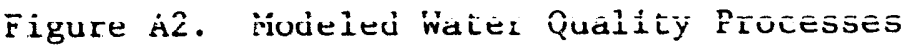


0.02 percent for water, -0.12 percent for phosphorus, -0.11 percent for inorganic nitrogen, and 0.75 percent for carbon. The mass balance check provided confidence in model results.

\section{TABLE A1}

Interpretation of Modeled Constituents

\section{Constituent}

inflow, outflow

temperature

suspended solids

dissolved oxygen

$\mathrm{pH}$, alkalinity

algae

nitrate-N

ammonia-N

phosphorus

detritus

dissolved organics

\section{Specia1 Significance in Model}

-affect mixing, inflow placement, withdrawal zone

-affects stratification, turnover, inflow placement, rates of biochemical processes

-inorganic (used for light attenuation only)

-primary variable of interest

-used to determine total inorganic carbon and $\mathrm{CO}_{2}-\mathrm{C}$

-assemblage of diatoms, greens, blue-greens; responds to temperature and 1 ight/nutrient limitations; takes up nutrients for growth; settles; produces and uses oxygen; contributes to light attenuation

$-\mathrm{N}$ for algae uptake (no preference over ammonia--N)

-N for algae uptake; also exerts DO demand

-free, available, inorganic $P$ for algal uptake (usually assumed to be dissolved-P)

-suspended organic material that exerts DO demand and releases nutrients upon decay; contributes to light attenuation; settles

-dissolved carbonaceous ultimate BOD; decay rate higher than detritus; is carbon source upon decay; does not settle

\section{Calibration Flows and Loadings}

Figures A3, A4, A5, A6, and A7 illustrate 1988 modeled inflows and loadings by accumulation. The best interpretation of these figures 


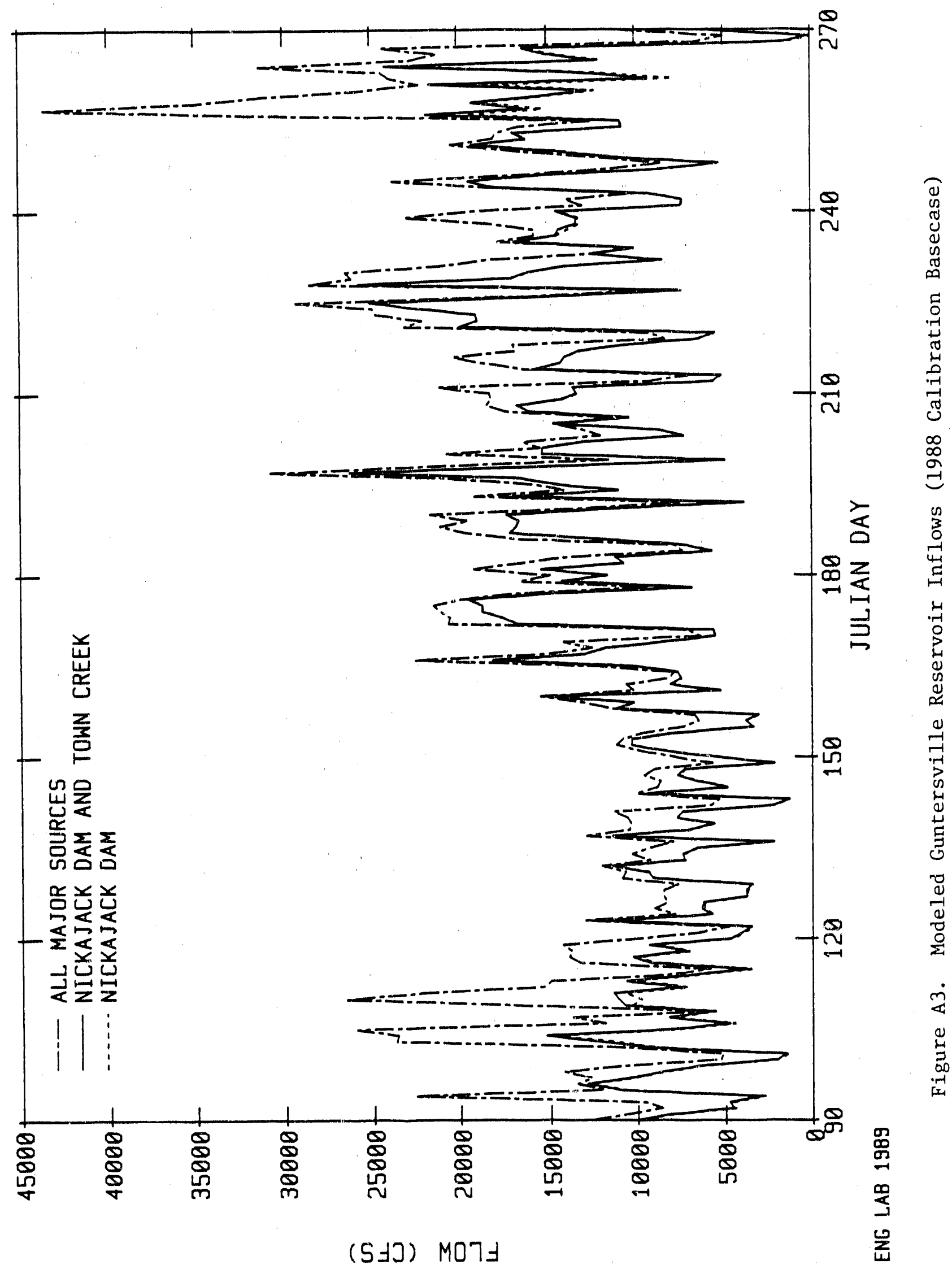




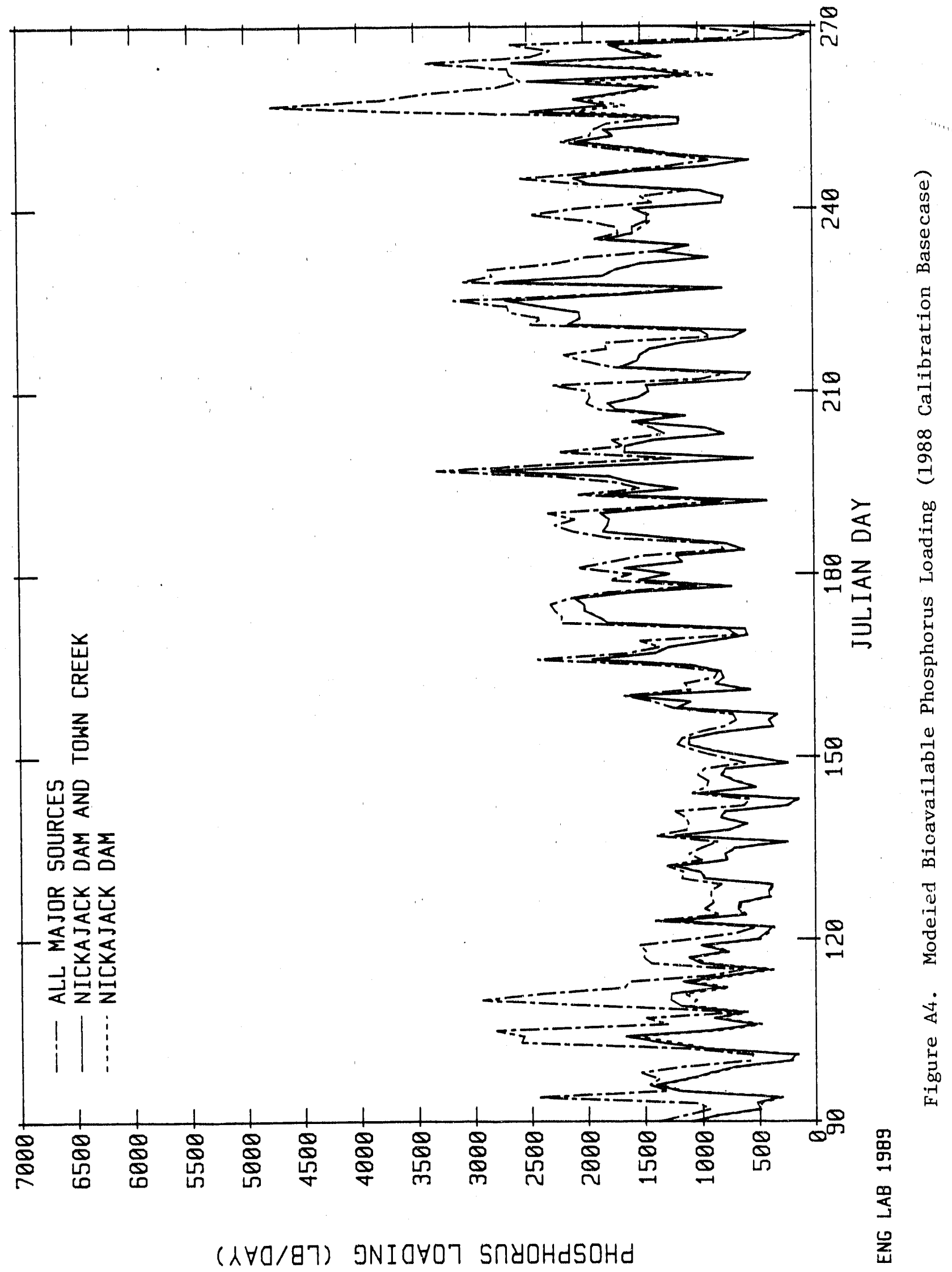




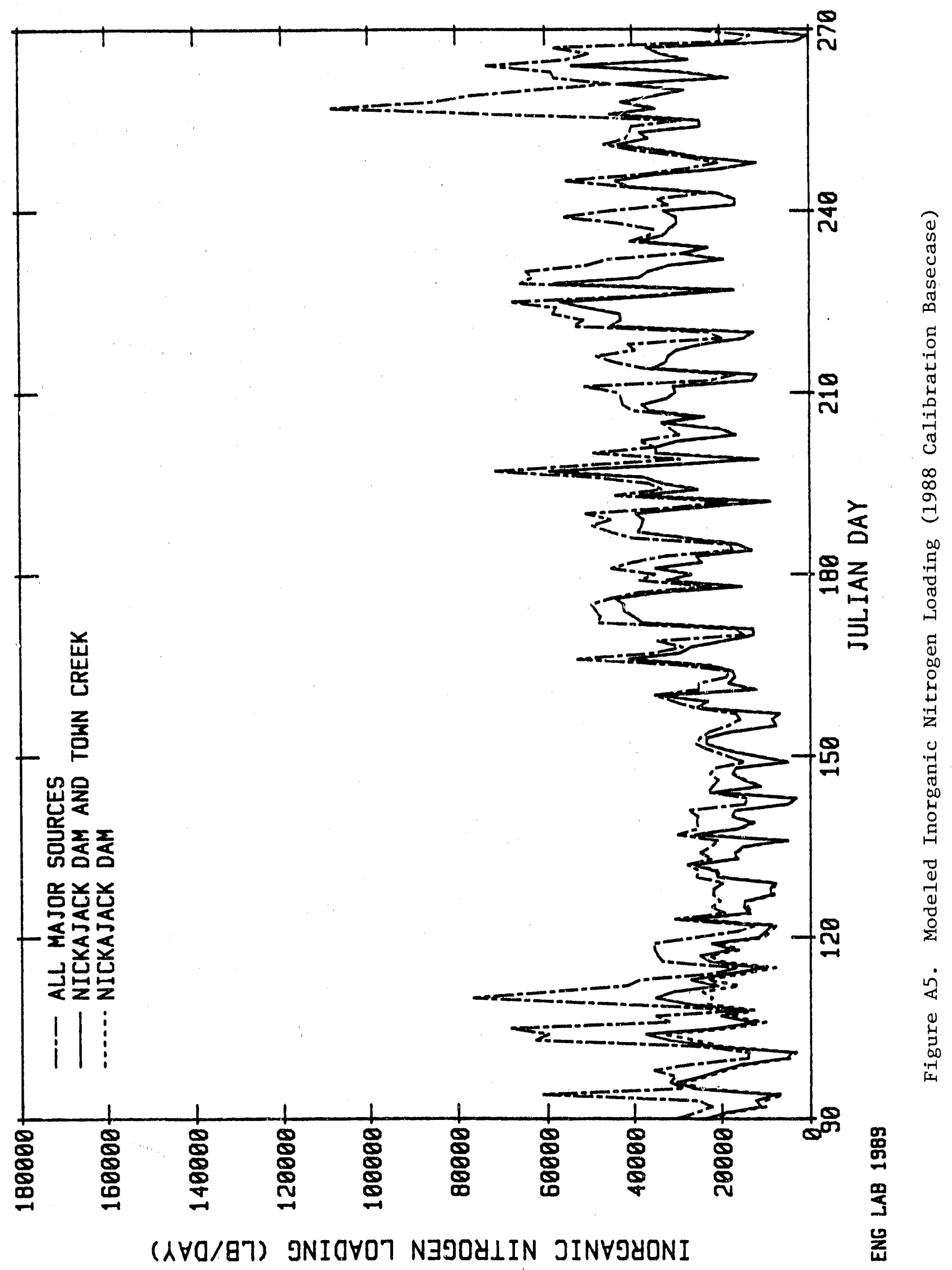




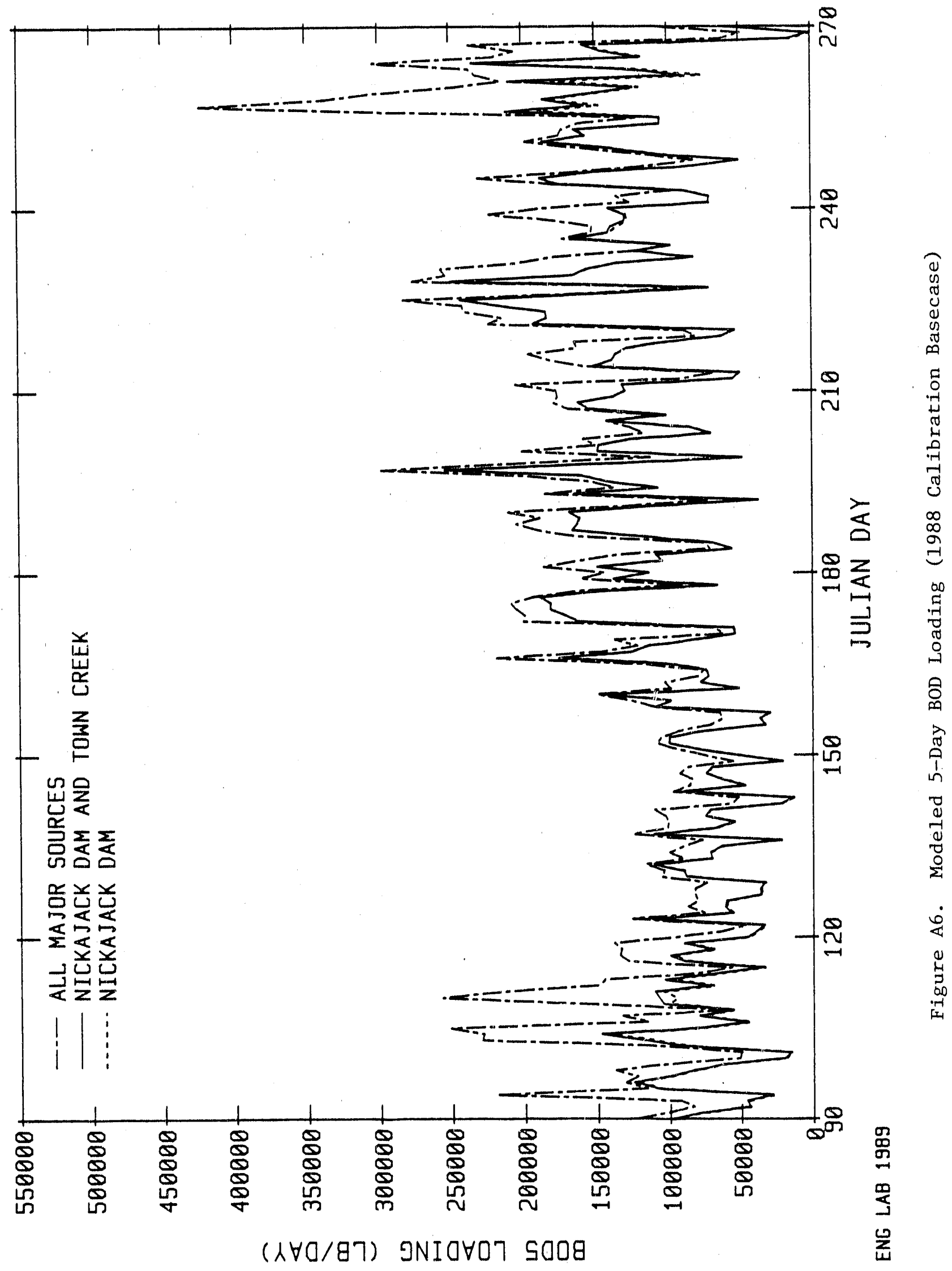




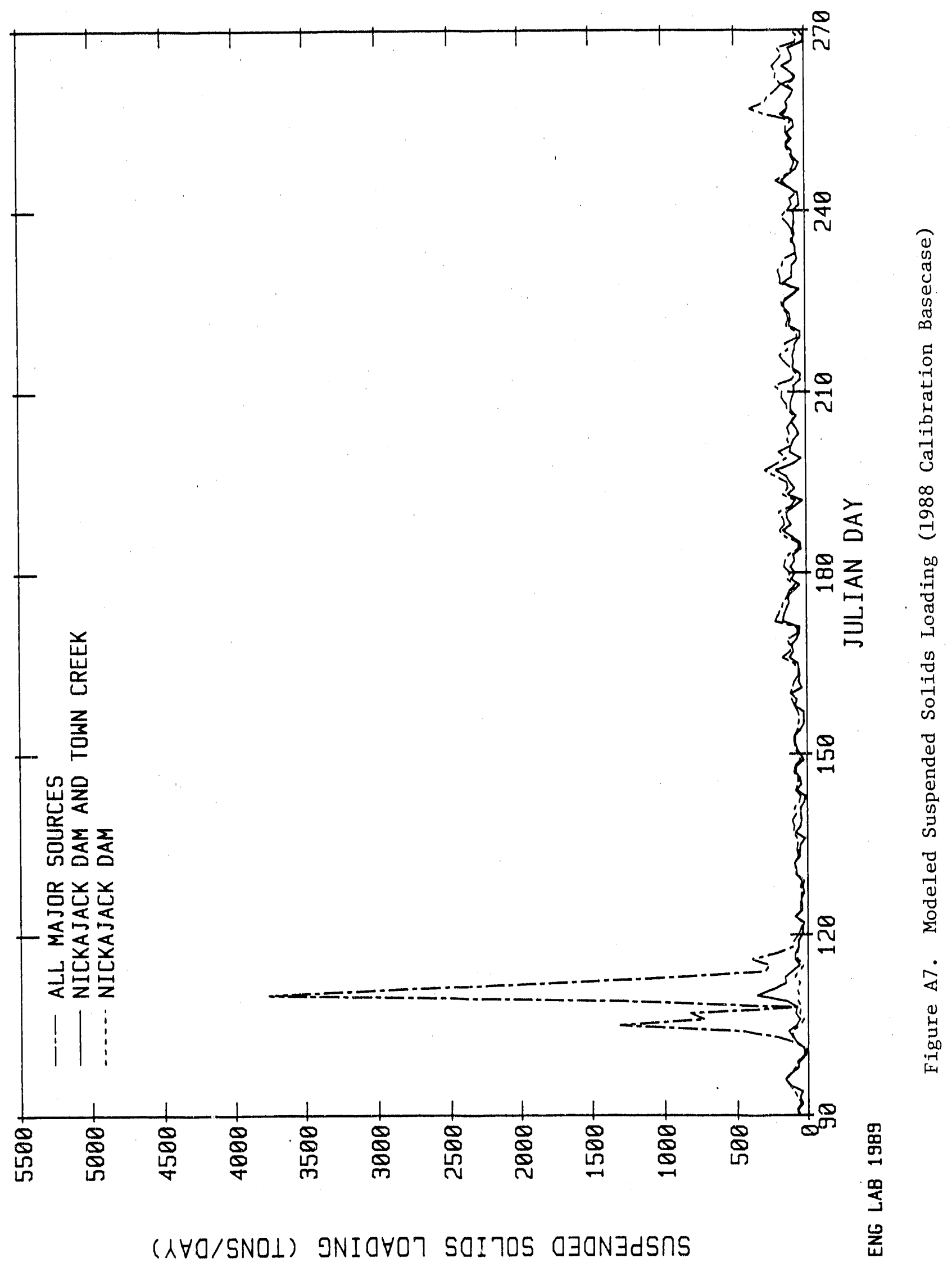


is to start at the bottom and add on major sources (Nickajack Dam + Town Creek + local inflows). Average modeled Nickajack Dam releases during April through September of 1988 were about 10,772 cfs. Town Creek modeled flows averaged $146 \mathrm{cfs}$. Average modeled local inflow was $4098 \mathrm{cfs}$, a large portion of the total reservoir flow. The small early spring storm and the release schedule for Nickajack Dam can be seen in Figure A3. Overal1 flows during 1988 were low. Small Nickajack Dam releases during May (Julian days 122 to 152) propagated an algal bloom due to a longer residence time. Town Creek lnflows can be seen more clearly in Figure B3. Detalis on calibration and simulation loadings are given in Appendix $B$.

Figures A4-A7 illustrate that nutrients, BOD, and suspended solids mimic the flow patterns shown in Figure A3. Figure A7 in combination with Figure B3 illustrates modeled suspended solids that entered Guntersville Reservoir during the spring storm in 1988.

Loading estimates for 1988 were slightly lower than observed reservoir profiles indicated, probably due to NPS loading concentrations that were derived primarily from samples during dry periods. Only one set of field data was taken near a rainfall event.

Loading estimates were slightly adjusted to better correspond with those needed for the nodel to match observed concentrations in the reservoir. This was considered reasonable because processing of nutrients and BOD is likely to have occurred before delivery to the embayment. Reservoir profiles provide a long-tern average of nutrient and BOD loads, and in conjunction with a model, provide a fair assessment of loadings to the reservoir. The amount of phosphorus lost in transit during 1988 was initially estimated from the report, "The Algal Growth Potential Test, a Sensitive and Reliable Monitoring Method for Nonpoint Nutrient Enrichment Assessment at the Sand Mountain Basin of Lake Guntersville, Alabama" (Raschke, 1988).

\section{Mode1 Calibration}

The mode1 was calibrated primarily by comparing two-dimensional temporal or spatial contour plots of field and model data. Most of the data was collected in Town Creek embayment; but the main channel was calibrated coarsely to provide a downstream boundary condition. Most 
data was collected primarily during late morning or noon. Model results were plotted at midnight except for temperature and DO. Temperature and DO were more responsive to diurnal variations and were plotted at noon. Model coefficients from calibration are summarized in Table A2, and intial conditions used are shown in Table $A 3$.

\section{TABLE A2}

Summary of BETTER Mode1 Coefficients Guntersville Reservoir/Town Creek Embayment

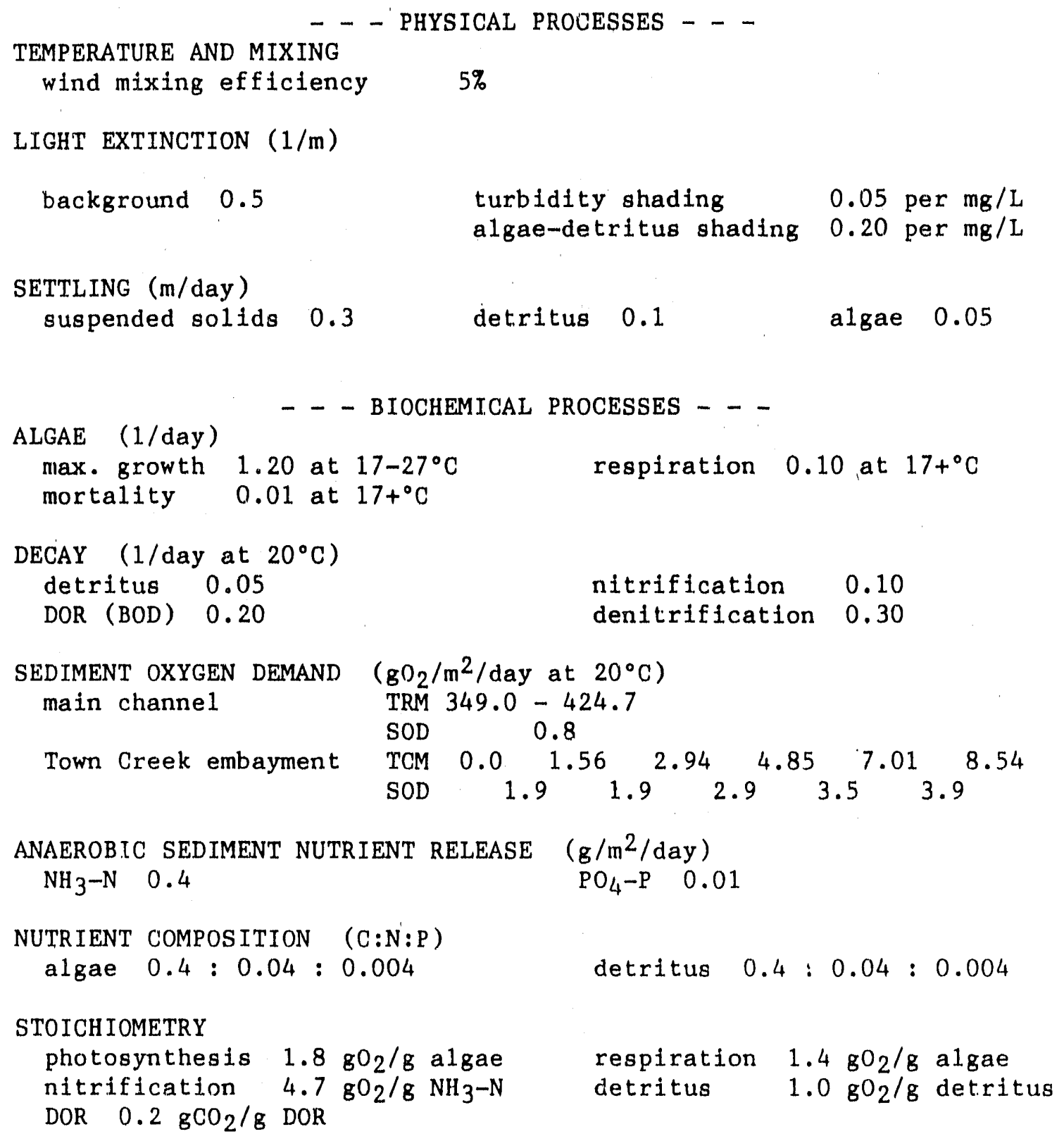


TABLE A3

Initial Conditions

$\begin{array}{lr}\text { Jullan day } & 90 \\ \text { temperature (deg C) } & 15 \\ \text { inorganic SS } & 3.9 \\ \text { DO (mg/L) } & 9.4 \\ \text { pH } & 7.6 \\ \text { alkalinity (mg/L) } & 52 \\ \text { algae (mg/L) } & 1.0 \\ \text { detritus (mg/L) } & 1.7 \\ \text { dissolved organics BOD (mg/L) } & 1.7 \\ \mathrm{NH}_{3}-\mathrm{N} \mathrm{(mg/L)} & 0.1 \\ \mathrm{NO}_{3}-\mathrm{N} \mathrm{(mg/L)} & 0.28 \\ \mathrm{PO}_{4}-\mathrm{P} \mathrm{(mg/L)} & 0.01\end{array}$

Temperature--Physical processes often dominate water quality profiles; therefore, model temperature calibration was critical. Modeled day temperature profiles match measured fleld data reasonably well (Figure A8). Differences between modeled night temperatures and modeled day temperatures were usually less than $2^{\circ} \mathrm{C}$. The main channe1 stratification patterns match mostly to within about one degree. Due to the limited amount of field data, mixing events were indicatea more frequently by the model. Due to the more frequent mixing events, model data was plotted with two degree contour intervals rather than one degree contour intervals as used for the field data. Water temperature profiles indicated mixing and flow patterns caused by densimetric differenceo between layers of different temperature. The model allows for mixing between segments and between Guntersville Reservoir and Town Creek embayment, as well as between vertical layers.

Upstream Town Creek modeled segments did not reproduce the stratification patterns indicated by field data. Apparently less vertical mixing occurs in Town Creek embayment than modeling indicates. Mixing in Town Creek embayment was reduced greatly in the mode1 (40 times less vertical mixing in the embayment than in the main channe1), but still this did not result in reproducing embayment stratification patterns. Meteorology and local inflows contributed significantly to the temperature stratification patterns. The bottom temperatures may be affected by cold water caught in natural depressions. 

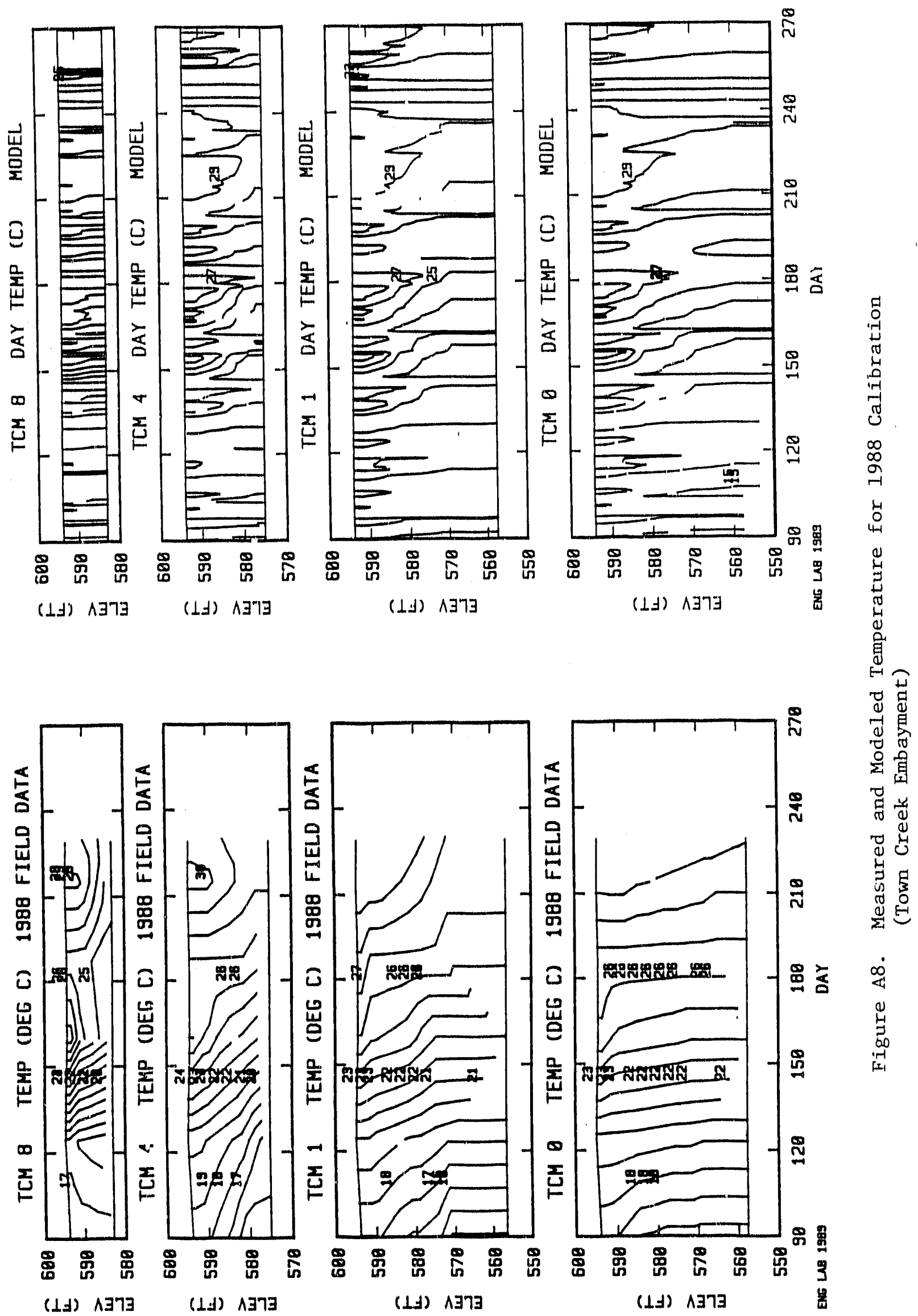

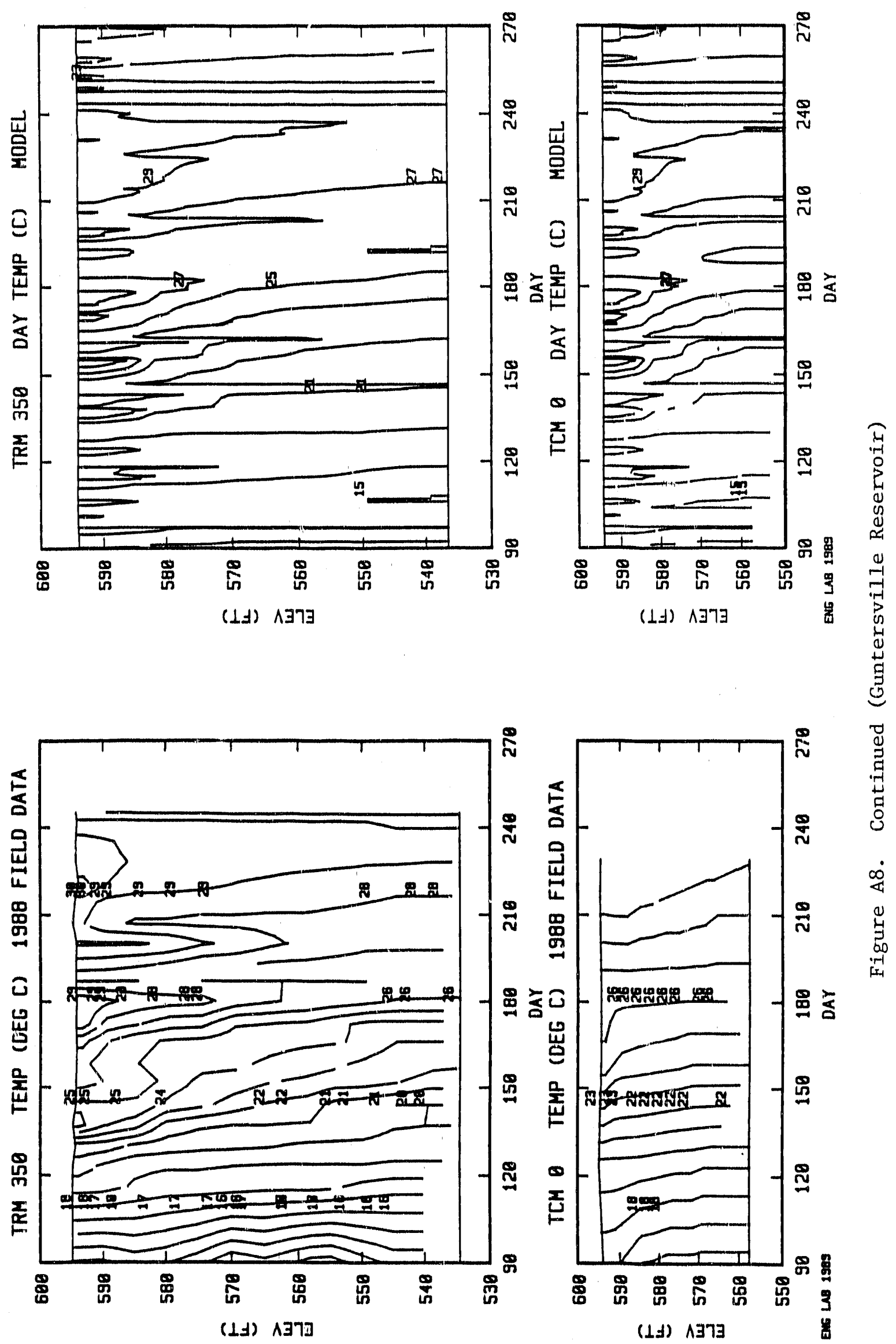
Surface temperatures of nearby reservoirs provided an indication of surface water temperatures ill Guntersville Reservoir. Surface temperatures at the mouth of Town Oreek (TCM 0.0) match surface temperatures recorded in Chickamauga Reservolr (Figures $A 9$ and $A 10$ ). Chickamauga Reservoir is just upstream of Nickajack Reservoir, and Nickajack Reservoir is just upstream of Guntersville Reservoir. Figure A9 shows temperature data at temperature station No. 13 (TRM 484.7) which is upstream of the underwater dam (TRM 483.76). The underwater dam traps cold water for Sequoyah Nuclear Plant. Bottom temperatures at TRM 484.7 during summer 1988 were cold due to the six-day continuous cold water slug that was released from Norris Dam starting on June 24 (Julian Day 176). Bottom temperatures at the mouth of Town Creek closely matched those recorded upstream of the cold water dam until the slug of cold water from Norris Dam reached the cold water darn in early July. Figure A10 shows temperature data at temperature station No. 8 (TRM 483.4). Bottom temperatures at station No. 8 were several degrees warmer as expected since this station is downstream of the cold water dam and warm diffuser discharges (TRM 483.65), which act to vertically mix the water colum, warming the deep layer. Nickajack Dam release temperatures fall between Chickamauga and Guntersville Reservoir surface and bottom temperatures for most of the season (Figure A10). Guntersville observed release (tailrace) temperatures appear to be about one or two degrees higher than modeled release temperatures (Figure A11). But, field data was typically collected during the day while modeled release temperatures were plotted at midnight.

Dissolved Oxygen--Figure A1.2 shows measured and modeled day DO for the 1988 basecase. Overall reservoir Do profiles match field data except for a spring algal bloom in the main channel during the middle of May. Dissolved oxygen and $\mathrm{pH}$ at Honey Bluff (TRM 350) showed an algal bloom during mid-May which produced surface DO concentrations of 13 to $14 \mathrm{mg} / \mathrm{L}$. It is possible that this supersaturated condition was a localized occurrence that was not representative of the entire Guntersville forebay. Modeling sensitivity to surface reaeration and 


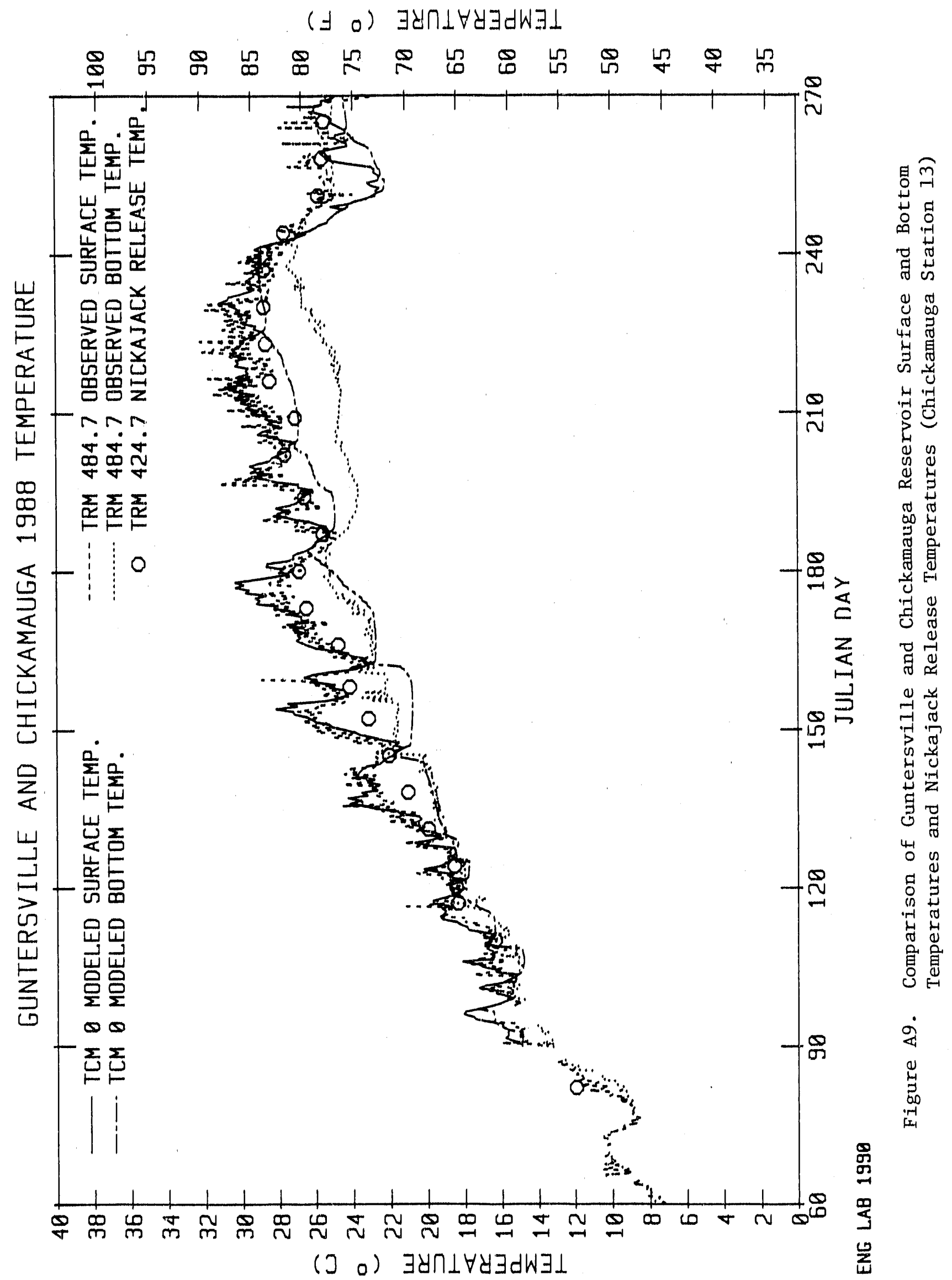




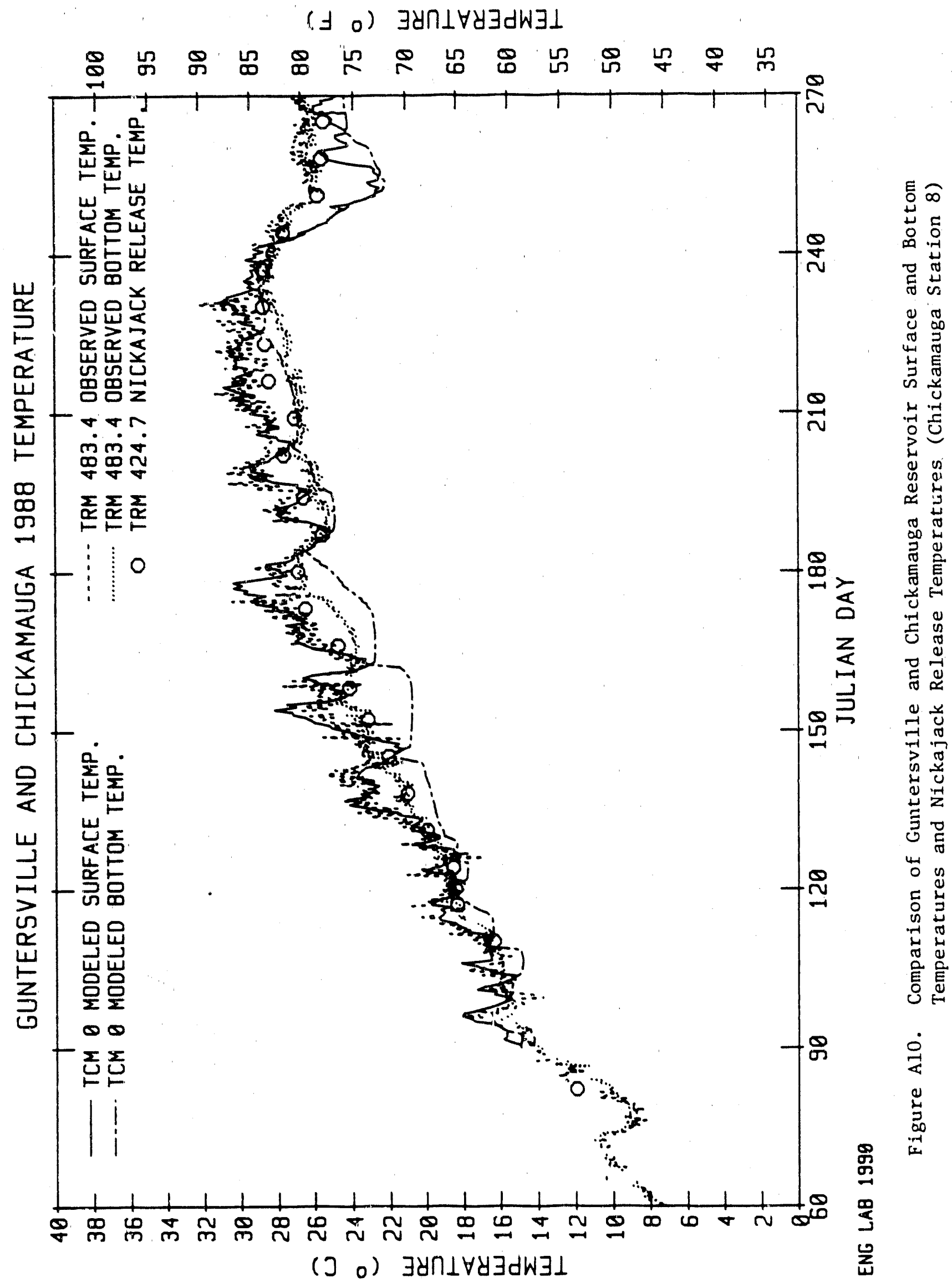



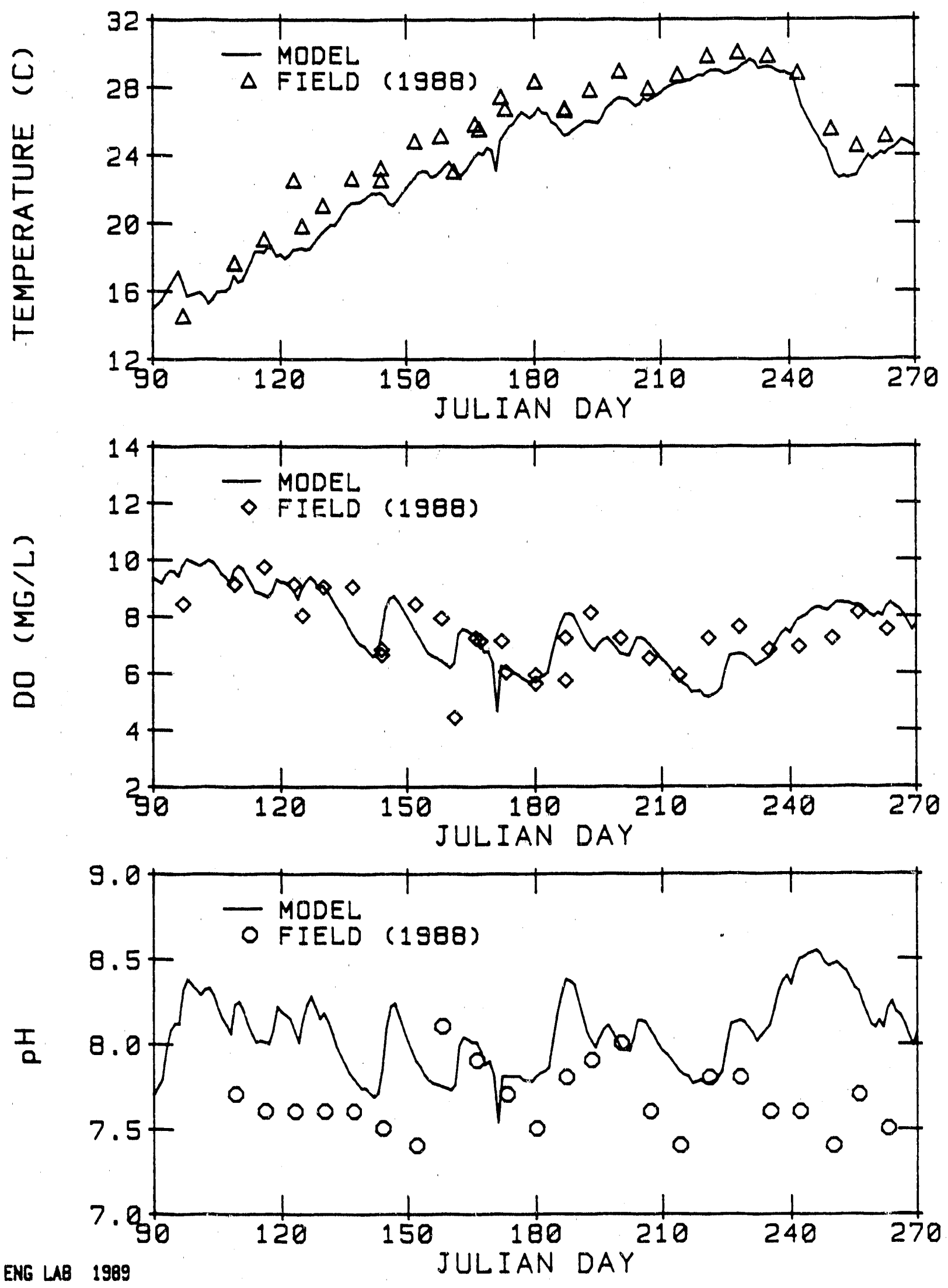

Figure All. Measured and Modeled Guntersville Dam Release Temperature, DO, and pH (1988 Calibration) 

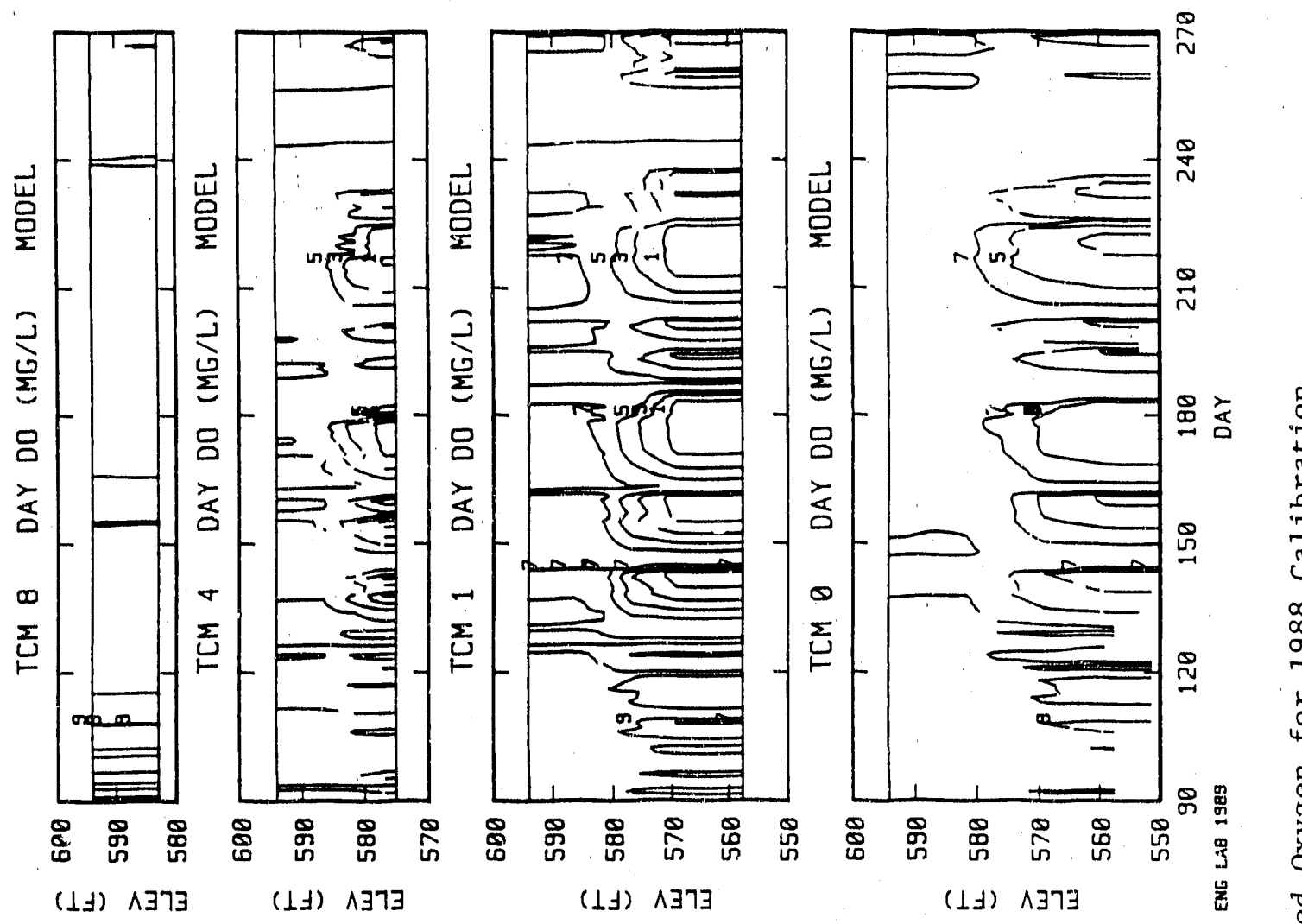

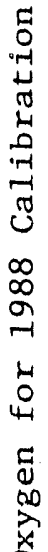
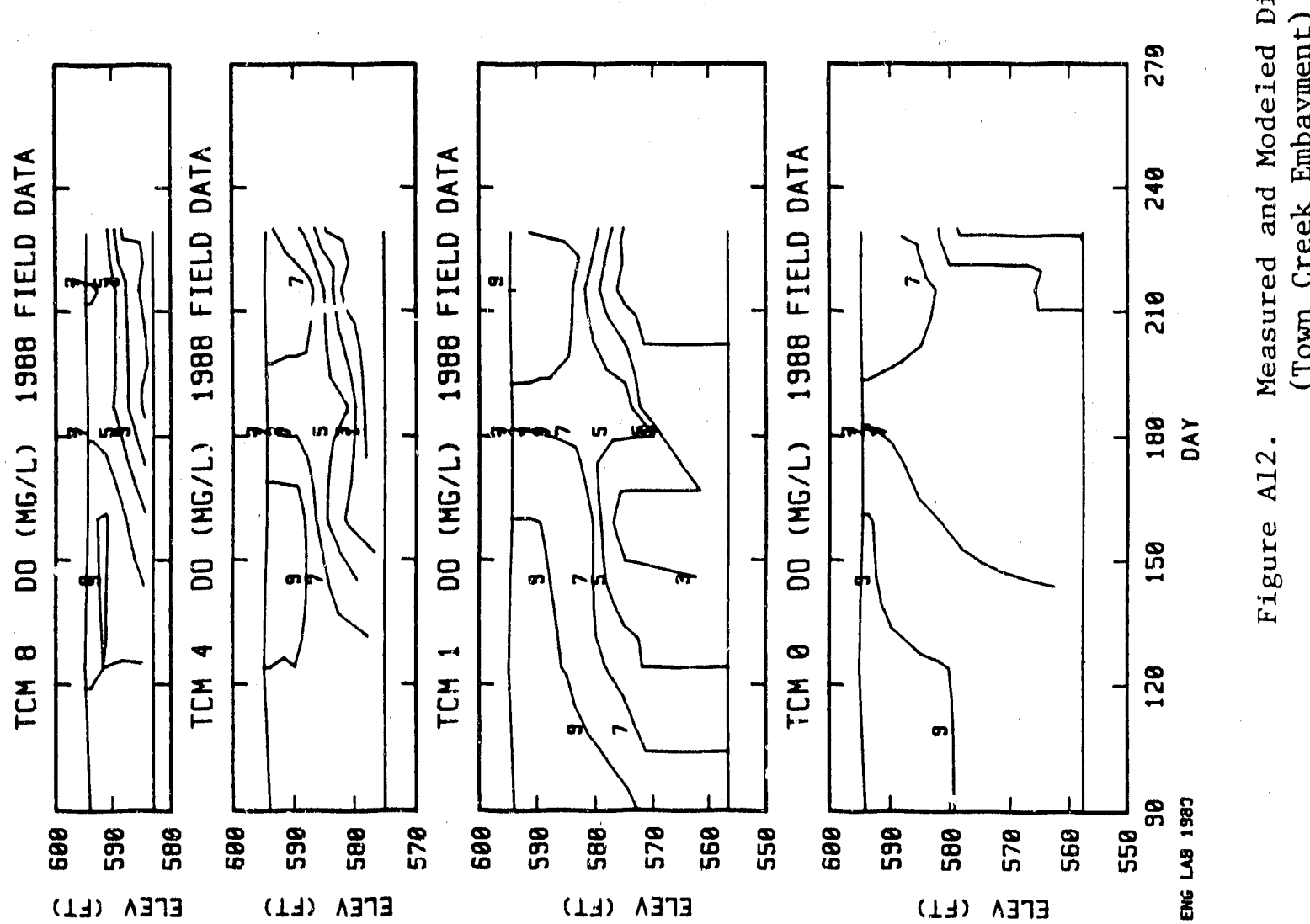

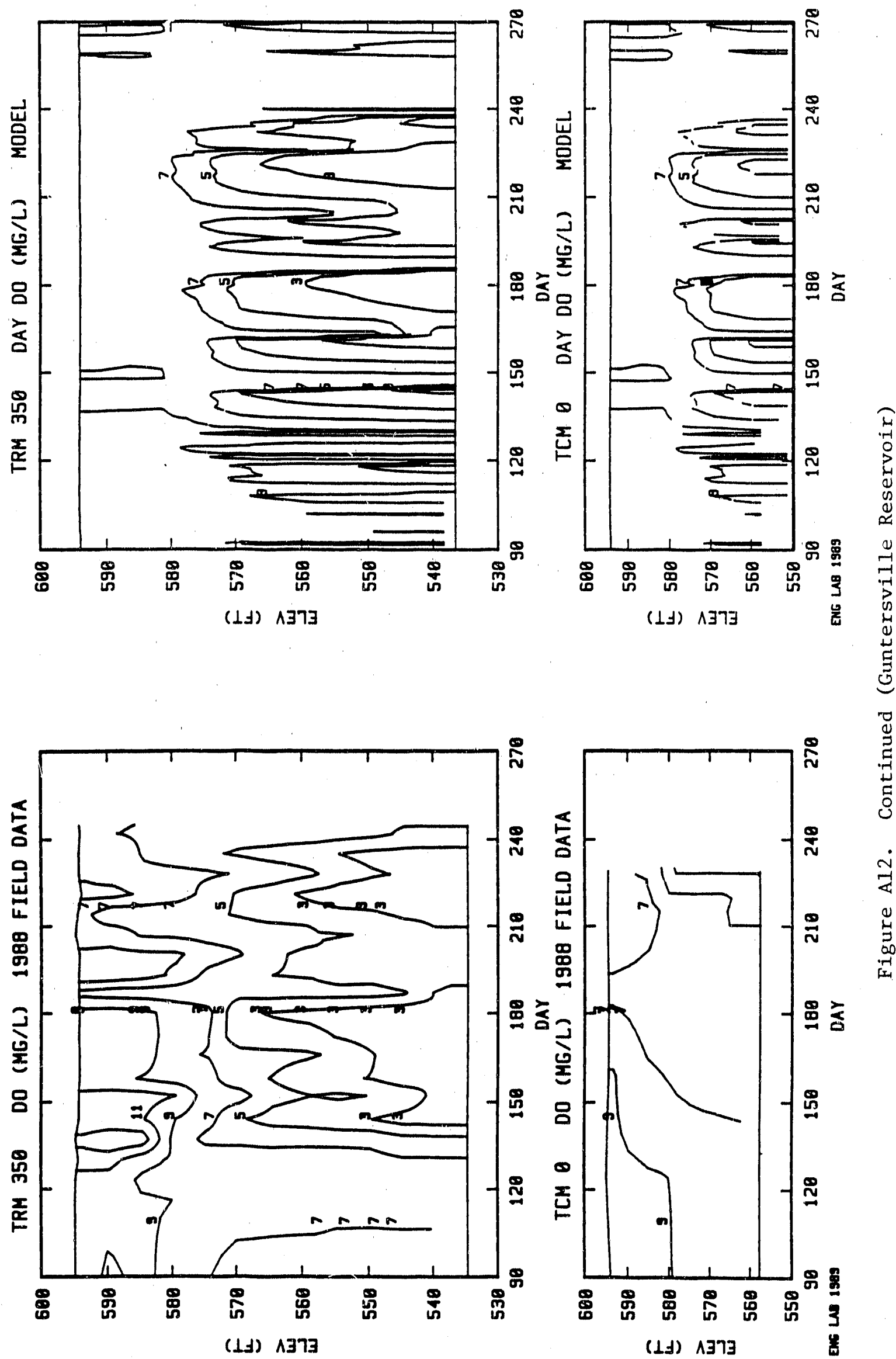
deaeration indicates surface exchange has a significant influence on surface DO. No zone of metalimnetic depletion exists. Low DO concentrations at the lower depths can be partly attributed to the cold stagnant water caught behind riffles. Model calibration suggested sediment oxygen demand of the upstream end of Town Creek embayment was about twice as large as the downstream end. This can be partly attributed to detritus and suspended organics settling out of the water column as velocities decrease going into. Town Creek embayment. Town Creek embayment overall matches field data better than the main reservoir channel except for the period around July 5, 1988 (Julian Day 187). Field data during this period indicated mixed couditions and lower DO concentrations at the surface. The field data on June 5, 1988 reflected a storm event that was not representative of the entire month.

Guntersville observed release (tailrace) DO concentrations match those modeled (Figure All). Field data was typically collected during the day while modeled release DO concentrations were plotted at midnight. Release DO concentrations typically fluctuate in response to upstream stratification, pulsing operations, time and location of measurement, and density currents.

Algae, Detritus, and pH--Figure A13 shows modeled algal biomass for the 1988 basecase. Algae and detritus carbon/nitrogen/phosphorus ratios were assumed to be 40 percent $/ 4$ percent $/ .4$ percent. For modeling, $1 \mathrm{mg} / \mathrm{L}$ of algal biomass is often considered roughly equivalent to 4 to $10 \mu \mathrm{g} / \mathrm{L}$ of chlorophy11-a content (Jorgensen, 1979). Based on the range of these criteria, algal biomass was modeled at concentrations higher than most observed chlorophy11-a data indicated. Large modeled algae concentrations were necessary to obtain desirable no concentrations. Large $\mathrm{pH}$ values are also an indicator of algae. Figure A14 shows measured and modeled $\mathrm{pH}$ values. Modeled bottom $\mathrm{pH}$ values are a 1 ittle higher and surface values are a little lower than field data indicates. These differences may be due to less vertical mixing than modeling indicates. Observed release $\mathrm{pH}$ values indicate that modeled release $\mathrm{pH}$ is slightly high (Figure A11). 

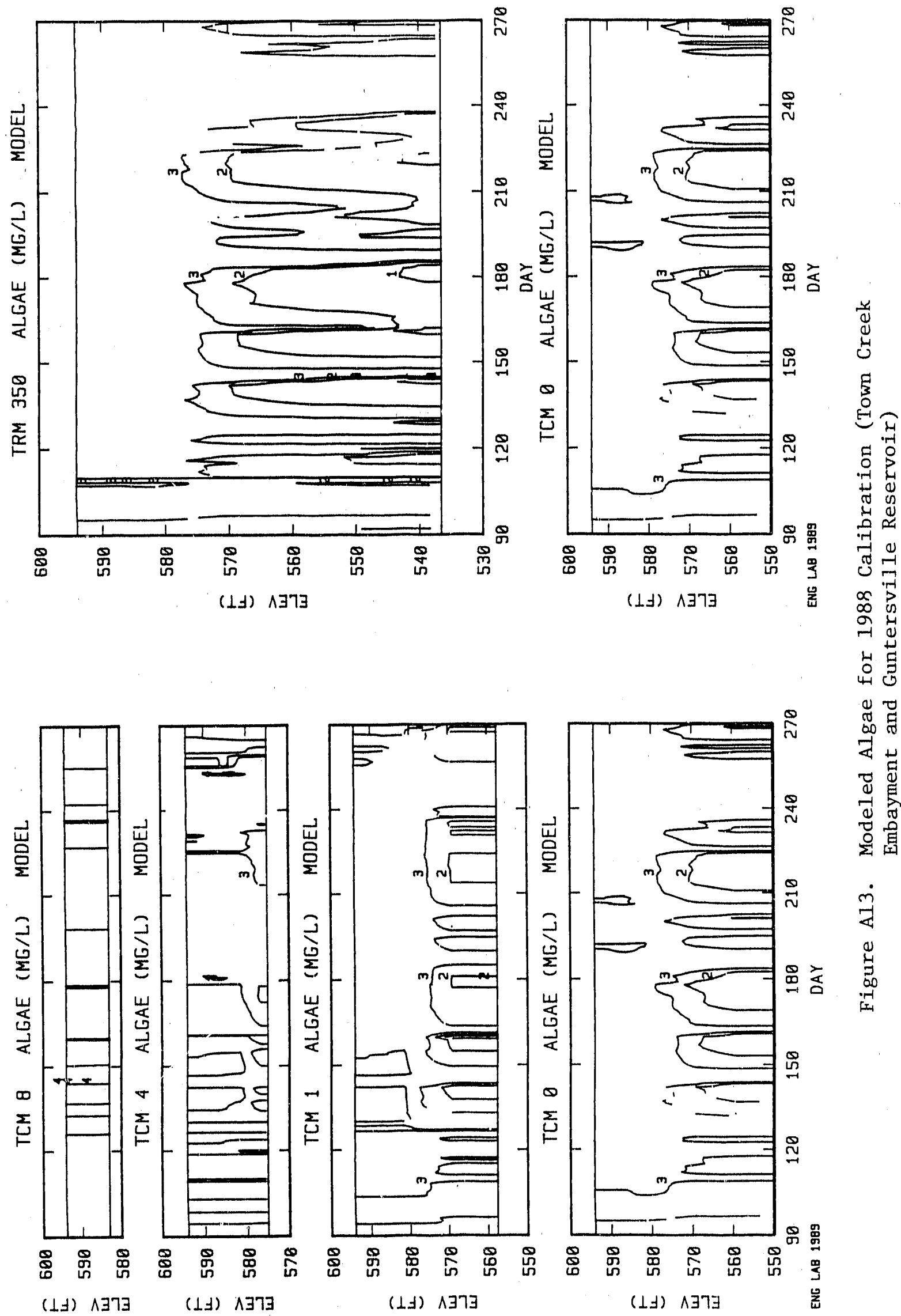

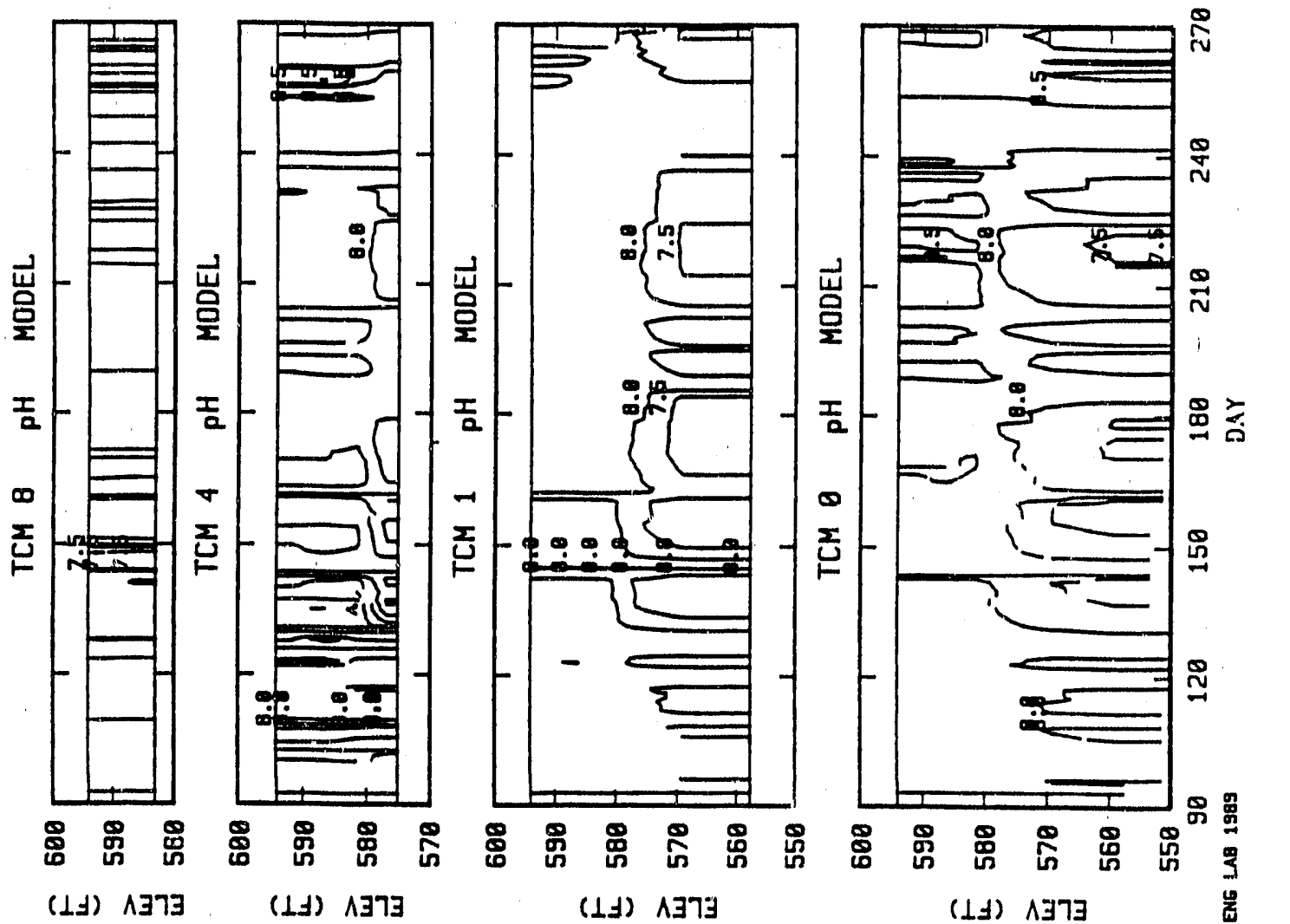

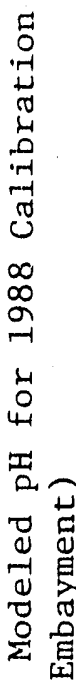
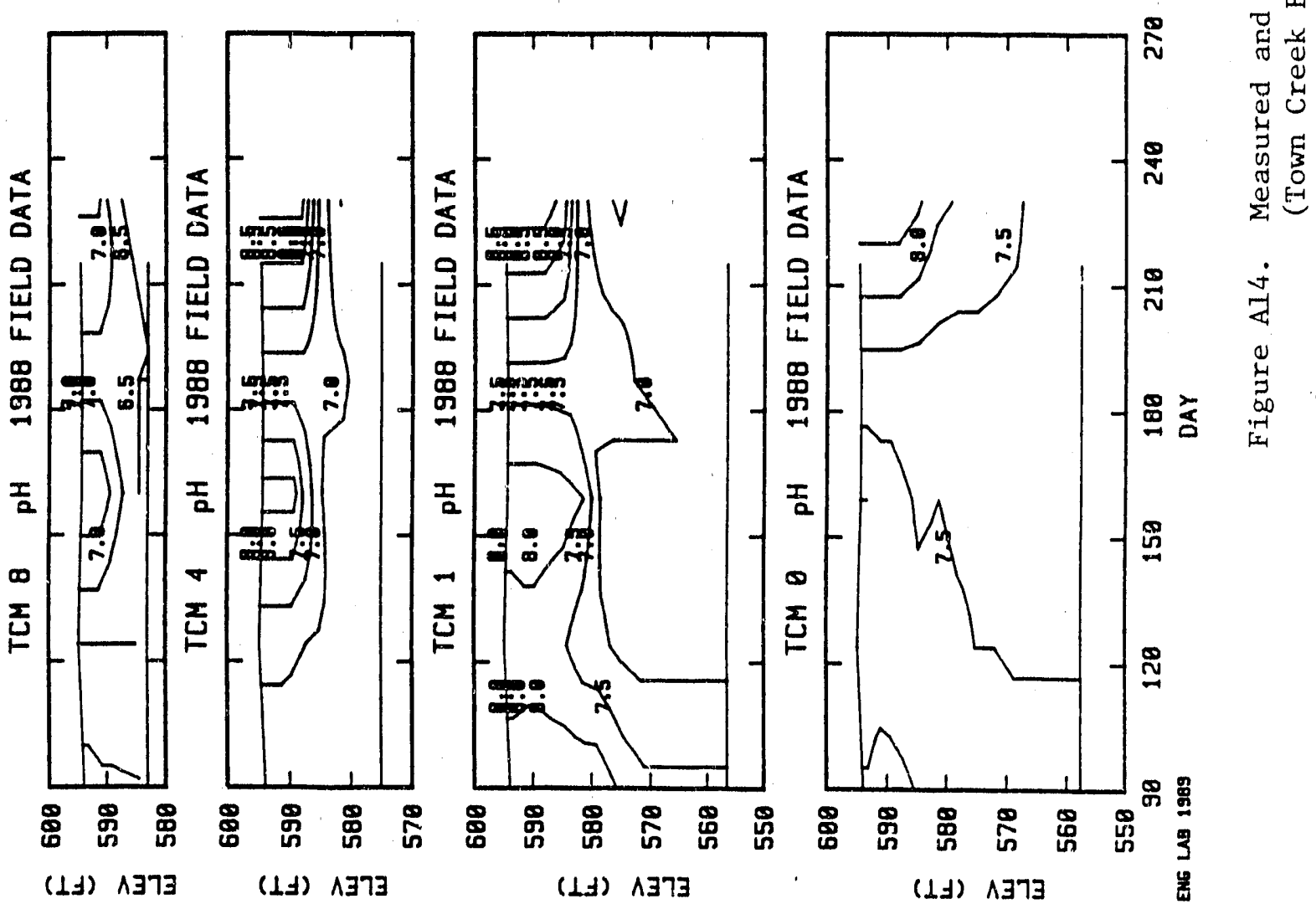


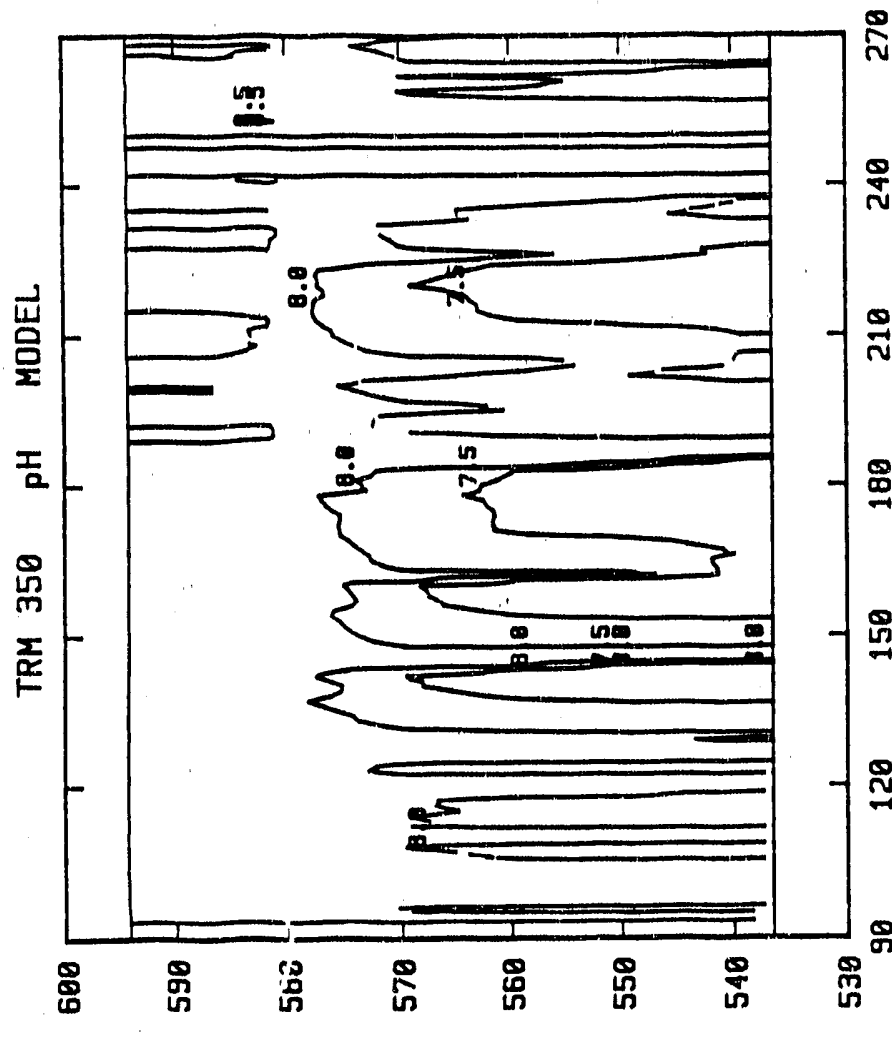

(1.) 19773
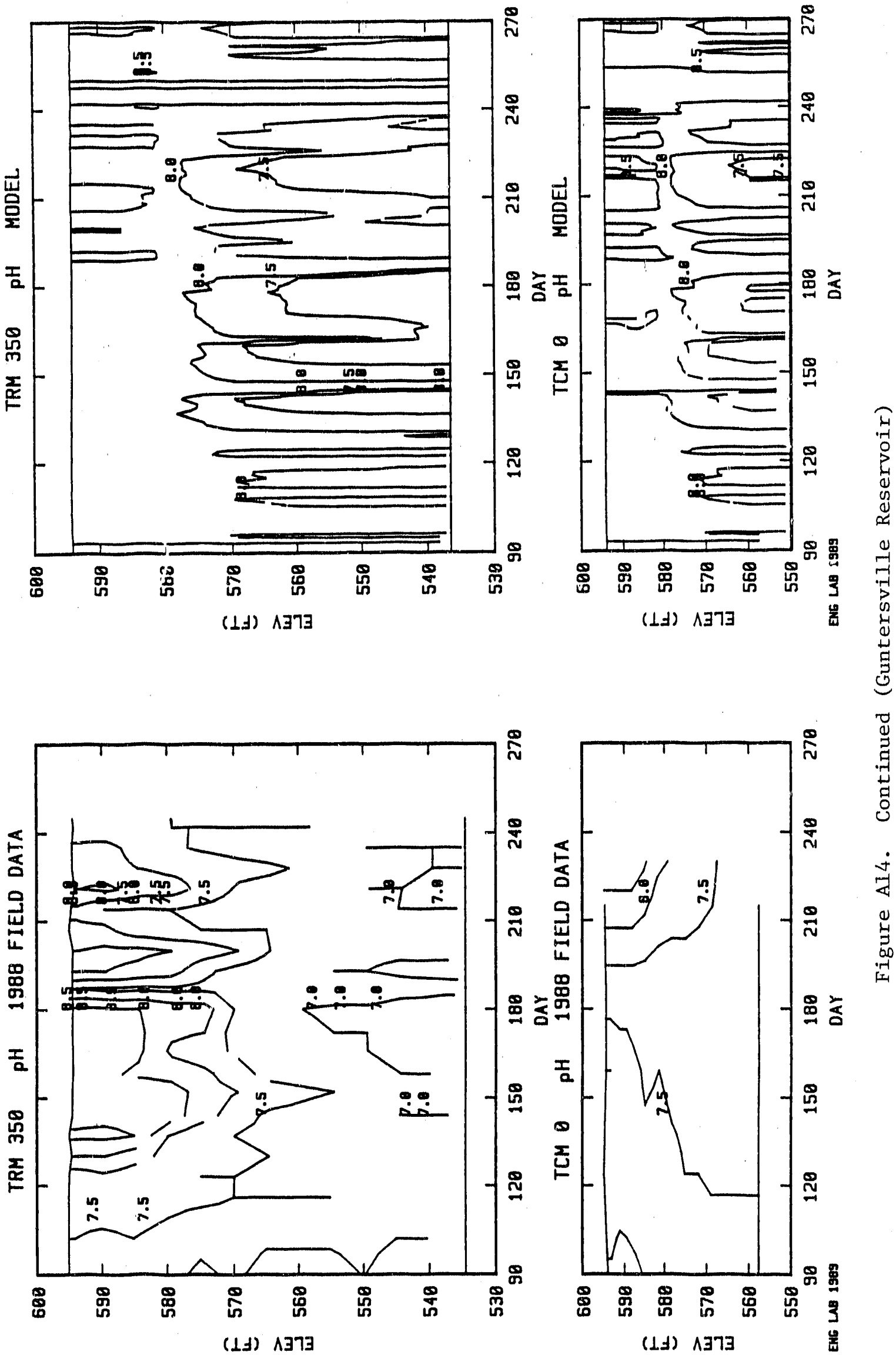
Suspended Solids--Suspended solids limit light for algal growth. Figure A.15 indicates that modeled suspended solids from Town Creek inflow settle in the upstream end of the embayment. The suspended solids introduced during the 1988 spring storm settled within a couple of weeks.

Nutrients-Modeled bloavailable phosphorus and measured dissolved phosphorus $\left(\mathrm{PO}_{4}\right)$ profiles are shown in Figure $\mathrm{A} 16$. Observed profiles show spikes which may have been due to inaccurate chemical analysis or contamination juring collection and analysis. Observed dissolved phosphorus concentrations at TCM 1.0 were a11 $0.010 \mathrm{mg} / \mathrm{L}$. Phosphorus depletion occurs in the surface since it is the primary limiting nutrient for algal growth. Figure A17 shows measured and modeled ammonia. The modeled surface ammonia concentrations appear to be higher than those observed. Figure A18 shows measured and modeled nitrate. Observed nitrate profiles indicated large nitrate concentrations during the spring which diminished to low concentrations during summer and fall. Modeled nitrate profiles indicated a more steady concentration.

Summer water residence time during 1988 was higher than normal. Modeled water cumulative travel time, or water age since the beginning of simulation or the time it enters the reservoir, is shown in Figure A19. There was minimum difference between modeled surface and modeled bottom residence times in either the main reservoir or Town Creek embayment due to weakly stratified conditions. Midsummer Guntersville Reservoir main-channel cumulative water travel times were about 35 days by the time water reached the forebay; Town Creek embayment midsummer cumulative water travel times below the bridge were over 60 days. 

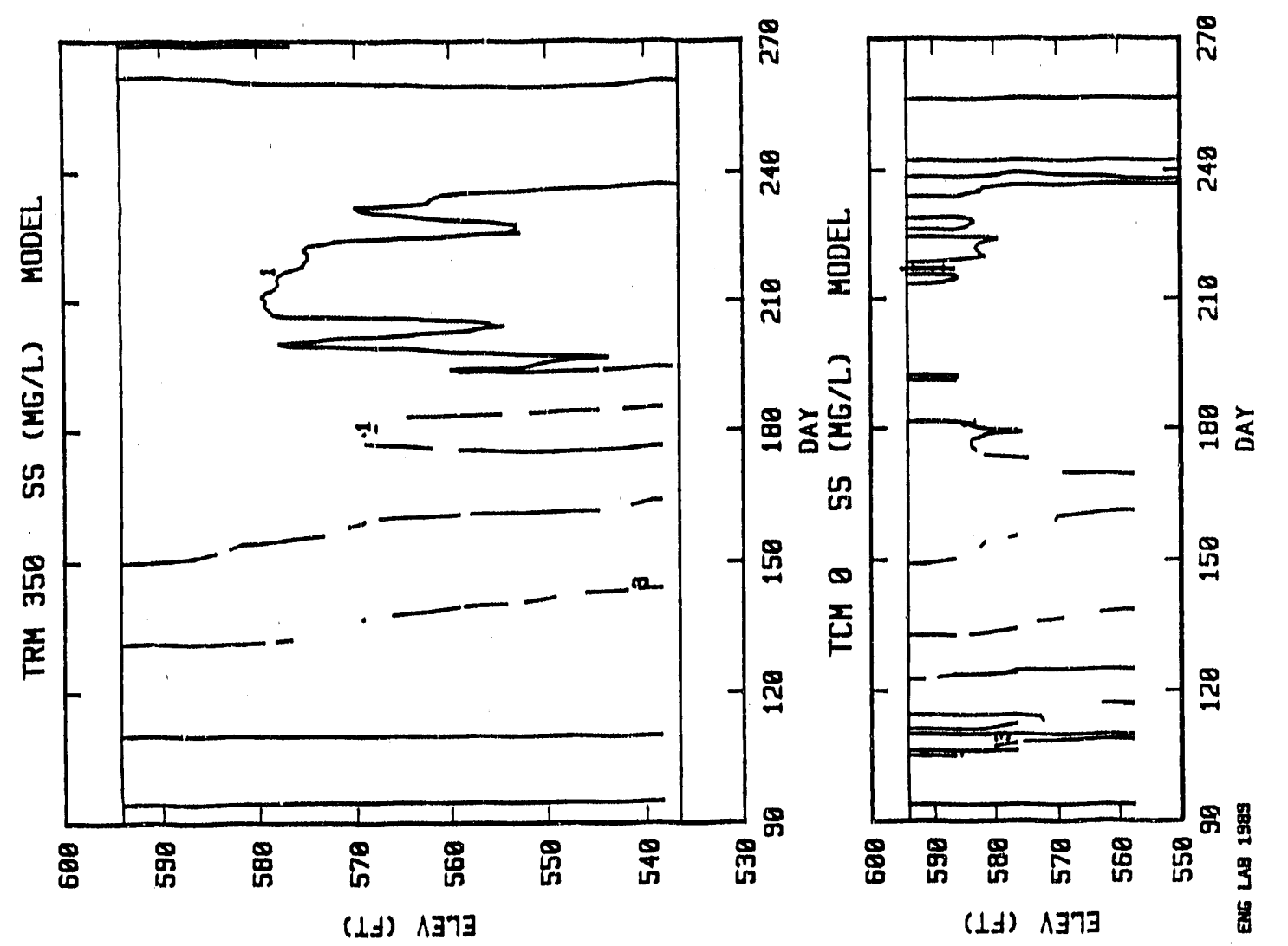

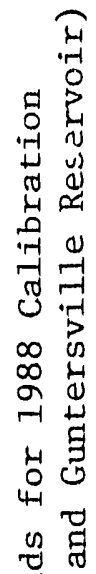

望

क

ए

岂 常
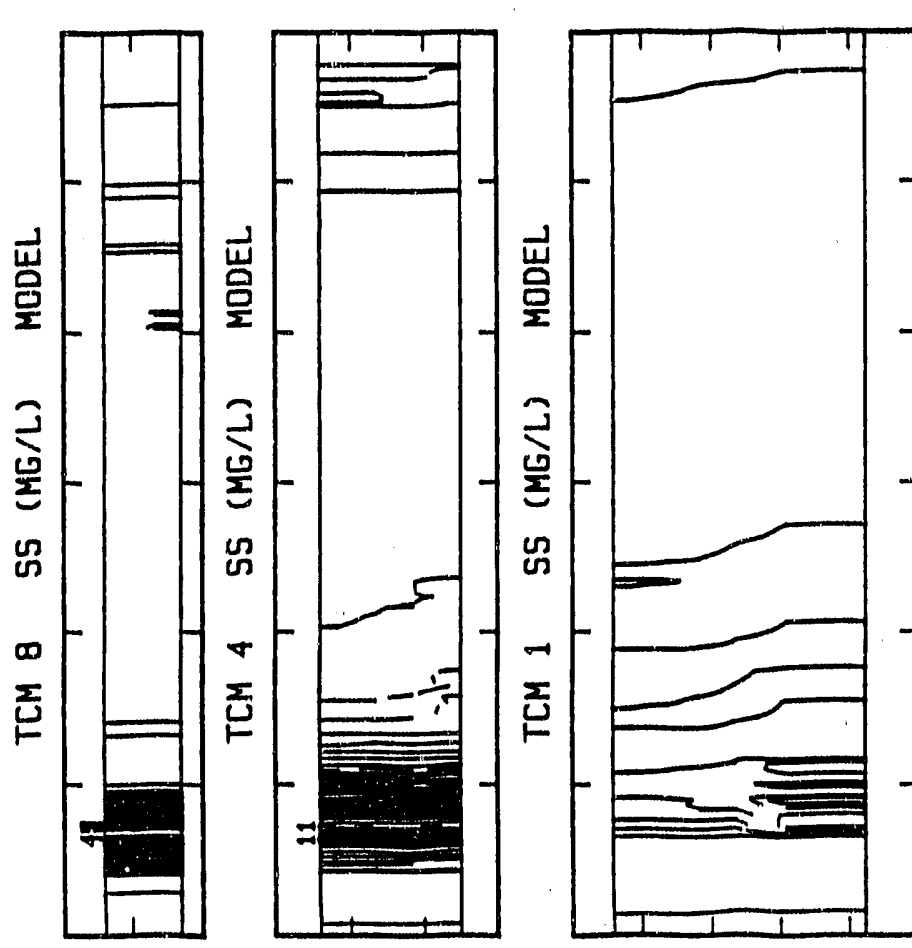

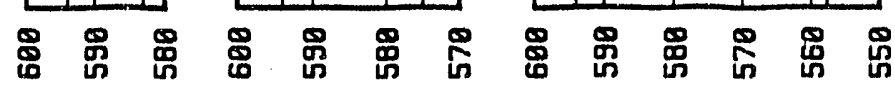

(1.) 1.373

(1.d) 1379

(1d) 1373

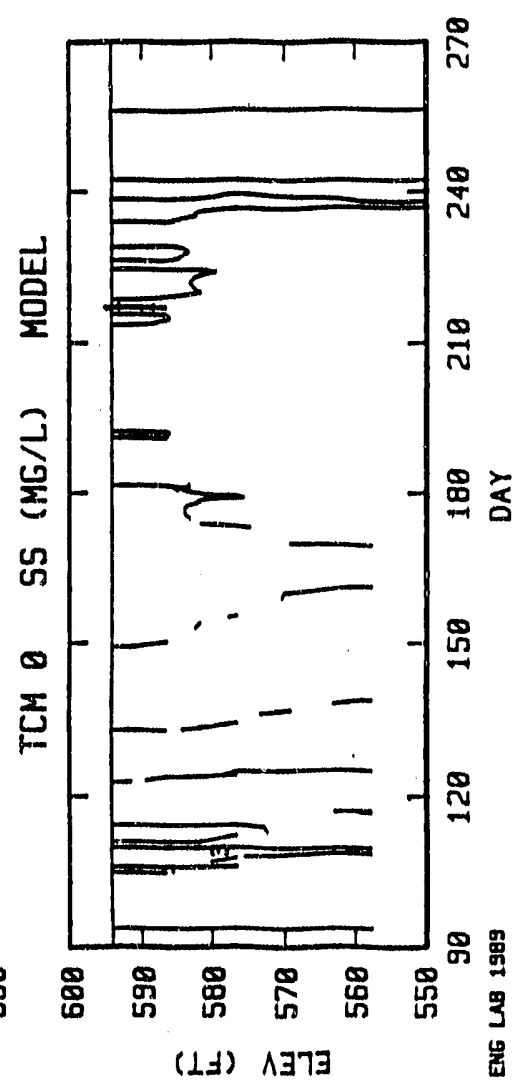



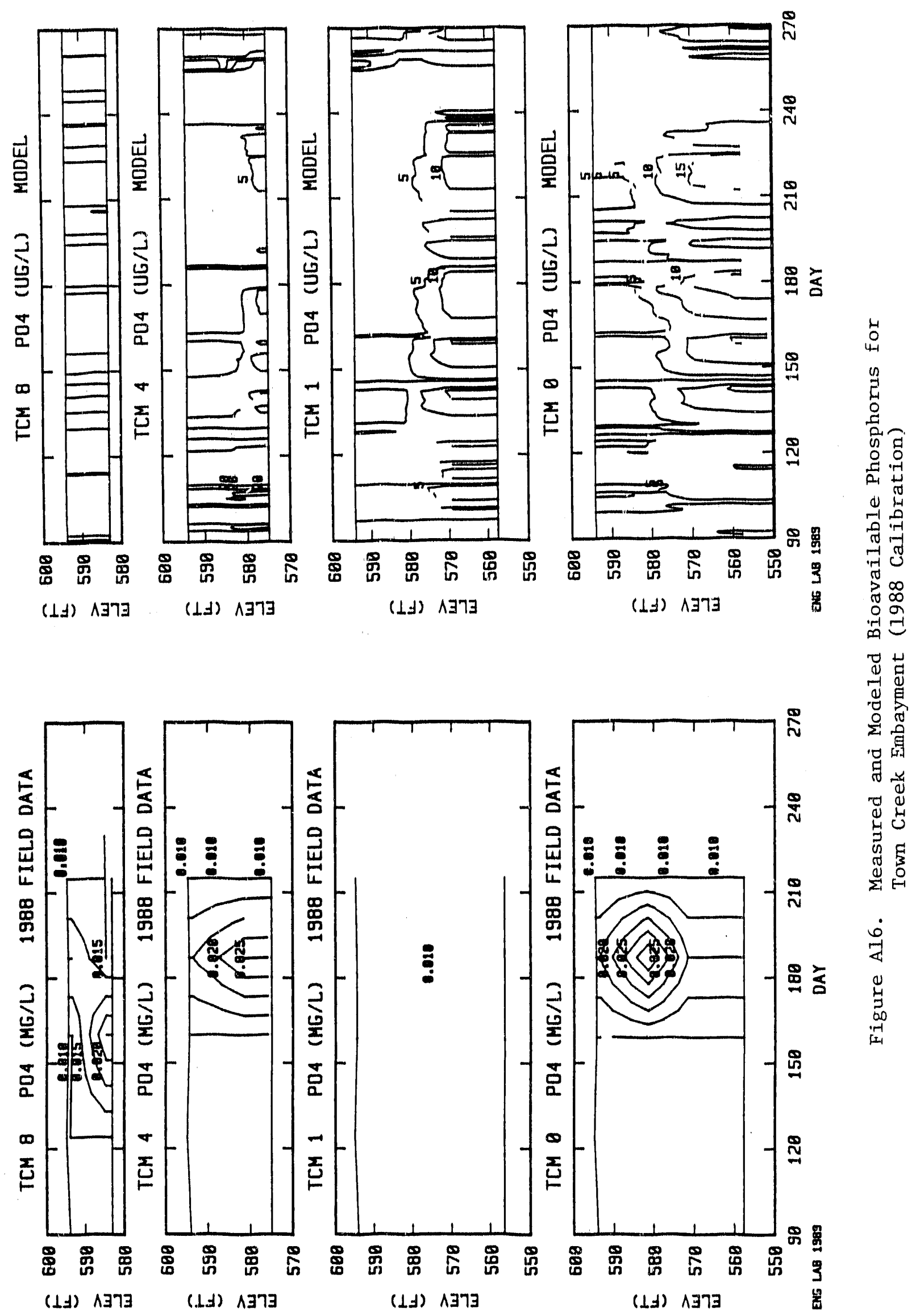

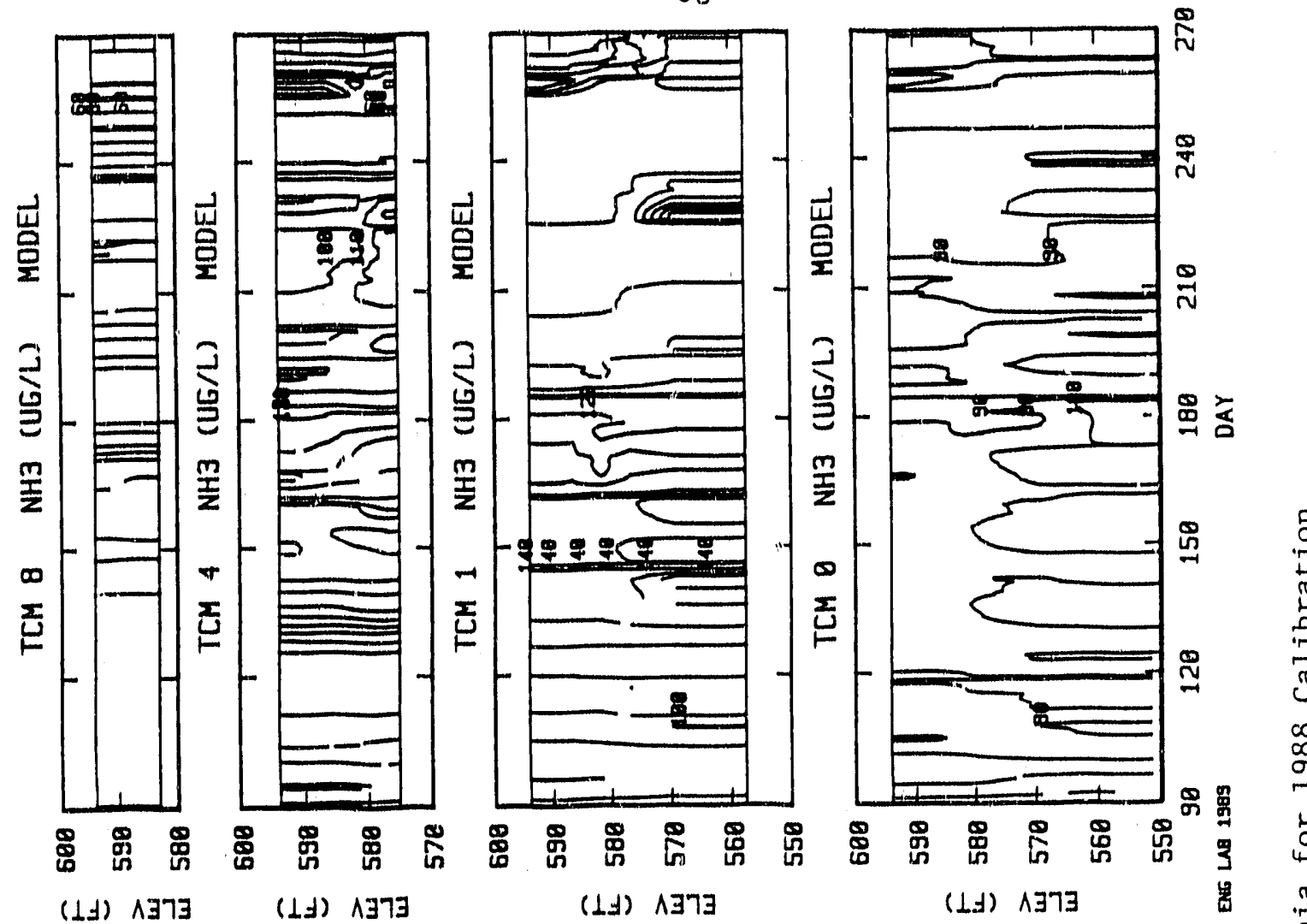

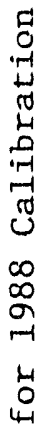
$\begin{array}{ll}\text { (1d) } \wedge 373 & \text { (1d) } \wedge 37 \exists\end{array}$

(1) $\wedge$ งา

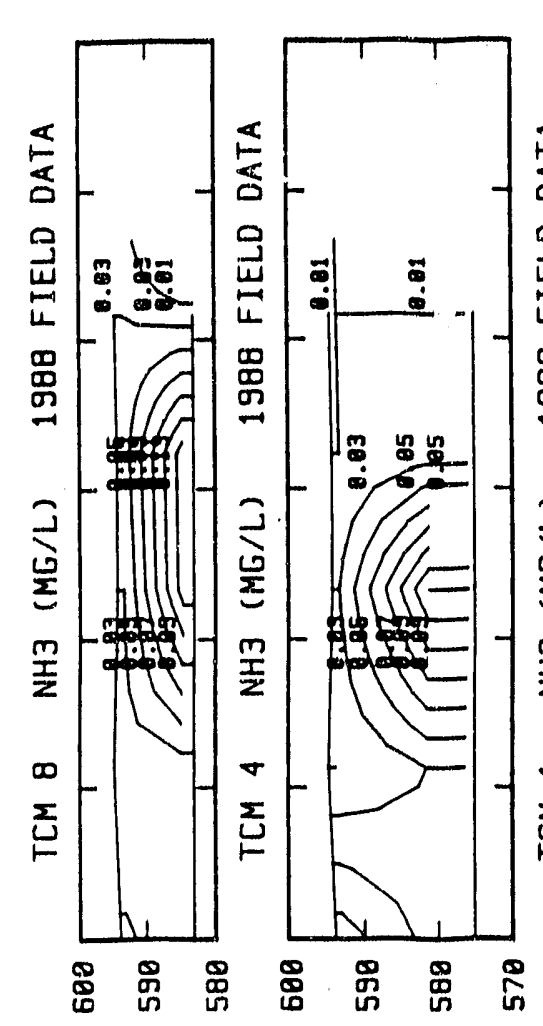

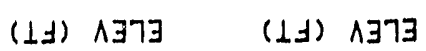

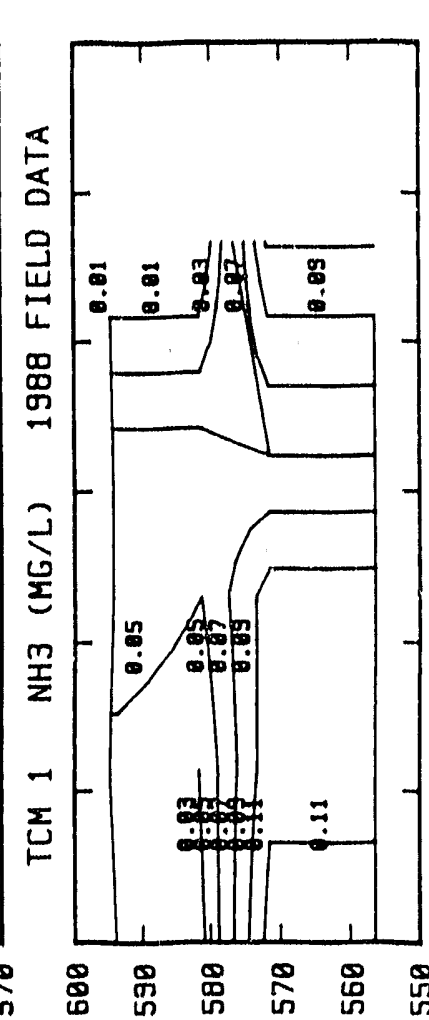

(1) $\wedge 373$

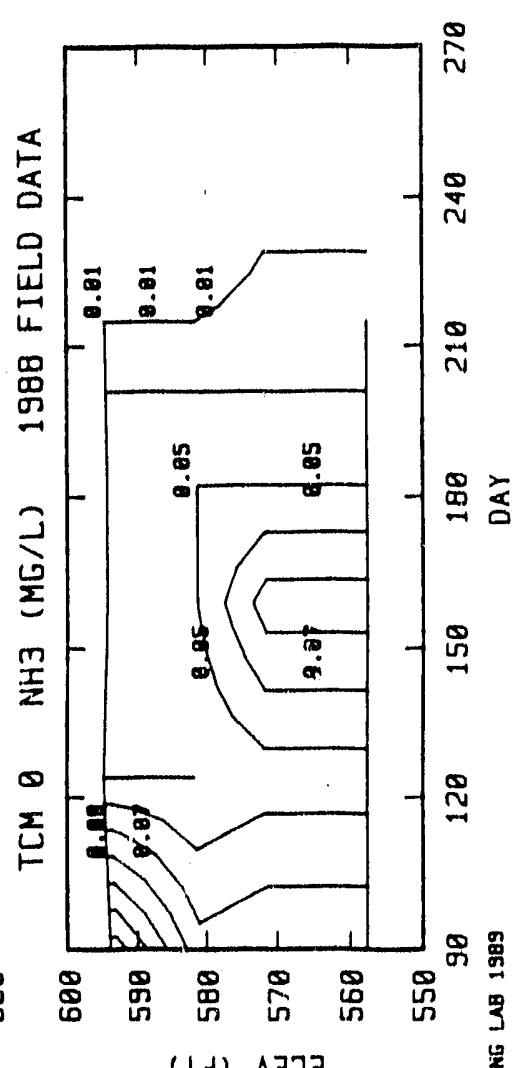

(1.) $\wedge \exists 7 \exists$ 

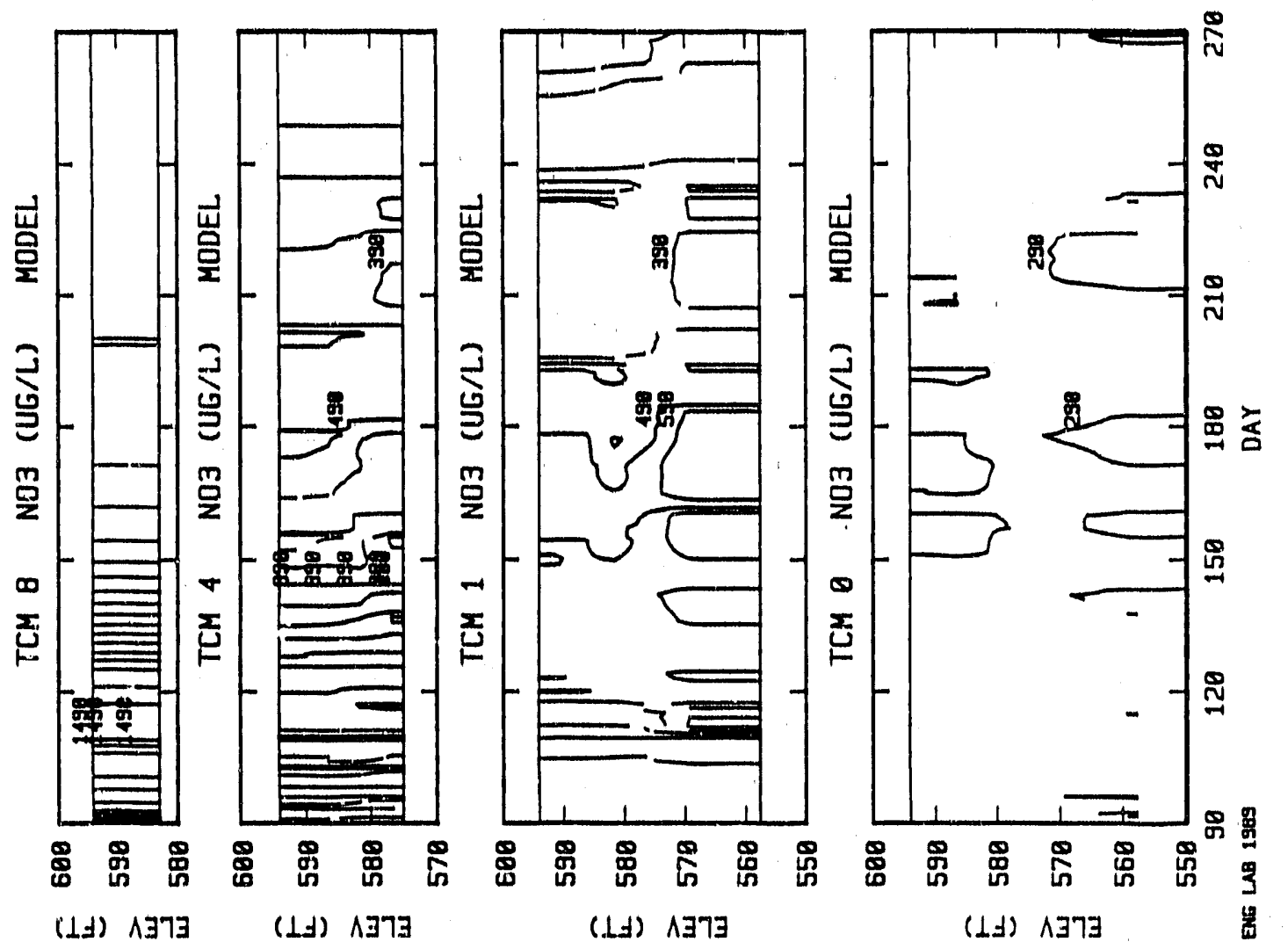

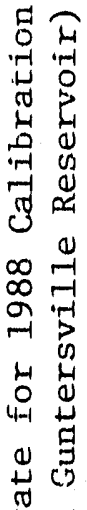

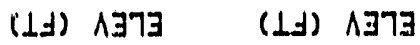

(.Ld) $1 \exists 7 \exists$

(1d) 1377

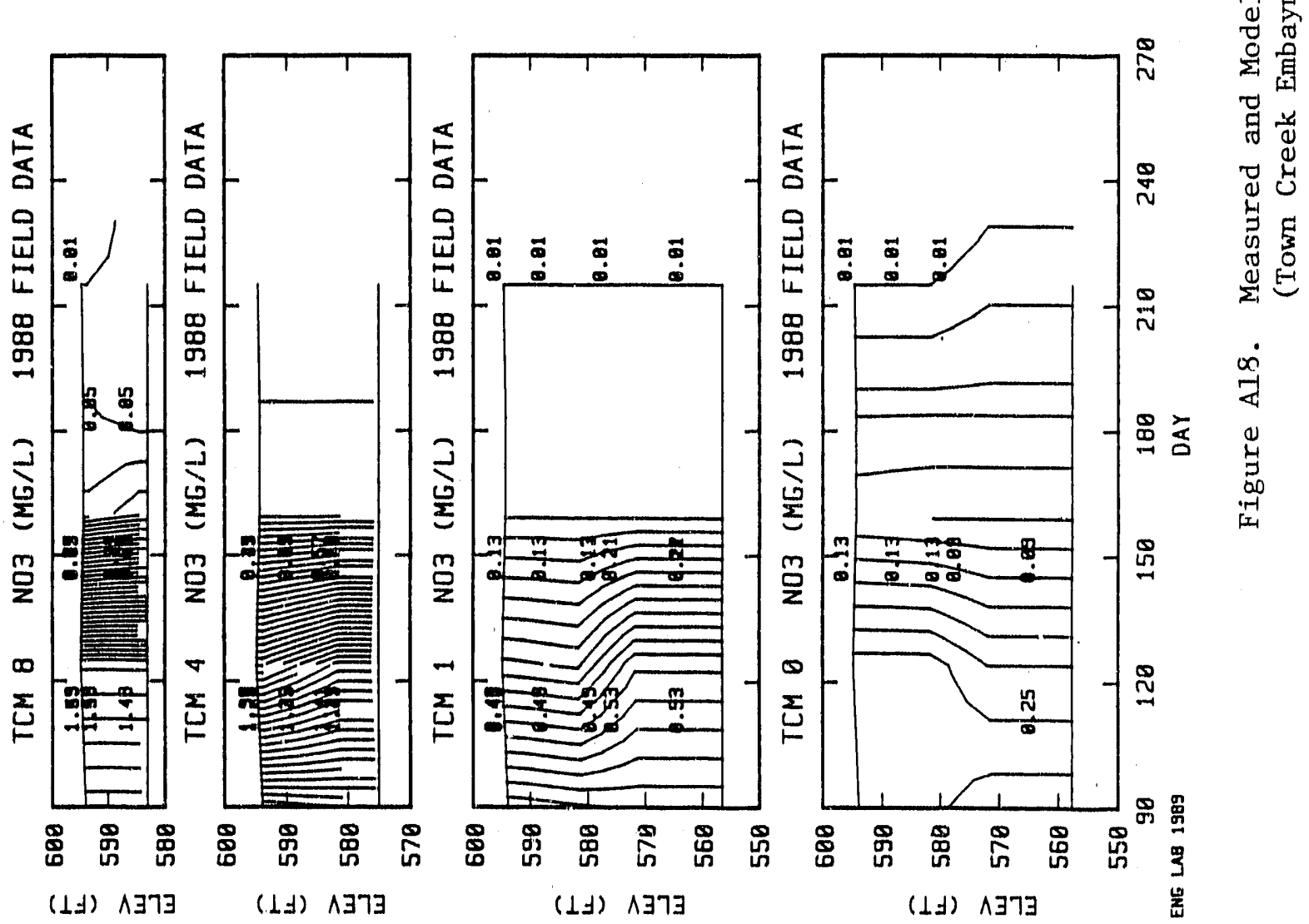



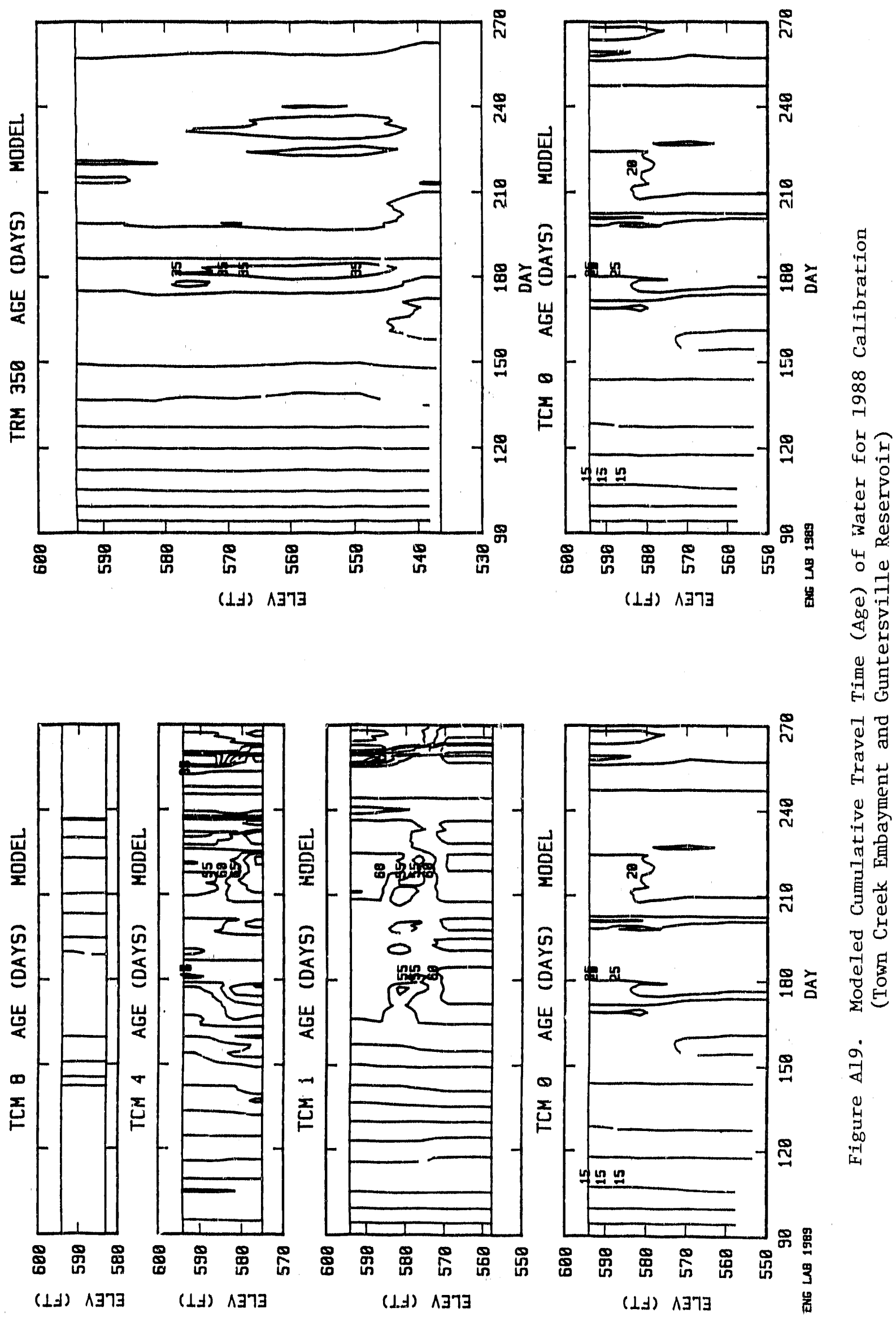


\section{APPENDIX B}

Loading Estimation for Calibration and Simulations

Loadings are concentrations multiplied by flow. Initial 1988 concentrations were estimated from historical data or data measured in 1988. These initial concentration estimates were then adjusted to correspond to reservoir profiles for the 1988 calibration. Table B1 provides a summary of the various data sources for precalibration stimates and inp: : concentrations for the 1988 calibration.

\section{Local Loadings}

Local loadings for 1988 were estimated by multiplying local flows by estimated local concentration for 1988. Daily local inflows were backcalculated from a "ass balance of releases from Nickajack and Guntersville Dams and Guntersville Reservoir headwater elevation. Local NPS runoff loadings for 1988 were estimated using total annual loadings for 1973 (Poppe, 1987b), the only available local runoff data other than Town Creek loadings for 1988. But 1973 was a wet year. More loadings would be expected in a wet year than in a dry year such as 1988 . PS loadings (Poppe, 1.987a) were incorporated into the local loadings estimation by multiplying estimated NPS loadings by the ratio of (NPS+PS)/NPS. Local suspended solids concentrations were taken equal to those determined for Town Creek base flow. For most of the simulations (Runs 7-23) the Town Creek inflow hydrograph was split into storm flow and base flow portions. Storm concentrations were applied to the storm flow por'ion.

\section{Nickajack Dam Loadings}

Nickajack Dam loadings luring 1985 were not known. Estimates for release concuntrations were made using release data collected during the perind from i,74-1983 (Poppe, 1987a, p 33). Dam flow for 1988 were multiplied by these concentrations to estimate loadings. Bioavailable phosphorus was asrumed to be 50 percent. total phosphorus. This estimate corresponded to ortho-phosphorus. verage concentration of 
total phosphorus for 1986, a dry year, corresponded to the average from 1974-1983. Turbidity measurements from South Pittsburg water treatment plant intaike (TRM 418.0) were used for suspended solids. This intake is 6.7 miles downstream of Nickajack Dam.

\section{Town Creek Inflow Concentrations}

Most Town Creek concentrations were determined from 1988 flow-weighted data collected at TCM 9.0. Nitrate concentrations were estimated by linearly interpolating between data. Nitrate concentrations decreased steadily during the 1988 period, partly due to little rainfal1. BOD data was estimated from data collected at TCM 22.7.

\section{Town Creek Embayment Inflow Hydrograph Separation}

Runoff hydrographs were divided into storm runoff (direct) and base flow (primarily groundwater runoff and interflow) according to the following rule of thumb approximation (Linsley, et al., 1975).

$$
N=(A)^{0.2}
$$

where $N=$ number of days after peak

$A=$ drainage area in square miles

For the drainage area above TCM 9 (191 square miles), the number of days after the hydrograph peak (N) equals 2.9 days. Thus, the direct runoff was terminated 3 days after the peak of the hydrograph. Complex hydrograph separation (multiple rain storms) was done by forming a queue of days of rain flow until a period of recession of 3 days occurred. Base flow during a storm would tie from the flow at the beginning of the storm to the adjusted base flow approximation 3 days after the final storm peak. Figures B1-BE show the hydrograph separation for the years 1966, 1967, 1969, 1971, 1979, and 1988, which were listed in Table 2.

\section{Town Creek Storm and Base Flow Concentrations}

Due largely to the drought conditions in 1988, no storm events were sampled for the calibration of the model. Concentrations of BAP, 

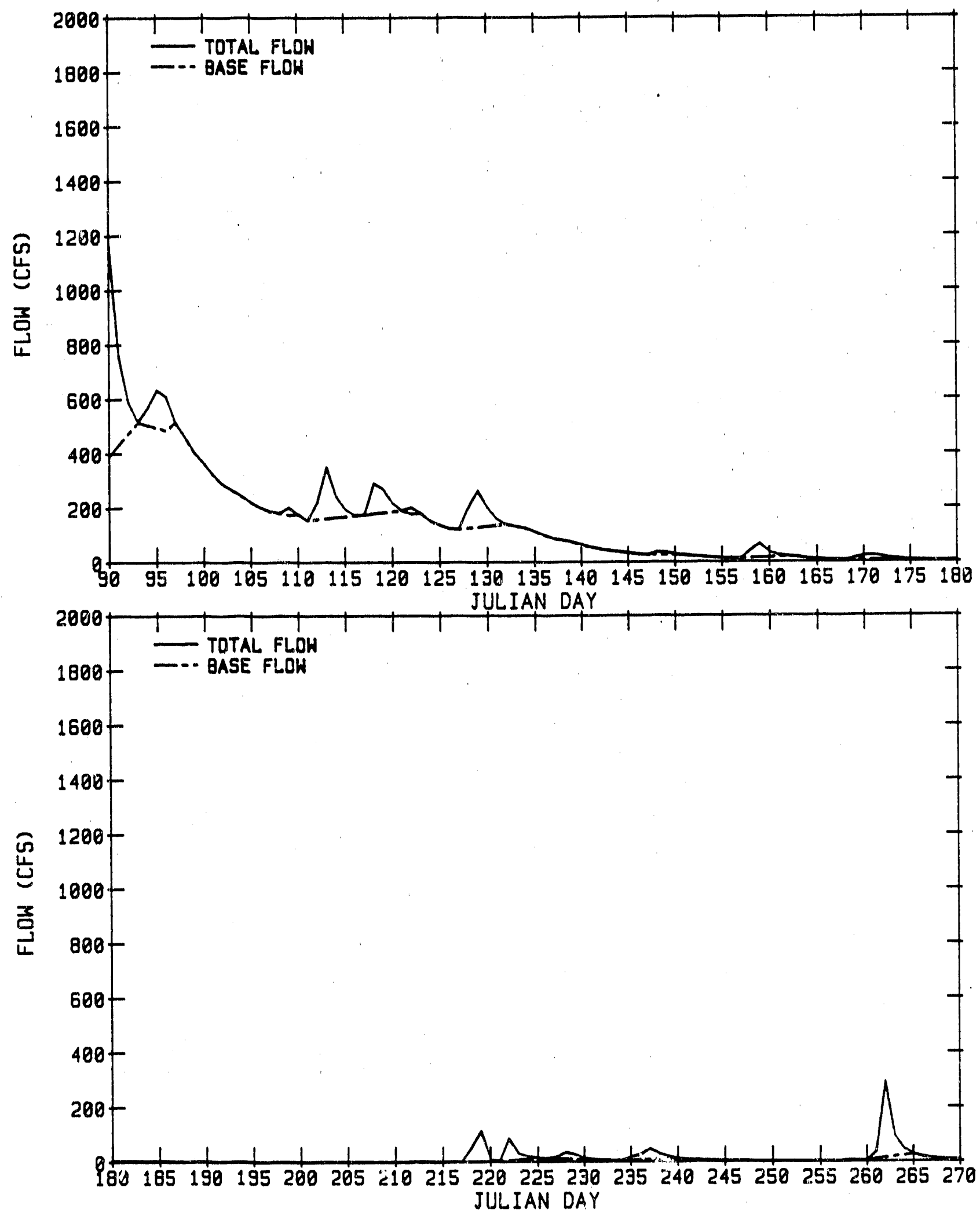

ENG LAB 1989

Figure Bl. Very Dry (Year 1960) Town Creek Inflows 

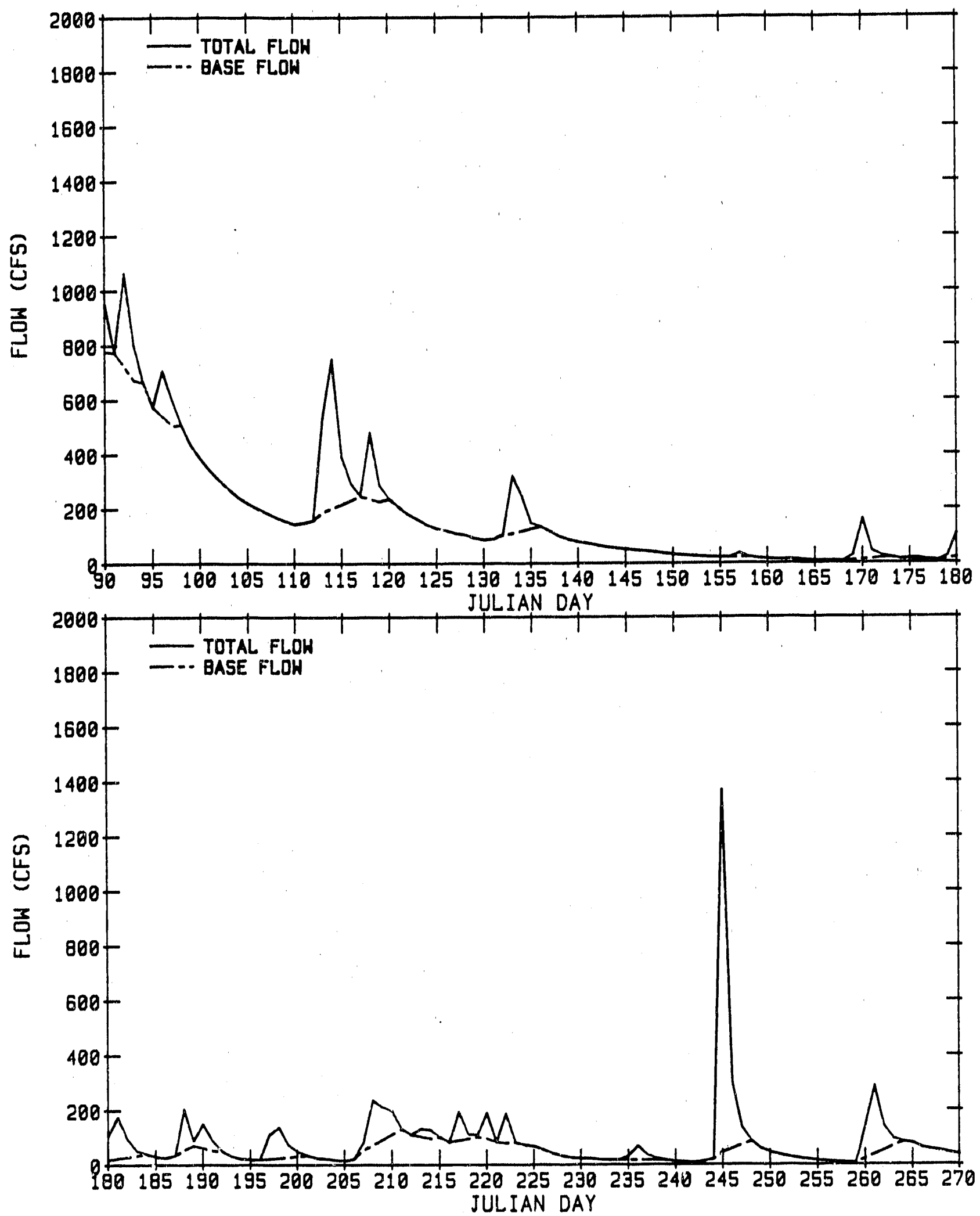

ENG LAB 1989

Figure B2. Dry (Year 1971) Town Creek Inflows 

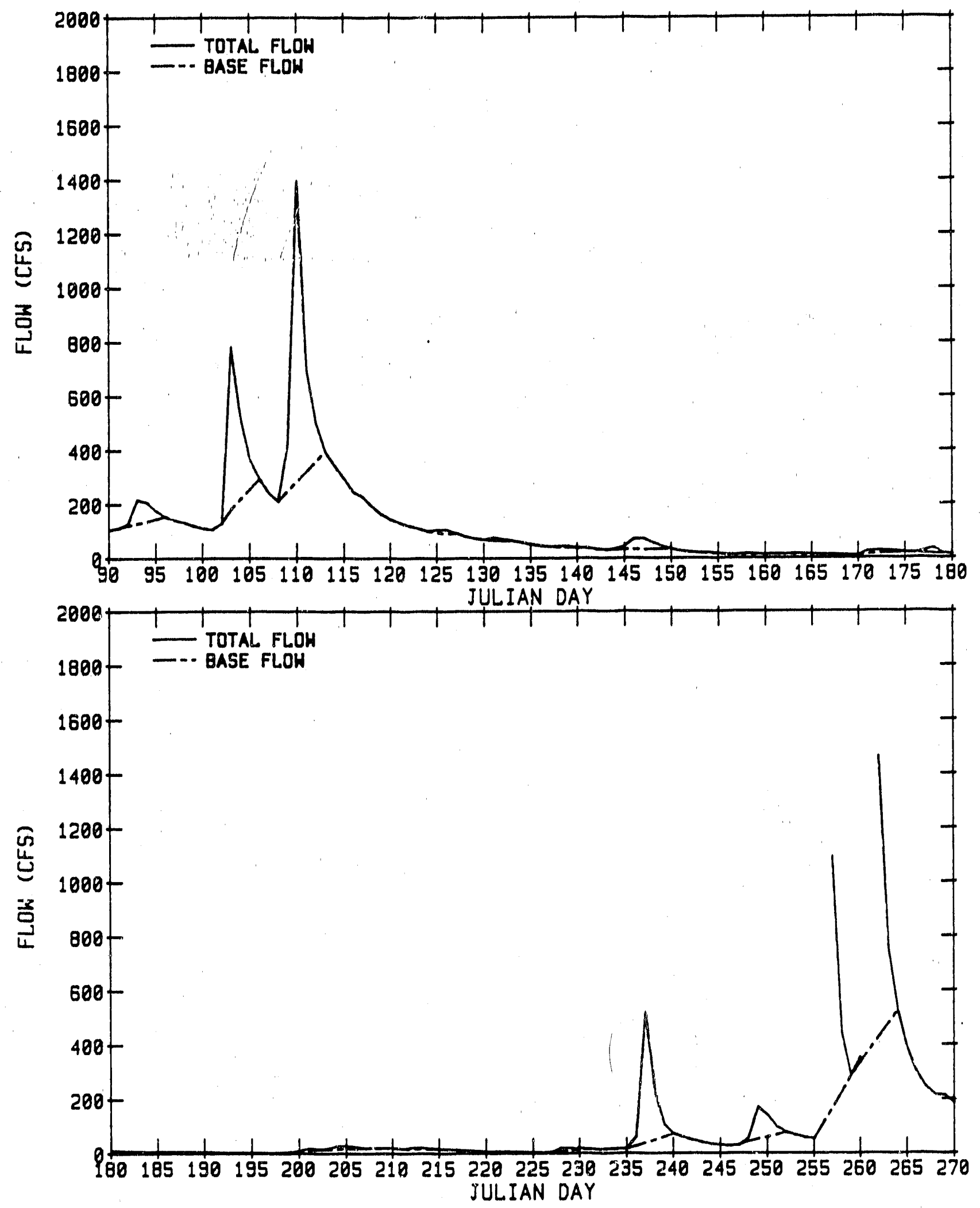

ENG LAB 1989

Figure B3. Calibration (Year 1988) Town Creek Inflows 

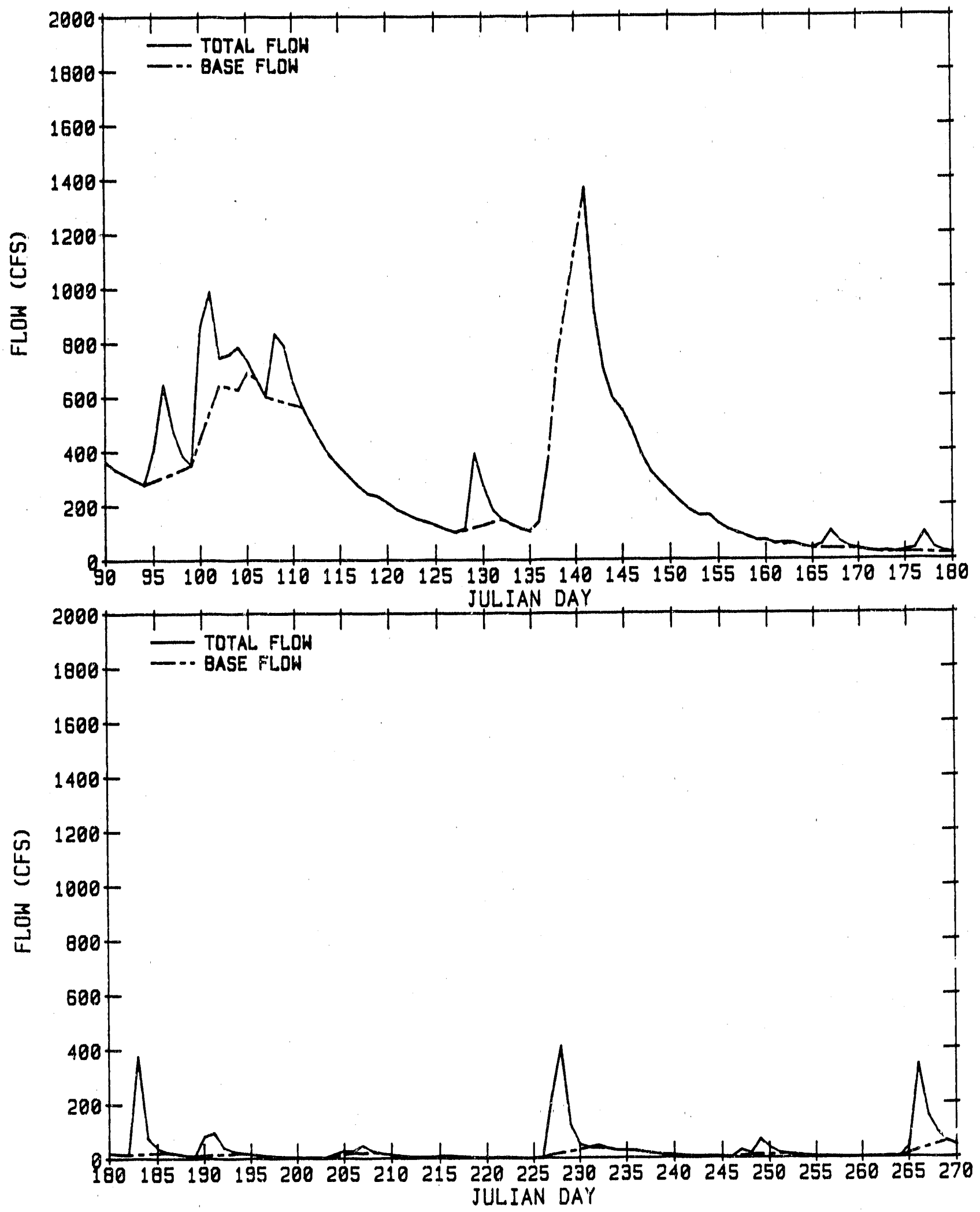

ENG LAB 1989

Figure B4. Average (Year 1969) Town Creek Inflows 

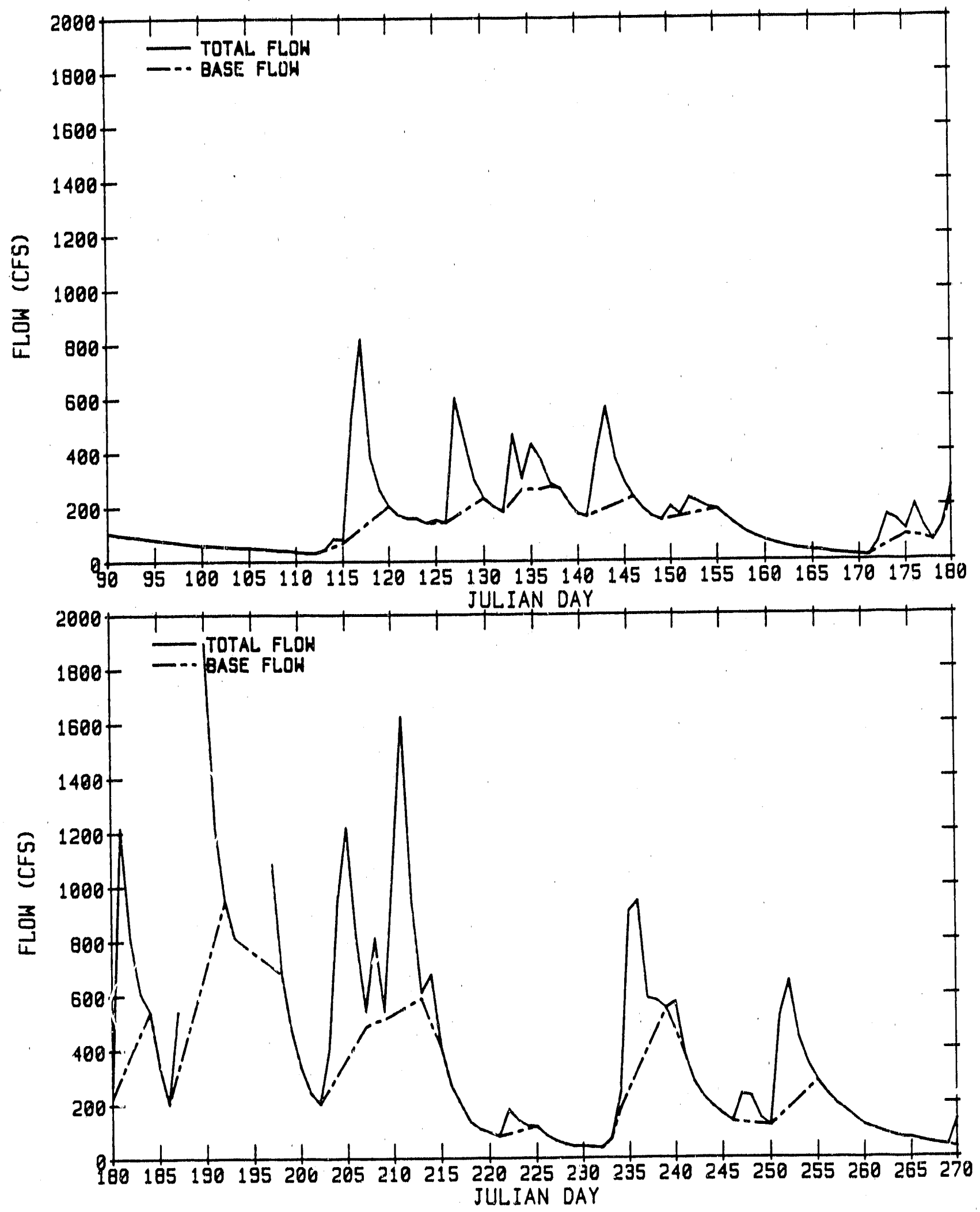

ENG LAB 1989

Figure B5. Wet (Year 1967) Town Creek Inflows 

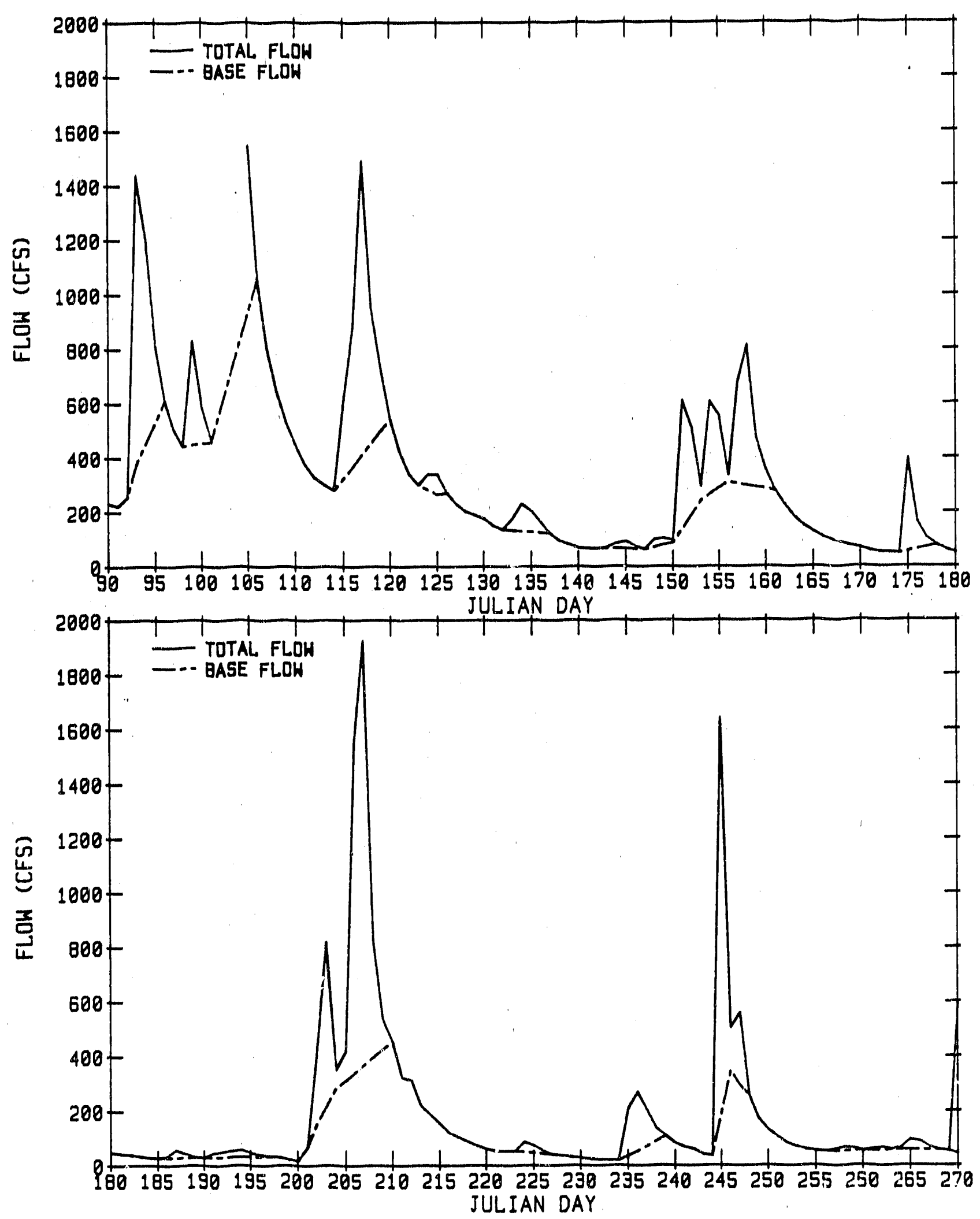

ENG LAB 1989

Figure B6. Very Wet (Year 1979) Town Creek Inflows 
BAN, BOD, and suspended solids in storm flow runoff were dertved from several information sources specific to the Town Creek watershed. Stornwater concentrations were estimated separately for two nonpoint pollution sources: animal waste and soll erosion.

Table B2 presents the information used to estimate storm flow runoff concentrations due to land application of animal waste. The percent of land use for crops and pasture, an estimate of the land that receives animal waste, and runoff concentrations associated with specific land use and application practice were used to derive concentrations of total phosphorus, nitrogen and chemical oxygen demand in storn flow. Forest and other land uses were assumed not to be contributing to the storm flow runoff concentrations (Haith and Shoemaker, 1987). Total phosphorus concentrations were reduced to reflect the availability to algal growth, using the median value measured at TCM 9 with the algal growth potential test (Raschke, 1988). Total nitrogen concentrations associated with animal waste reductions were not reduced since it was assumed most of the nitrogen from animal waste would be dissolved and biologically available. Five-day BOD was approximated from the ratio of five-day $B O D$ to chemical oxygen demand (COD) typically found in domestic wastewater (Tchobanogious and Schroeder, 1985).

Table B3 presents the information used to estimate the contribution of soli erosion to storm flow runoff concentrations. The average soil. loss in Town Creek watershed was determined using the Universal Soil Loss Equation on data collected by aerial photography and ground truth inspections (Hagerman, 1990). Based on the watershed size, seven percent of the eroded soil is estimated to be delivered to Town Creek embayment as suspended solids (Vanoni, 1975, p 460). The water quality plan for the watershed estimates the average annual suspended solids concentration to be $273 \mathrm{mg} / \mathrm{L}$ (SMLGWQC, 1986). This concentration is more typical of a storm event and therefore was used as the concentration in storm flow runoff due to soil erosion. Nutrient concentrations were figured by the product of the average soil nutrient concentrations for Sand Mountain, a typical annual erosion enrichment ratio, and the median percent availability measured for algal growth. 
TABLE B2

Information Used to Estimate Storm Flow Concentrations Contributed from Anima1 Waste

Land Use in

Sand Mountain Watershed
Pastureland

$2.4 \%$
Cropland

$30 \%$
Reference

(SMLGWQC, 1987)

with without with without

Estimated Land

Animal Waste Application

Total Land Use

Runoff Concentrations

Associated with Land Use

Total Phosphorus (mg/L)

Tota1 Nitrogen (mg/L)

Chemical Oxygen Demand ( $\mathrm{mg} / \mathrm{L})$

$\begin{array}{cccc}90 \% & 10 \% & 25 \% & 75 \% \\ 21.6 \% & 2.4 \% & 7.5 \% & 22.5 \%\end{array}$

(Do11ar, 1989)

$\begin{array}{llll}3.0 & 0.44 & 1.7 & 0.40\end{array}$

(USDA, 1979)

11.9

3.2

7.1

3.0

(USDA, 1979)

$360 \quad 50$

88

55

(USDA, 1979)

BAP $=25 \%$ of Total Phosphorus

(Raschke, 1988)

BOD, 5 day $=40 \%$ of Chemical Oxygen Demand

(Tchobanoglous and

Schroeder, 1985)

Storm Flow Runoff Concentrations in Town Creek Watershed associated with Ancin 1 Waste

Biologically Available Phosphorus $=0.219 \mathrm{mg} / \mathrm{L}$

Total Nitrogen (assumed bioavailable) $=3.854 \mathrm{mg} / \mathrm{L}$

Biochemical Oxygen Demand $\quad=39.2 \mathrm{mg} / \mathrm{L}$

Management simulations were performed by reducing the pollutant concentrations in storm flow and base flow runoff based on planned activities in the watershed. Concentrations were reduced on the portion contributed by soil erosion, animal waste land application, or both combined. The most optimistic projection for reduction in soll erosion is expecterl to be 60 percent by the year 2015 (presented 8/29/89 at the Interagency Work Group Meeting). This value was used to reduce suspended solids concentrations. The water quality plan (SMLGWQC, 1986) estimates that 75 percent of the cropland in the Sand Mountain watershed requires conservation treatment for soil erosion at a cost of $\$ 11.6$ million. The 
proportional cost for Town Creek watershed with the optimistic reduction profection is approximately $\$ 4.0$ militon. The water quality plan estimates that 453 animal waste management systems require installation or upgrading at a cost of $\$ 3.1$ million. With 914 confined operations in Sand Mountain Watershed, it was assumed the pollutant reduction from current levels would be 50 percent. Since 33 percent of the operations are In Town Creek watershed (Hagerman, 1990), the proportional cost would be approximately $\$ 1.0$ million. A11 stated costs are in 1986 dollars.

\section{TABLE B 3}

Information Used to Estimate Storm Flow Concentrations Contributed from Soll Erosion

Values Used in Calculating

Runoff Concentrations

Reference

Average Soil Loss from Town

Creek Watershed $=2.5$ tons/acre*year (Hagerman, 1990)

Sediment Delivery to Embayment

(based on watershed area) $=7 \%$

(Vanoni, 1975)

Suspended Solids Concentration

in Runoff $=273 \mathrm{mg} / \mathrm{L}$

(SMLGWQC, 1986)

Average Nutrient Concentration

of Soil on Sand Mountain:

$$
\begin{aligned}
& \text { Tota1 Phosphorus }=220 \mathrm{mg} / \mathrm{kg} \\
& \text { Total Nitrogen }=1500 \mathrm{mg} / \mathrm{kg}
\end{aligned}
$$

(Mil1s, et al., 1985)

Soil Enrichment Ratio fcr

Annual Loads $=2.0$

(Haith and Tubbs, 1981)

Biologica1ly Available

Phosphorus $=25 \%$ of Total Phosphorus (Raschke, 1988)

Biologicaliy Avallable

Nitrogen $=23 \%$ of Total Nitrogen

(Raschke, 1988)

storm Flow Runoff Concentrations in Town Creek Watershed Associated with Soil

Biologically Available Phosphorus $=0.145 \mathrm{mg} / \mathrm{L}$

Biologically Available Nitrogen $=0.912 \mathrm{mg} / \mathrm{L}$

Suspended Solids $=273 \mathrm{mg} / \mathrm{L}$ 
Base flow concentrations were taken as the average 1988 concentrations used in calibration. Calibration loadings for 1988 were small due to the dry sumer and the lack of samples during storm runoff events. Table B4 1ists the nutrient, suspended solids, and BOD loadings used in simulations. Table B5 lists Town Creek inflow loadings, average seasonal water quality, and cost of control technologles. Loadings in Tables B4 and B5 are tota1 loadings for the period, Julian Day 90-270. Water quality values are averages of the daily model results for the same period.

\section{TABLE B4}

Loadings Used In Model Simulations

(Julian Days 90-270)

\begin{tabular}{llllrrr}
\hline RUN & DESCR IPTION & Year & MAIN & TOWN CR & LOCAL & TOTAL \\
1 CALIBRATION BASECASE & 1988 & 210090 & 4259 & 79933 & 294282 \\
2 CUT ALL SOURCES P 50\% & 1988 & 105045 & 2132 & 39967 & 147144 \\
3 CUT TOWN CR. P 50\% & 1988 & 210090 & 2132 & 79933 & 292155 \\
4 CUT TOWN CR. IN 50\% & 1988 & 210090 & 4259 & 79933 & 294282 \\
5 CUT TOWN CR. BOD 50\% & 1988 & 210090 & 4259 & 79933 & 294282 \\
6 CUT TOWN CR. SS 50\% & 1988 & 210090 & 3411 & 79933 & 293434 \\
\hline 7 DRY BASECASE & 1971 & 210090 & 17598 & 80130 & 307818 \\
8 CUT SS 60\% & 1971 & 210090 & 13410 & 80130 & 303630 \\
9 CUT AW 50\% & 1971 & 210090 & 12323 & 80130 & 302543 \\
10 & CUT SS 60\% and AW 50\% & 1971 & 210090 & 8135 & 80130 & 298355 \\
11 WET BASECASE & 1967 & 210090 & 54549 & 78446 & 343085 \\
12 CUT SS 60\% & 1967 & 210090 & 41545 & 78446 & 330081 \\
13 CUT AW 50\% & 1967 & 210090 & 38206 & 78446 & 3.5742 \\
14 CUT SS 60\% and AW 50\% & 1967 & 210090 & 25209 & 78446 & 31.3745 \\
15 AVG BASECASE & 1969 & 210090 & 35611 & 79089 & 324790 \\
16 CUT SS 60\% & 1969 & 210090 & 27125 & 79089 & 316304 \\
17 & CUT AW 50\% & 1969 & 210090 & 24943 & 79089 & 314122 \\
18 CUT SS 60\% and AW 50\% & 1969 & 210090 & 16453 & 79089 & 305632 \\
19 & VERY DRY BASECASE & 1960 & 210090 & 9205 & 80777 & 300072 \\
20 & AVG FLOW COOI. MET. & 1969 & 210090 & 35611 & 79089 & 324790 \\
21 & AVG FLOW COOL INFLOW & 1969 & 210090 & 35611 & 79089 & 324790 \\
22 & CAL. BASECASE (SPLIT) & 1988 & 210090 & 25569 & 79645 & 315304 \\
23 AVG FLOW (CUT STORM) & 1969 & 210090 & 21347 & 79089 & 310526
\end{tabular}


TABLE B4

(continued)

\begin{tabular}{|c|c|c|c|c|c|c|}
\hline $\mathbf{N}$ & DESCR IPTION & YEAR & MAIN & TOWN CR & LOCAL & TOTAL \\
\hline & OALIBRATION BASECASE & 38 & 4411908 & 102478 & & 512702 \\
\hline 2 & CUT ALL SOURCES P $50 \%$ & 1988 & 4411908 & 102478 & 1998316 & 6512702 \\
\hline 3 & CUT TOWN CR. P $50 \%$ & 1988 & 4411908 & 102478 & 1998316 & 6512702 \\
\hline 4 & CUT TOWN CR. IN 50\% & 1988 & 4411908 & 51309 & 1998316 & 6461533 \\
\hline 5 & CUT TOWN CR. BOD 50\% & 1988 & 4411908 & 102478 & 199 & 512702 \\
\hline & CUT TOWN CR. SS 50\% & 1988 & 4411908 & 93901 & 19 & 125 \\
\hline & SPLIT HYDRO & INTO & ASE FLOW & ND PEAK & FLOW & \\
\hline & DRY BASECASE & 1971 & 4411908 & 248853 & 200 & \\
\hline 8 & CUT SS $60 \%$ & 1971 & 08 & & & \\
\hline & CUT AW $50 \%$ & 1971 & 4411908 & 147 & & \\
\hline 10 & CUT SS $60 \%$ AND AW $50 \%$ & 1971 & 44 & 11 & 20 & \\
\hline 11 & WET BASECASE & 1967 & 441 & 750 & 196 & 51 \\
\hline 12 & CUT SS $60 \%$ & 1967 & 44 & 666 & 196 & 9623 \\
\hline 13 & CUT AW $50 \%$ & 1967 & 44 & 94 & 19 & 58 \\
\hline 14 & CUT SS $60 \%$ AND AW $50 \%$ & 1967 & 908 & 361402 & 19 & $\$ 66$ \\
\hline 15 & AVG BASECASE & 1969 & 44. & 493325 & & 455 \\
\hline 16 & CUT SS $60 \%$ & 1.969 & 44 & 27 & & \\
\hline 17 & CUT AW $50 \%$ & 1969 & 44 & 292542 & $197-(x) \cdot r \cdot r$ & 72 \\
\hline 18 & CUT SS $60 \%$ AND AW $50 \%$ & 1969 & 908 & 237538 & 1977 & 68 \\
\hline 19 & VERY DRY BASECASE & 1960 & 4411908 & 13.3168 & 2019449 & 525 \\
\hline 20 & AVG FLOW COOL MET. & 1969 & 4411908 & 493325 & 1977222 & 6882455 \\
\hline 21 & AVG FLOW COOL INFLOW & 196 & 441 & 493325 & 1977 & 455 \\
\hline 22 & CAL. BASECASE (SPLIT) & 19 & & & 1991 & 846 \\
\hline 23 & AVG FLOW (CUT STORM) & 1969 & 441 & 314252 & 1977222 & 6703382 \\
\hline
\end{tabular}


TABLE B4

(continued)

\begin{tabular}{|c|c|c|c|c|c|c|}
\hline RUN & DESCRIPTION & YEAR & MAIN & TOWN CR & LOCAL & TOTAL \\
\hline 1 & CALIBRATION BASECASE & 1988 & 18908176 & 249896 & 7193956 & 26352028 \\
\hline 2 & CUT ALL SOURCES P $50 \%$ & 1988 & 18908176 & 249896 & 7193956 & 26352028 \\
\hline 3 & CUT TOWN CR. P 50\% & 1988 & 18908176 & 249896 & 7193956 & 26352028 \\
\hline 4 & CUT TOWN CR. IN $50 \%$ & 1988 & 18908176 & 249896 & 7193956 & 26352028 \\
\hline 5 & CUT TOWN CR. BOD $50 \%$ & 1988 & 18908176 & 124944 & 7193956 & 26227076 \\
\hline & CUT TOWN CR. SS $50 \%$ & 1988 & 18908176 & 249896 & 7193956 & 26352028 \\
\hline & SPLIT HYDROGRAPH & INTO & BASE FLOW & AND PEAK & FLOW & \\
\hline 7 & DRY BASECASE & 1971 & 18908176 & 1743520 & 7211628 & 3324 \\
\hline 8 & CUT SS $60 \%$ & 1971 & 18908176 & 1743520 & 7211628 & 3324 \\
\hline 9 & CUT AW $50 \%$ & 1971 & 8176 & 51 & 7211628 & 555 \\
\hline 10 & CUT SS $60 \%$ AND AW $50 \%$ & 1971 & 18908176 & 871751 & 7211628 & 26991555 \\
\hline 11 & WET BASECASE & 1967 & 18908176 & 5575928 & 7060165 & 31544269 \\
\hline 12 & CUT SS $60 \%$ & 196 & 13908176 & 5575928 & 7060165 & 31544269 \\
\hline 13 & CUT AW $50 \%$ & 1967 & 18908176 & 2787945 & 7060165 & 28756286 \\
\hline 14 & CUT SS $60 \%$ AND AW $50 \%$ & 196 & 18908176 & 2787945 & 7060165 & 28756286 \\
\hline 15 & AVG BASECASE & 19 & 18908176 & 3613167 & 7118013 & 29639356 \\
\hline 16 & CUT SS $60 \%$ & 1969 & 18908176 & 3613167 & 7118013 & 29639356 \\
\hline 17 & CUT AW $50 \%$ & 1969 & 18908176 & 1806579 & 711 & 27832768 \\
\hline 18 & CUT SS $60 \%$ AND AW $50 \%$ & 1969 & 76 & 1806579 & 711 & 1768 \\
\hline 19 & VERY DRY BASECASE & 19 & 18908176 & 58 & 727 & 6760 \\
\hline 20 & AVG FLOW COOL MET. & 1969 & 18908176 & 3613167 & 7118013 & 29639356 \\
\hline 21 & AVG FLOW COOL INFLOW & 1969 & 18908176 & 3613167 & 7118013 & 29639356 \\
\hline 22 & CAL. BASECASE (SPLIT) & 1988 & 18908176 & 2639156 & 7167998 & 28715330 \\
\hline 23 & AVG FLOW (CUT STORM) & 1969 & 18908176 & 2014535 & 7118013 & 28040724 \\
\hline
\end{tabular}


TABLE B4

(continued)

\begin{tabular}{|c|c|c|c|c|c|c|}
\hline RUN & DESCRIPTION & YEAR & MAIN & TOWN CR & LOCAL & TOTAL \\
\hline 1 & CALIBRATION BASECASE & 1988 & 14302 & 1126 & 19611 & 35039 \\
\hline 2 & CUT ALL SOURCES P $50 \%$ & 1988 & 14302 & 11.26 & 19611 & 35039 \\
\hline 3 & CUT TOWN CR. P $50 \%$ & 1988 & 14302 & 1126 & 19611 & 35039 \\
\hline 4 & CUT TOWN CR. IN $50 \%$ & 1988 & 14302 & 1126 & 19611 & 35039 \\
\hline 5 & CUT TOWN CR. BOD $50 \%$ & 1988 & 14302 & 1126 & 19611 & 35039 \\
\hline 6 & CUT TOWN CR. SS $50 \%$ & 1.988 & 14302 & 563 & 19611 & 34476 \\
\hline & - SPLIT HYDROGRAPH & INTO BAS & E FLOW & AND FEAK & FLOW & \\
\hline 7 & DRY BASECASE & 1971 & 14302 & 5639 & 20040 & 39981 \\
\hline & CUT SS $60 \%$ & 1971 & 14302 & 2251 & 20040 & 36593 \\
\hline 9 & CUT AW $50 \%$ & 1971 & 14302 & 5639. & 20040 & 39981 \\
\hline 10 & CUT SS $60 \%$ AND AW $50 \%$ & 1971 & 14302 & 2251 & 20040 & 36593 \\
\hline 11 & WET BASECASE & 1967 & 14302 & 18563 & 19999 & 52864 \\
\hline 12 & CUT SS $60 \%$ & 1967 & 14302 & 7411 & 19999 & 41712 \\
\hline 13 & CUT AW $50 \%$ & 1967 & 14302 & 18563 & 19999 & 52864 \\
\hline 14 & CUT SS $60 \%$ AND AW $50 \%$ & 1967 & 14302 & 7411 & 19999 & 41712 \\
\hline 15 & AVG BASECASE & 1969 & 14302 & 11948 & 19437 & 45687 \\
\hline 16 & CUT SS $60 \%$ & 1969 & 14302 & 4770 & 19437 & 38509 \\
\hline 17 & CUT AW $50 \%$ & 1969 & 14302 & 11948 & 19437 & 45687 \\
\hline 18 & CUT SS $60 \%$ AND AW $50 \%$ & 1969 & 14302 & 4770 & 19437 & 38509 \\
\hline 19 & VERY DRY BASECASE & 1960 & 14302 & 2799 & 20138 & 37239 \\
\hline 20 & AVG FLOW COOL MET. & 1969 & 14302 & 11948 & 19437 & 45687 \\
\hline 21 & AVG FLOW COOL INFLOW & 1969 & 14302 & 11948 & 19437 & 45687 \\
\hline 22 & CAL. BASECASE (SPLI'T) & 1988 & 14302 & 8862 & 19583 & 42747 \\
\hline 23 & AVG FLOW (CUT STORM) & 1969 & 14302 & 6202 & 19437 & 39941 \\
\hline
\end{tabular}


TABLE B4

(continued)

\begin{tabular}{llrrrrr} 
RUN DESCRIPTION & YEAR & MAIN & TOWN CR & LOCAL & TOTAL \\
1 CALIRRATION BASECASE & 1988 & 10772 & 146 & 4098 & 15016 \\
2 CUT ALL SOURCES P 50\% & 1988 & 10772 & 146 & 4098 & 15016 \\
3 CUT TOWN CR. P 50\% & 1988 & 10772 & 146 & 4098 & 15016 \\
4 CUT TOWN CR. IN 50\% & 1988 & 10772 & 146 & 4098 & 15016 \\
5 CUT TOWN CR. BOD 50\% & 1988 & 10772 & 146 & 4098 & 15016 \\
6 CUT TOWN CR. SS 50\% & 1988 & 10772 & 146 & 4098 & 15016 \\
\hline-9 DRY BASECASE & 1971 & 10772 & 146 & 4108 & 15026 \\
7 CUT SS 60\% & 1971 & 10772 & 146 & 4108 & 15026 \\
9 CUT AW 50\% & 1971 & 10772 & 146 & 4108 & 15026 \\
10 CUT SS 60\% and AW 50\% & 1971 & 10772 & 146 & 4108 & 15026 \\
11 & WET BASECASE & 1967 & 10772 & 345 & 4022 & 15139 \\
12 CUT SS 60\% & 1967 & 10772 & 345 & 4022 & 15139 \\
13 CUT AW 50\% & 1967 & 10772 & 345 & 4022 & 15139 \\
14 & CUT SS 60\% AND AW 50\% & 1967 & 10772 & 345 & 4022 & 15139 \\
15 AVG BASECASE & 1969 & 10772 & 242 & 4055 & 15069 \\
16 CUT SS 60\% & 1969 & 10772 & 242 & 4055 & 15069 \\
17 CUT AW 50\% & 1969 & 10772 & 242 & 4055 & 15069 \\
18 CUT SS 60\% AND AW 50\% & 1969 & 10772 & 242 & 4055 & 15069 \\
19 & VERY DRY BASECASE & 1960 & 10772 & 92 & 4141 & 15005 \\
20 & AVG FLOW COOL MET. & 1969 & 10772 & 242 & 4055 & 15069 \\
21 & AVG FLOW COOL INFLOW & 1969 & 10772 & 242 & 4055 & 15069 \\
22 & CAL. BASECASE (SPLIT) & 1988 & 10772 & 146 & 4083 & 15001 \\
23 AVG FLOW (CUT STORM) & 1969 & 10772 & 242 & 4055 & 15069
\end{tabular}




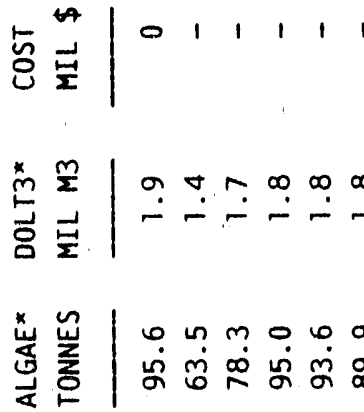

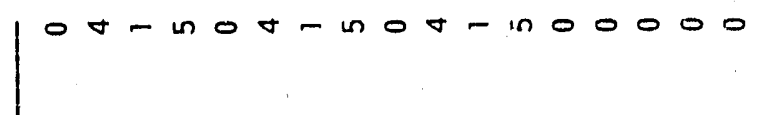

勇出|

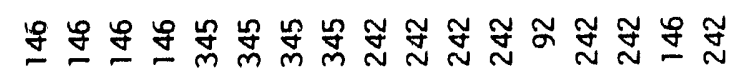

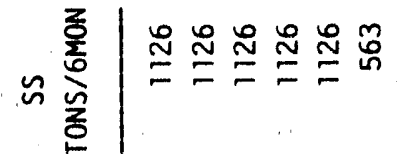

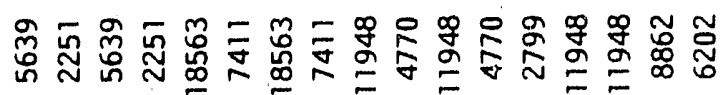

总旁

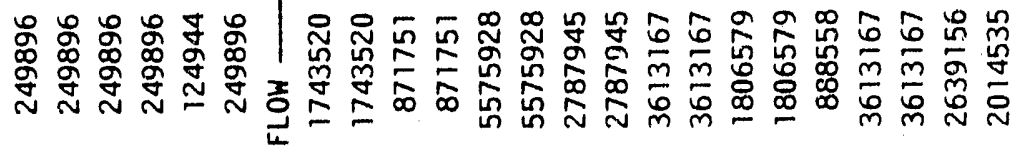

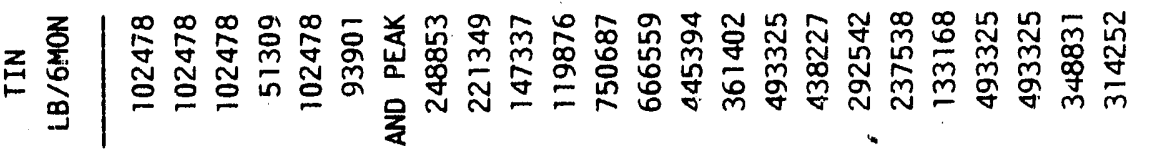

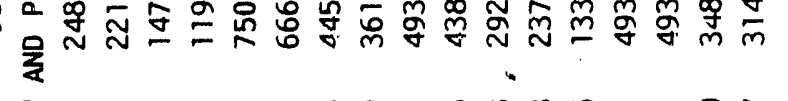

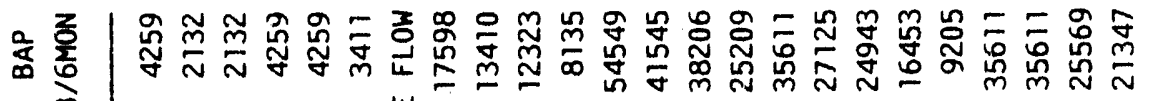

岁

茫|

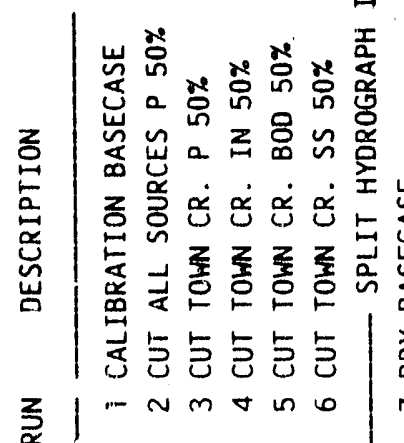

今े

峞

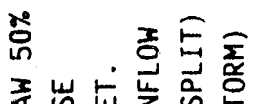

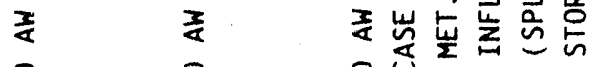

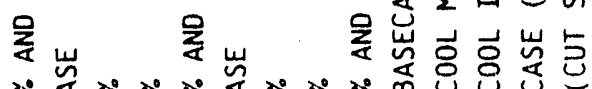

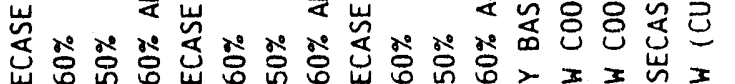

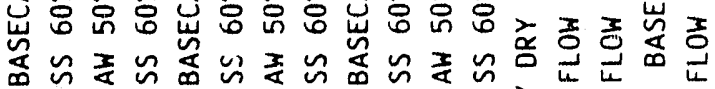

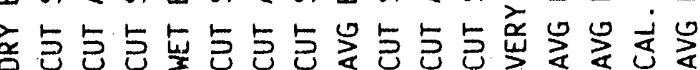

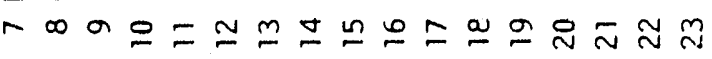




\section{APPENDIX C}

Miscellaneous Sensitivity Simulations

Upstream Versus Total Embayment Water Quality

Figure $\mathrm{C} 1$ has two purposes. First, it shows the relative magnitude of upstream (above the bridge at TCM 2.9) versus total embayment volume with DO less than $3 \mathrm{mg} / \mathrm{L}$. For model caliuration, upstream embayment sediment oxygen demands were taken to be twice as large as those near the mouth. Approximately 5 million cubic meters, one-sixth, of Town Creek total embayment volume is located in the upstream end of the embayment.

Second, Figure $\mathrm{C} 1$ shows that cutting 50 percent of the phosphorus from Town Creek inflows does not affect the upstream end more than the downstream end. Reductions were made to the 1988 calibration basecase in which hydrographs were not sp1:t. Town Creek embayment hypolimmetic DO near the mouth generally matches Guntersville Dam release DO (bottom plot) except for periods of stratification.

\section{Reductions to All Inflow Sources}

Figure $\mathrm{C} 2$ shows sensitivity to reducing phosphorus and sheds light on nutrient exchange between the embayment and the main channel. The figure also shows that reducing Town Creek inflowing phosphorus by 50 percent barely affects Guntersville Reservoir water quality. Cutting all phosphorus sources by 50 percent (Town Creek inflow, Nickajack releases, and local inflow) indicates that water quality in Town Creek embayment is affected by water quality in the main stem of the reservoir. The portion of Town Creek embayment below the bridge at TCM 2.9 acts as part of the main stem reservoir. Town Creek embayment mimics what happens in the main reservoir body since five-sixths of the volume is below the bridge. The plots of Guntersville reservoir (top left and bottom left) do not include Town Creek embayment. Town Creek embayment is shown separately in the top right and bottom right plots.

Reducing the 1988 calibration phosphorus in Town Creek inflows by 50 percent does not greatly affect volume of DO less than $3.0 \mathrm{mg} / \mathrm{L}$ in 
TOWN CREEK EMBAYMENT
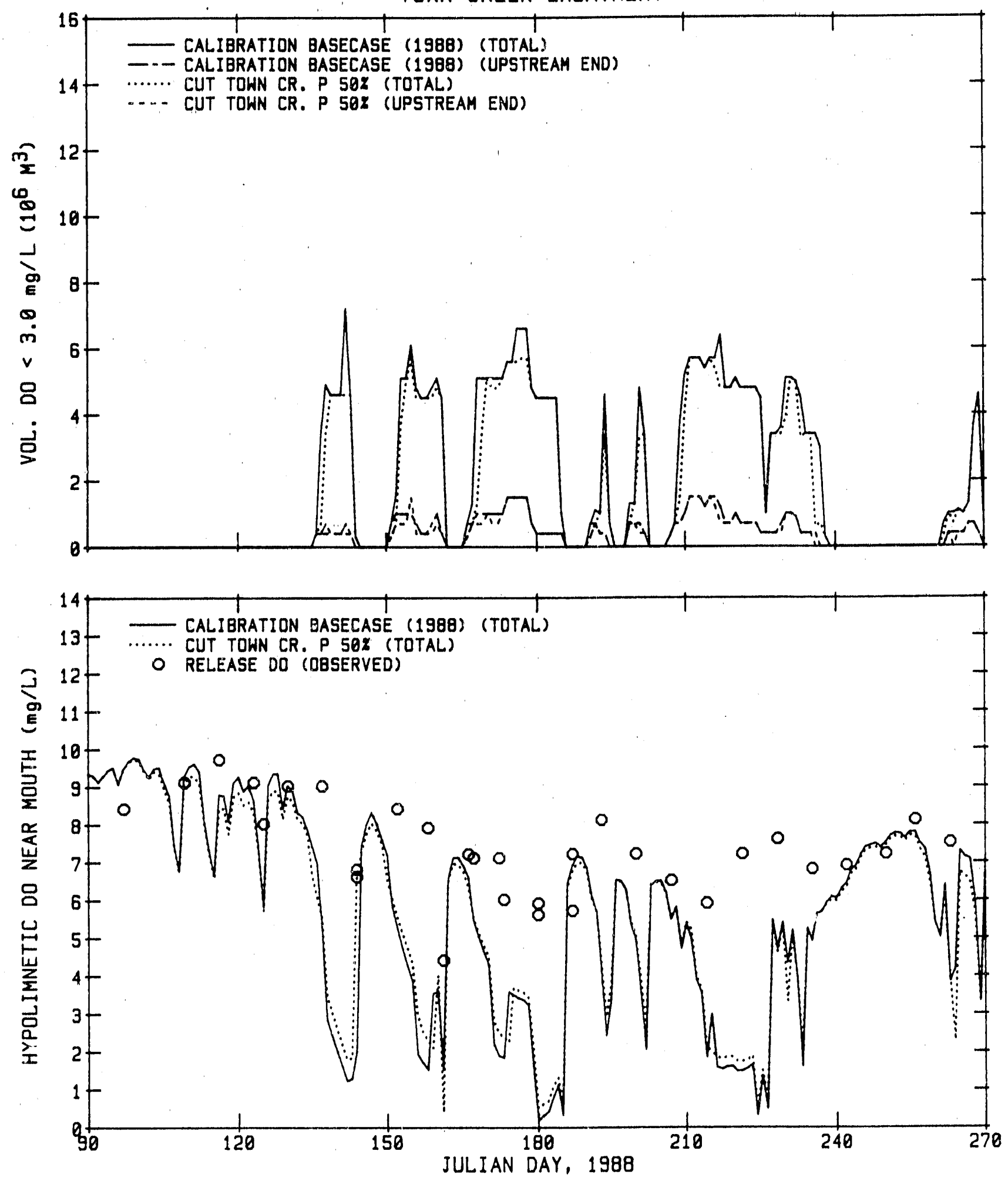

Figure C1. Effects of Phosphorus Reductions on the Upstream versus Total Town Creek Embayment 

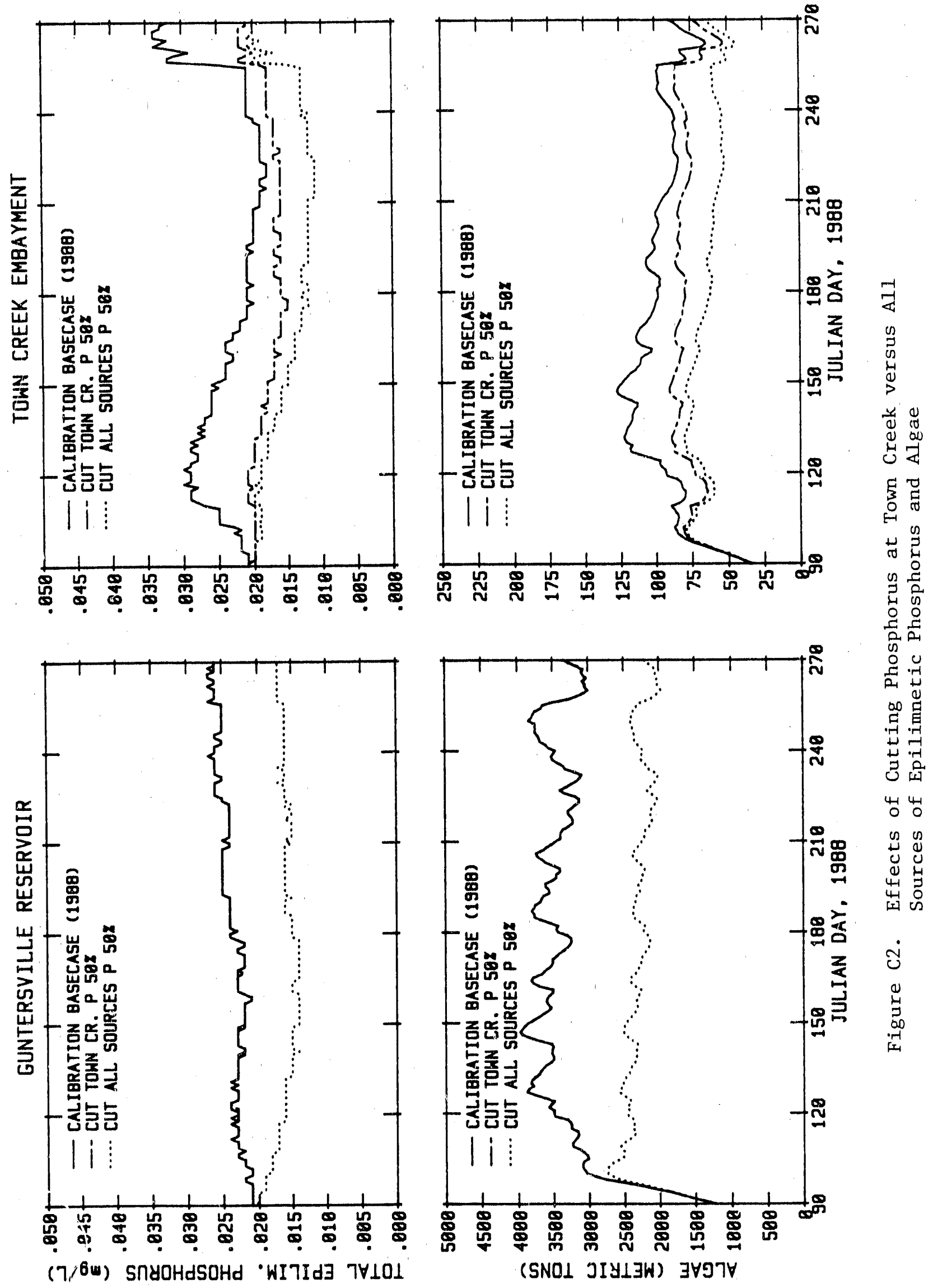

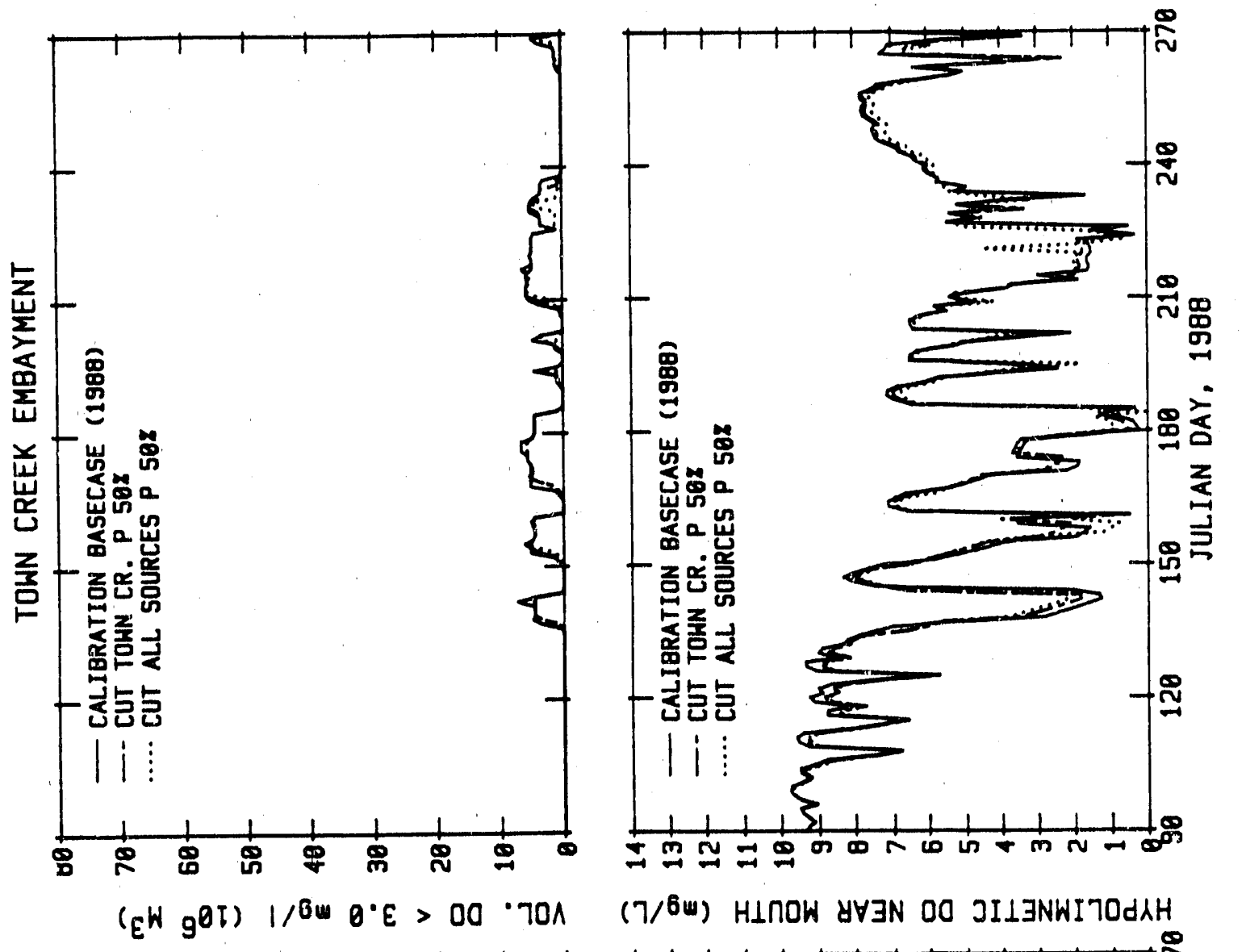

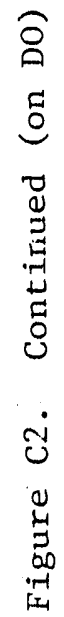

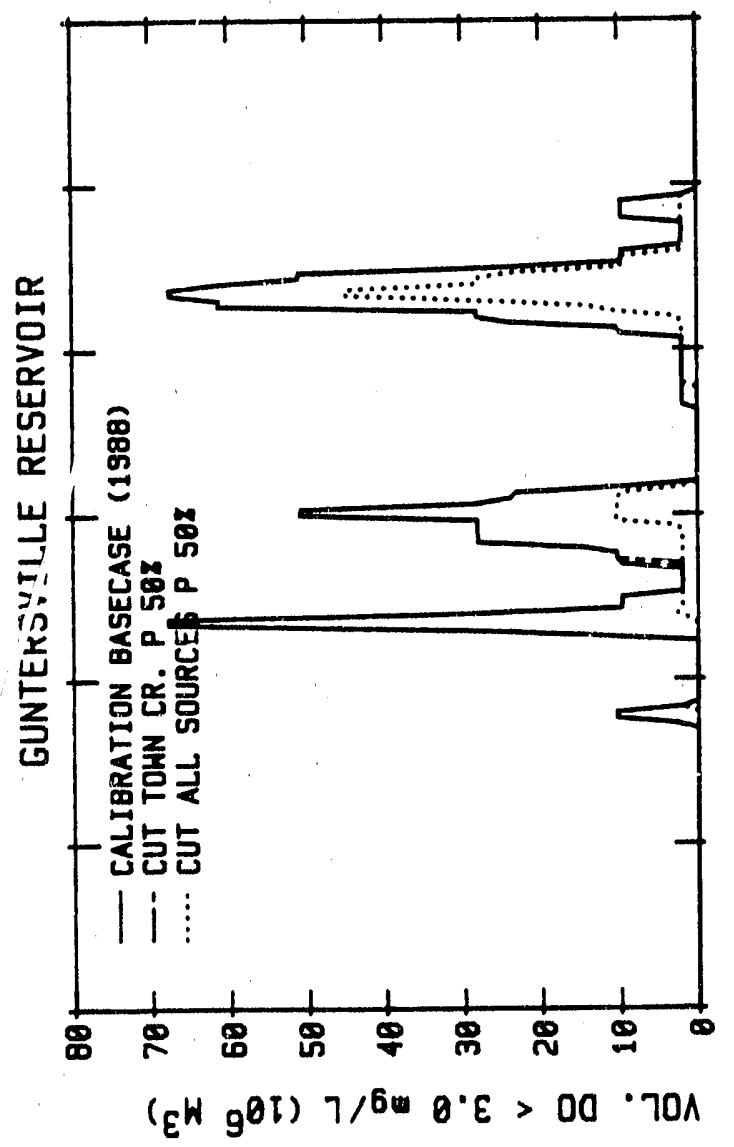

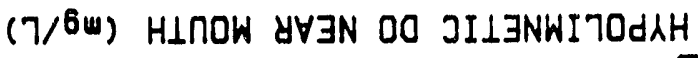

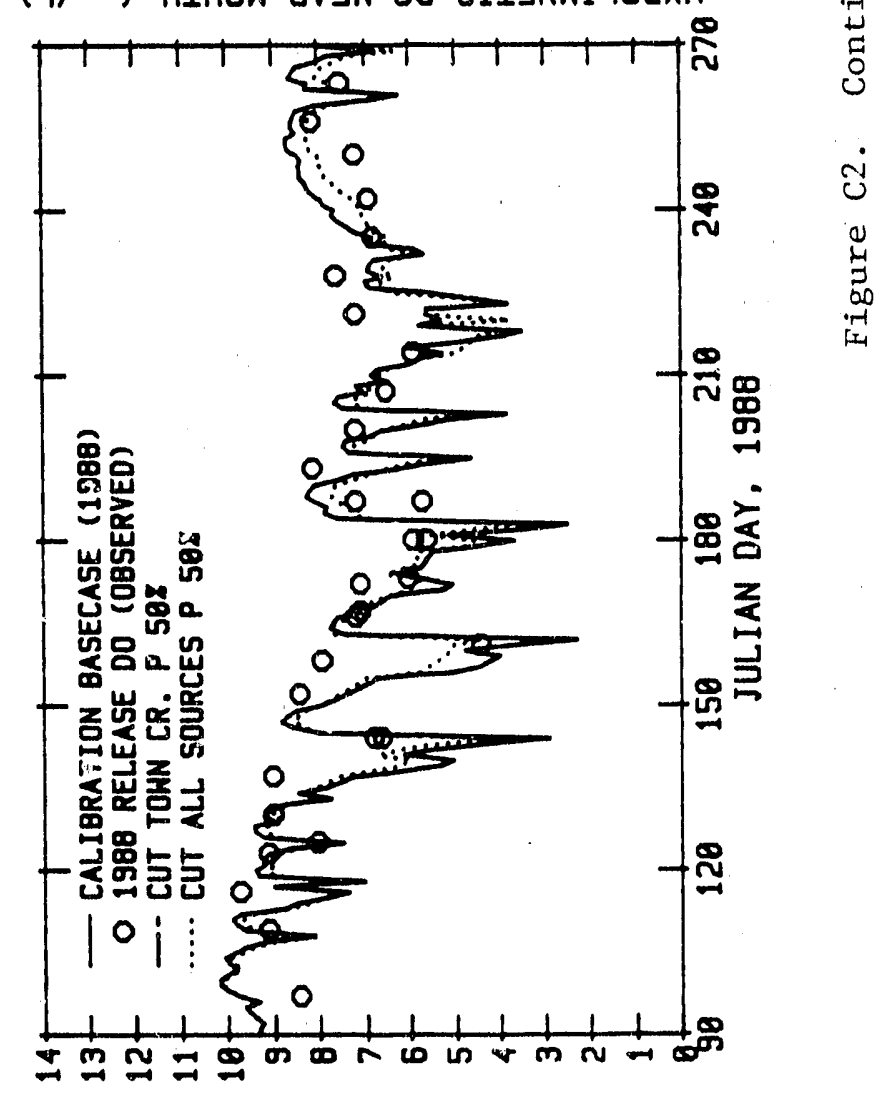

(7/6w) OO JILJNWI70dגH ᄉ $\forall 93 \mathrm{YOJ}$ 
either Town Creek embayment or Guntersville Reservoir. Reducing a11 phosphorus sources by 50 percent reduces volume of Do less than $3.0 \mathrm{mg} / \mathrm{L}$ by about one-half in the main reservoir and hardly at a11 in Town Creek embayment. Town Creek embayment appears to be largely affected by SOD and long retention times, appears to receive an abundance of nutrients, and therefore DO is not greatly affected by a 50 percent cut in Town Creek inflowing phosphorus.

Guntersville forebay hypolimnetic DO is not greatly affected by cuts in phosphorus. This is because Guntersville Reservoir has little storage and is operated as a run-of-the-river hydropower operation. Likewise, Town Creek embayment hypolimnetic DO near the mouth is not affected greatly by phosphorus reductions. Hypolimnetic DO is more a function of meteorology, such as wind and surface cooling events. 
APPENDIX D

Meteorology

Meteorology used in simulations are given in Figure D1. Meteorology during 1988 was hot and dry, while that in 1974 was cool and wet. 

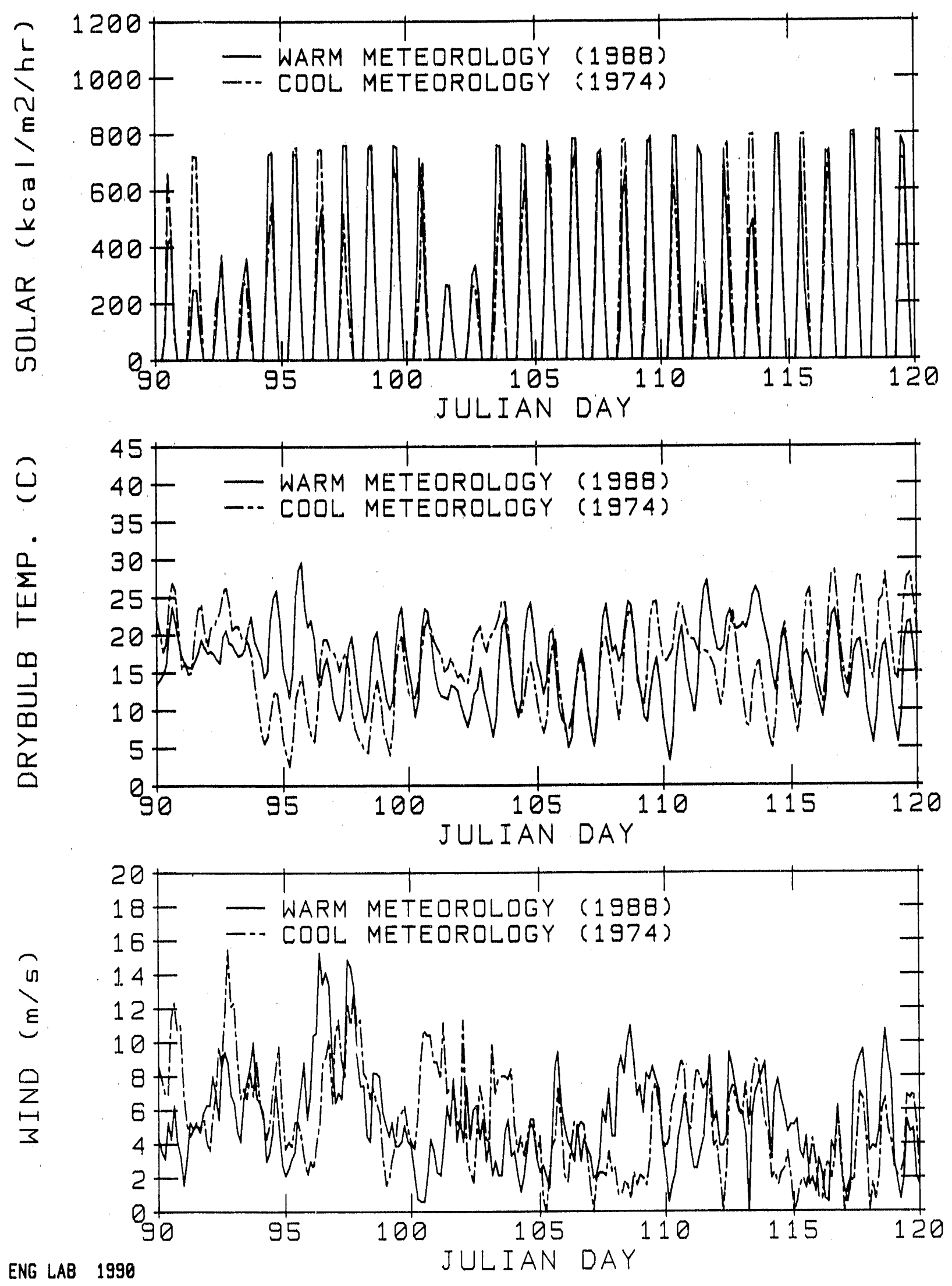

Figure D1. Warm (1988 Calibration) versus Coo1 (1974) Meteorology at Huntsville, Alabama, Airport 

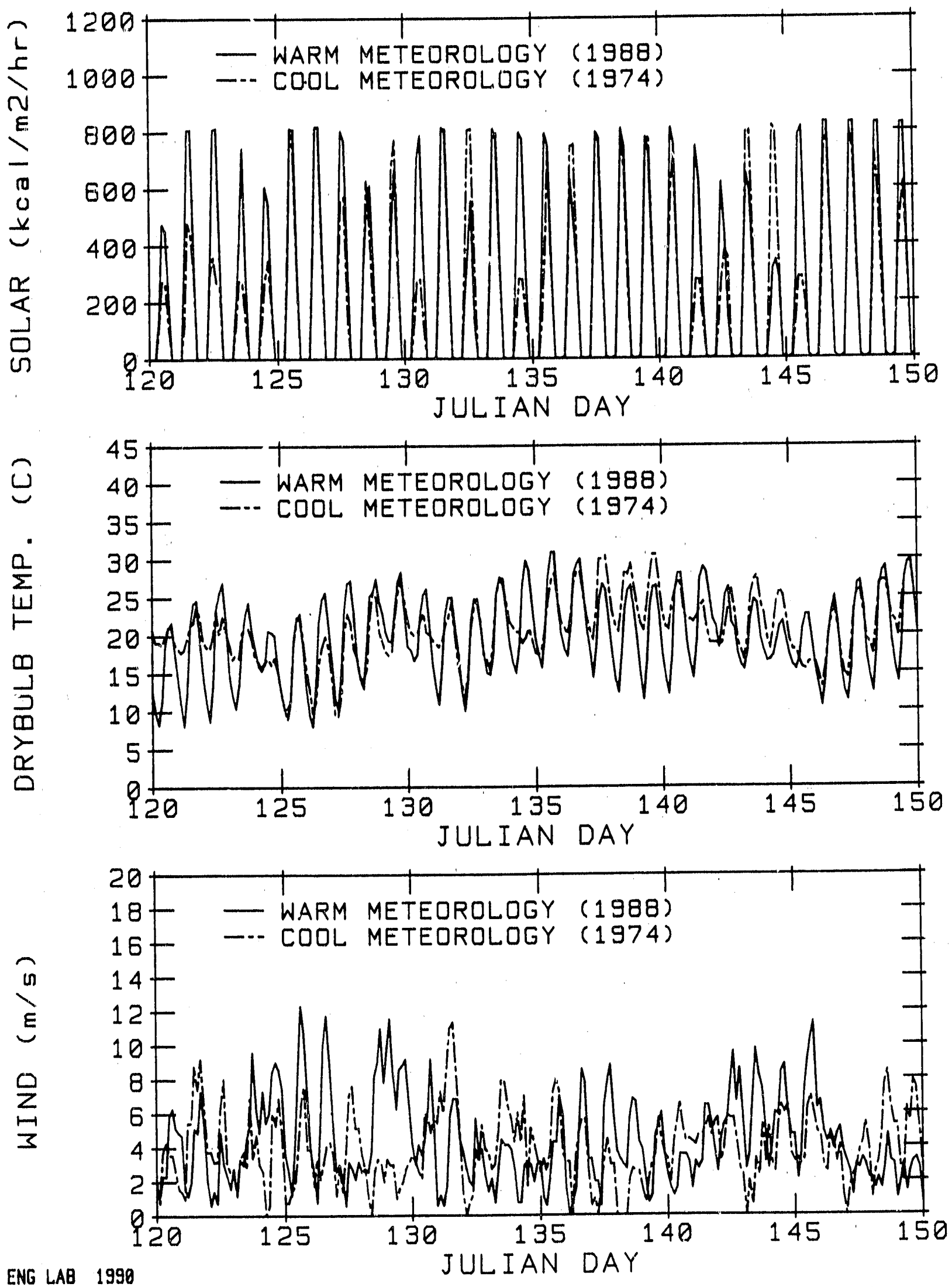

Figure D1. Continued (Huntsville, Alabama) 

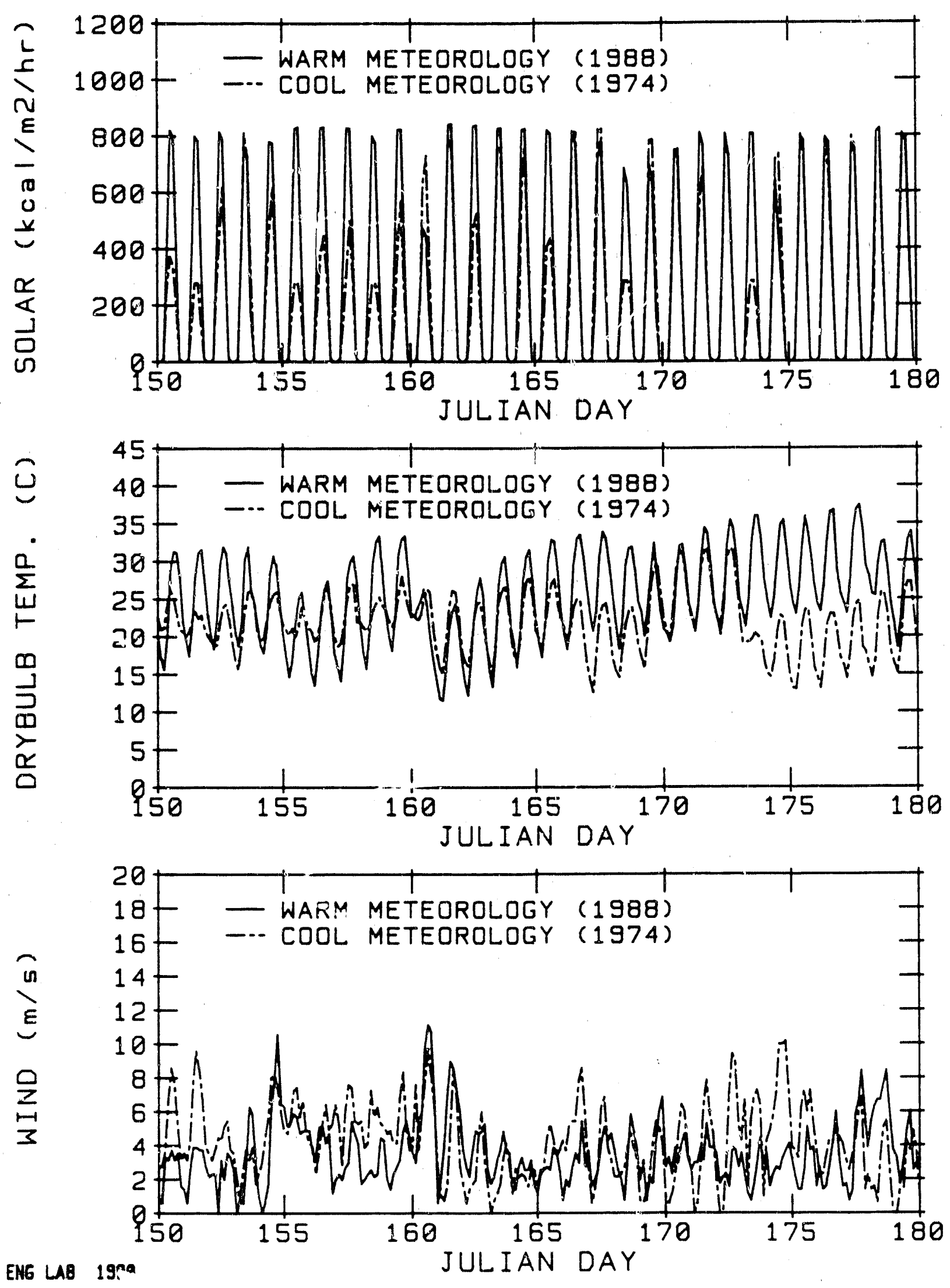

Figure D1. Continued (Huntsville, Alabama) 

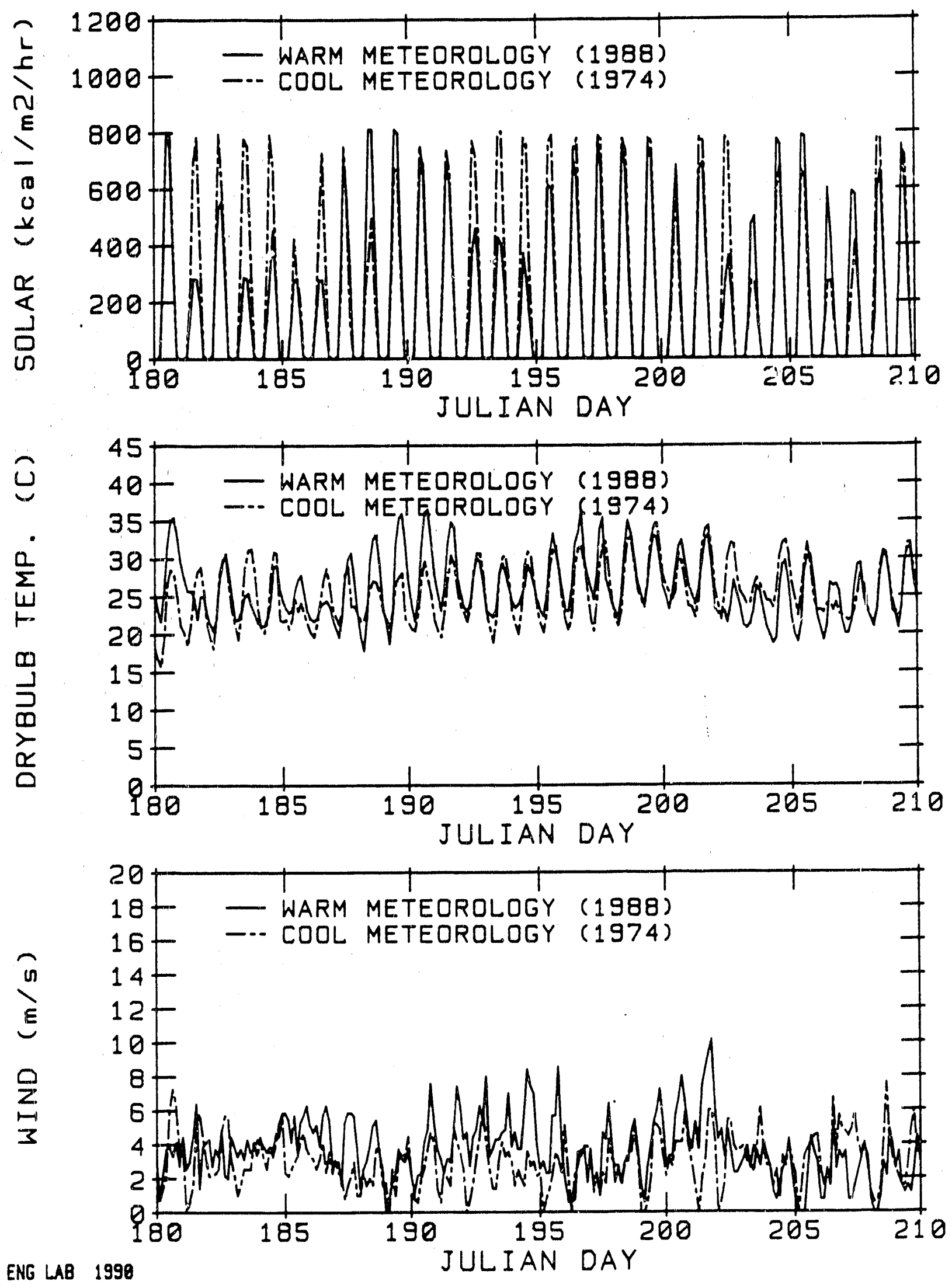

Figure D1. Continued (Huntsville, Alabama) 

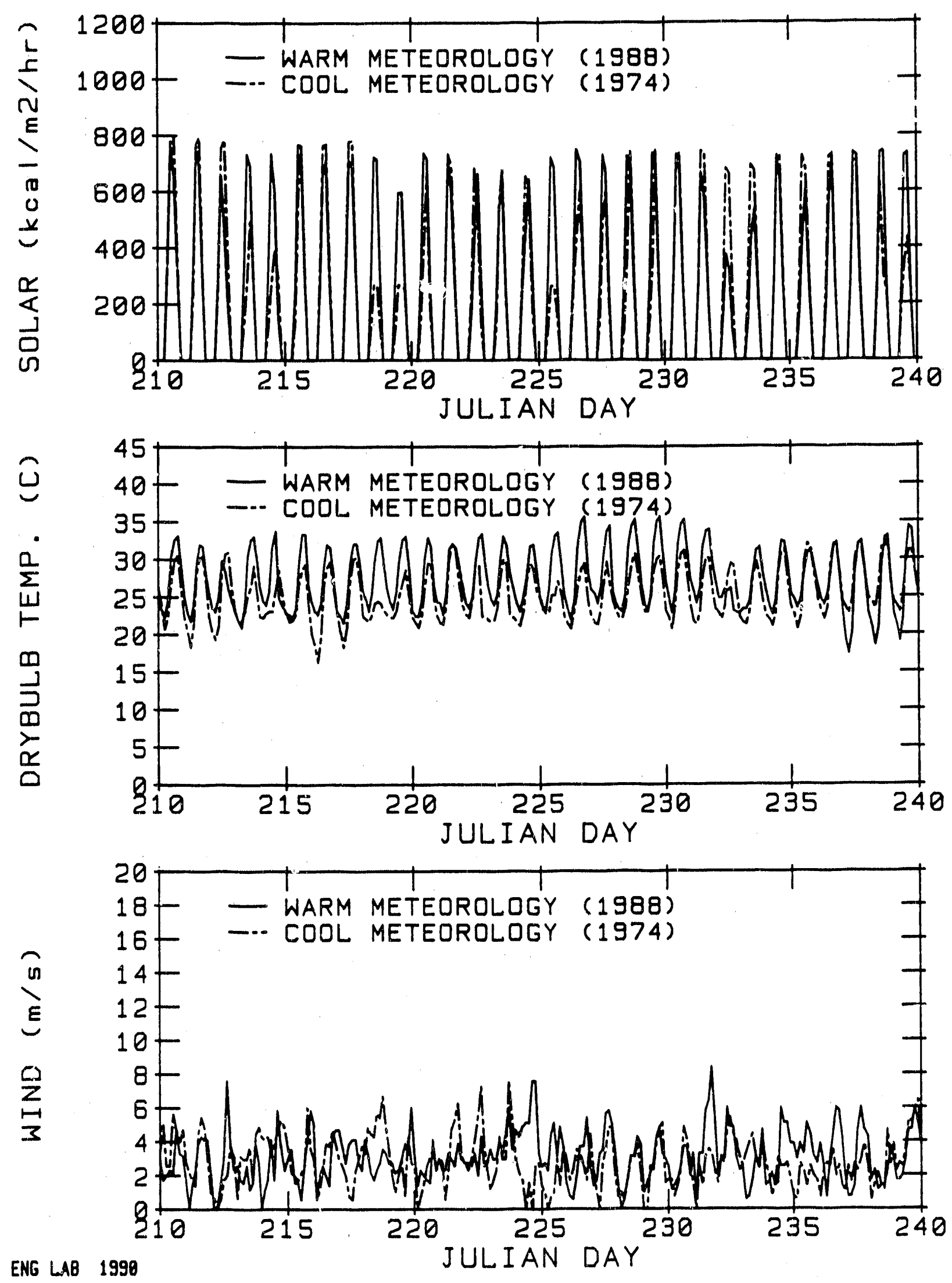

Fagure D1. Continued (Huntsville, Alabama) 

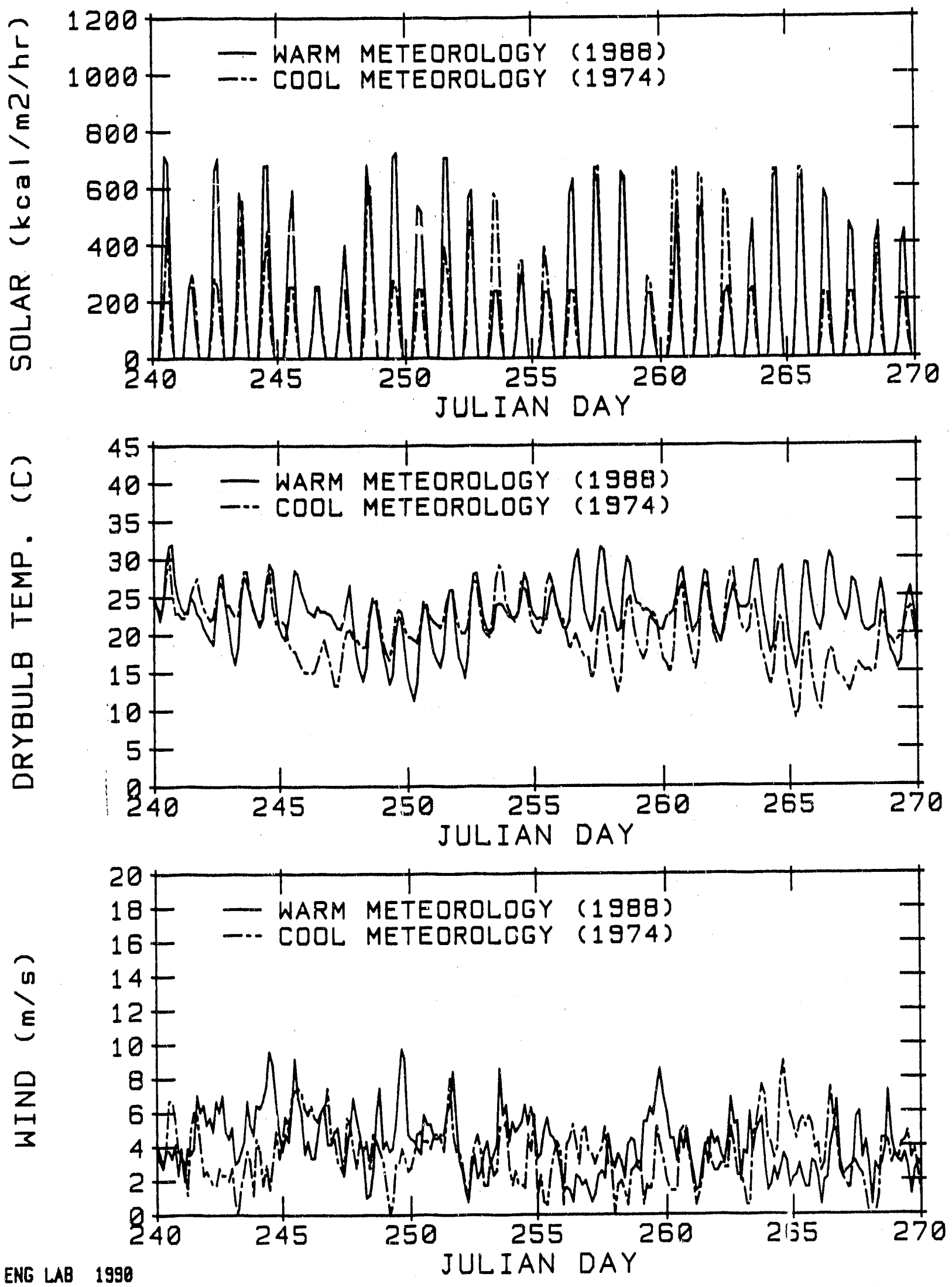

Figure D1. Continued (Huntsville, Alabama) 


\section{APPENDIX E \\ Rate of Sediment Deposition in Town Creek Embayment}

Concern over accumulation of solids in Town Creek embayment through deposition prompted an analysis based on watershed local sediment yields for Guntersville Reservoir. Local sediment yields, based on the Churchill and Brune methods (Trimble and Carey, 1984), ranged from 102 tonnes $/ \mathrm{km}^{2} / \mathrm{yr} \quad\left(580\right.$ tons $\left./ \mathrm{mi}^{2} / \mathrm{yr}\right)$ using the Churchill method to 128 tonnes $/ \mathrm{km}^{2} / \mathrm{yr} \quad\left(730\right.$ tons $\left./ \mathrm{mi}^{2} / \mathrm{yr}\right)$ using the Brune method. The Churchill analysis includes runoff for the local contributing area and fur the reservoir water which would include not only local water but also water which had flowed through one or more of the upstream reservoirs. Assuming that suspended load from the upstream reservoir is a small portion of the total local yield, the Guntersville Reservoir local yield can be used as a rough estimate of the local yie1d for Town Creek embayment. Applying these Guntersville Reservoir local yields to the drainage area upstream of Town Creek embayment $\left(495 \mathrm{~km}^{2}, 191 \mathrm{mi}^{2}\right)$, assuming a sediment density of $2 \mathrm{~g} / \mathrm{cm}^{3}$, and assuming $5 \mathrm{million}$ cubic meters for Town Creek embayment volume (approximate volume for the embayment portion above the bridge at TCM 2.9) gives a range of 77 to 97 years to fill. This is a worst case which assumes that all eroded sediment reaches the embayment, and all incoming sediment would not leave the upstream end of Town Creek embayment (i.e., no scouring or resuspension).

Expected floods would scour a considerable portion of settled solids from this narrow deep embayment. Flows in Town Creek range from 0 to $501 \mathrm{~m}^{3} / \mathrm{s}(17,700 \mathrm{cfs})$, based on the maximum discharge at the Geraldine gage (TCM 20.4) on April 29, 1963. Such dynamic hydraulics allows for deposition of settling suspended solids as well as transport of considerable bedload and scouring. Much longer filling times would be expected if scouring and resuspension during flooding was considered in calculations.

As a rough estimate and a method of shedding light on the subject, filling times were estimated by summing modeled inflowing 
suspended loads only (no bedload). It was estimated that the time to fill the upstream embayment ranged from 292 years for wet (1967) conditions to 972 years for dry (1971) conditions. Using average flow. conditions (1969) it was estimated to take 454 years to fill. These estimates were done by applying a storm suspended solids concentration of $273 \mathrm{mg} / \mathrm{L}$ to the peaks or storm portions of runoff hydrographs. When storm concentrations were not applied to the peaks much longer filling times resulted. For the 1988 calibration, in which storm concentrations were not applied, upstream embayment filling time was estimated at 4819 years.

The contribution of bedload to the total sediment load appears to be significant. This conclusion was based on the difference in embayment filling time between the aforementioned estimates using local sediment yield for Guntersville Reservoir (Trimble and Carey, 1984) and estimates from summing only suspended solid loadings. 

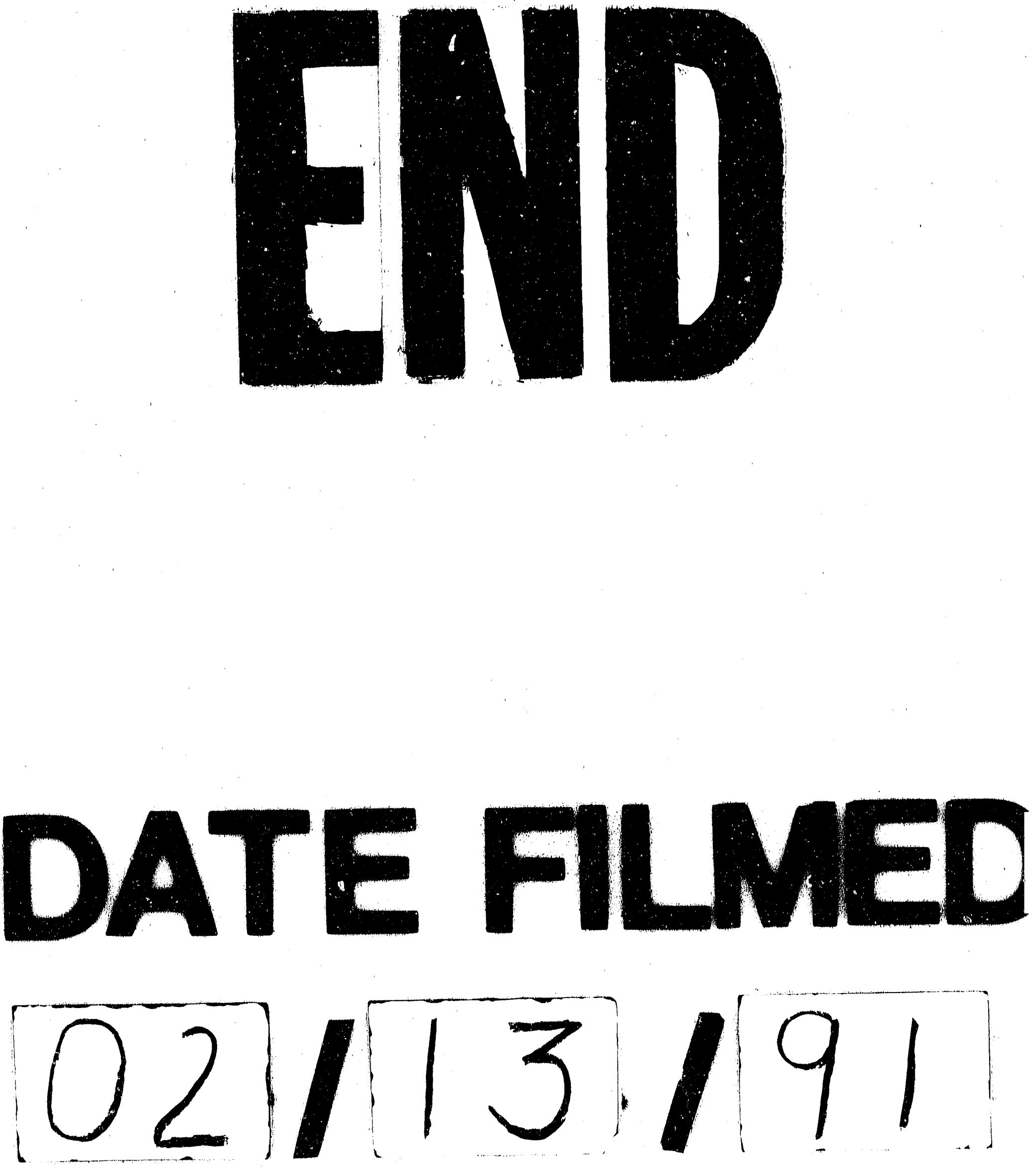

$\ldots$ 
